Kieler Arbeiten zur skandinavistischen Linguistik 4

Sabrina Goll

\title{
Südschleswigdänisch - Probleme einer varietätentypologischen Einordnung
}

Kiel 2019

Christian-Albrechts-Universität zu Kiel

Institut für Skandinavistik, Frisistik und Allgemeine Sprachwissenschaft 
(C) Sabrina Goll, Kiel 2019

Sabrina Goll

Christian-Albrechts-Universität zu Kiel

Institut für Skandinavistik, Frisistik und Allgemeine Sprachwissenschaft s.goll@isfas.uni-kiel.de

Veröffentlicht am 28. 2. 2019

DOI: $10.21941 / \mathrm{publ} / \mathrm{kasl}_{4}$

Diese Arbeit ist die geringfügig überarbeitete Fassung der Masterarbeit der Autorin aus dem Jahr 2014.

Die Kieler Arbeiten zur skandinavistischen Linguistik publizieren Arbeitspapiere und Forschungsergebnisse aus der skandinavistischen Linguistik am Institut für Skandinavistik, Frisistik und Allgemeine Sprachwissenschaft der Christian-Albrechts-Universität zu Kiel. 


\section{Inhalt}

Tabellen 5

Abbildungen 7

1 Einleitung 9

2 Südschleswigdänisch 11

2.1 Sprachkontaktsituation in Südschleswig 11

2.2 Dänische Minderheit 12

2.3 Südschleswigdänisch 15

2.4 Kategorisierung des Südschleswigdänischen 17

2.5 Problematik der Kategorisierung 22

3 Relevante Varietätentypen und ihre Kriterien 25

3.1 Varietätentypen 25

3.1.1 Personale Varietäten 29

3.1.2 Räumliche Varietäten 32

3.1.3 Situative Varietäten: Register 35

3.1.4 Soziale Varietäten 36

3.1.5 Kontaktbedingte Varietäten 42

3.1.6 Zusammenfassung der Varietätentypen 50

3.2 Kriterien 52

3.2.1 Sprachsoziale Kriterien 52

3.2.2 Strukturelle Kriterien 55

4 Südschleswigdänisch: ein Merkmalkatalog 57

4.1 Sprachsoziale Merkmale 57

4.1.1 Person 57

4.1.2 Raum 58

4.1.3 Situation 58

4.1.4 Soziale Gruppe 59

4.1.5 Kontakt 60

4.1.6 Kodifizierung 61

4.2 Strukturelle Merkmale 62

4.2.1 Prozesse 62

4.2.2 Medium 62

4.2.3 Spezifische Phänomene 63

4.3 Merkmalkatalog 63

5 Einordnung der Südschleswigdänischen 65

5.1 Kriterien der Varietätentypen und die Merkmale des SüD 65

5.2 Grobe Einordnung nach den begriffskonstituierenden Kriterien 67

5.3 Detaillierte Einordnung nach den weiteren Kriterien 68

5.3.1 Personale Varietäten 68

5.3.2 Räumliche Varietäten 69

5.3.3 Situative Varietäten 69

5.3.4 Soziale Varietäten 69 
Sabrina Goll

5.3.5 Kontaktbedingte Varietäten 71

5.4 Probleme einer Kategorisierung 73

6 Fazit 79

Literatur 81 


\section{Tabellen}

Tab. 1: Kriterien einer idiolektalen Varietät 30

Tab. 2: Kriterien einer Lernervarietät 32

Tab. 3: Kriterien einer dialektalen Varietät 34

Tab. 4: Kriterien einer Regionalsprache 35

Tab. 5: Kriterien eines Registers 36

Tab. 6: Kriterien einer Gruppensprache 38

Tab. 7: Kriterien einer soziolektalen Varietät 39

Tab. 8: Kriterien einer ethnolektalen Varietät 41

Tab. 9: Kriterien einer multiethnolektalen Varietät 42

Tab. 10: Kriterien einer Kontaktvarietät 43

Tab. 11: Kriterien einer Mischsprache 45

Tab. 12: Kriterien einer Pidginsprache 47

Tab. 13: Kriterien einer Kreolsprache 48

Tab. 14: Kriterien einer Kreoloidsprache 49

Tab. 15: Kriterien einer Zweitsprachen-Kreoloidsprache 49

Tab. 16: Kriterien der Varietätentypen 51

Tab. 17: Sprachsoziale Kriterien 52

Tab. 18: Strukturelle Kriterien 55

Tab. 19: Sprachsoziale Merkmale des SüD 64

Tab. 20: Strukturelle Merkmale des SüD 64

Tab. 21: Einordnung des SüD in den Kriterienkatalog 66 



\section{Abbildungen}

Abb. 1: Die drei Hauptfaktoren des SüD 17

Abb. 2: Schematische Darstellung der Versuche einer Kategorisierung des SüD 22

Abb. 3: Soziolinguistisches Varietätenmodell als Sprachwirklichkeitsmodell (nach Löffler 2010: 79) 26

Abb. 4: Die relevanten Varietätentypen 28

Abb. 5: Varietätentypologische Einordnung des SüD 73 



\section{Einleitung}

Die relativ einfache Frage nach dem ,Was?‘ erweist sich wie so oft als eine der am schwersten zu klärenden Fragen in der Forschung. So beschäftigt auch die Frage ,Was ist Südschleswigdänisch ${ }^{1}$ ?’ die Forscher der Kontakt-, Sozio- und Variationslinguistik seit nunmehr einigen Jahrzehnten und erfährt bis zum jetzigen Zeitpunkt keine zufriedenstellende Antwort. Die verschiedenen Perspektiven resultieren in ebenso verschiedenen varietätentypologischen Klassifizierungen des SüD. Eine Einigung darüber, als was das SüD endgültig zu klassifizieren ist, gibt es bisher nicht.

Die Forschung zur sprachlichen Varietät SüD, die von vielen der Angehörigen der dänischen Minderheit in Südschleswig verwendet wird, verfolgt bisher im Wesentlichen eine bestimmte Vorgehensweise: Die Autoren setzen sich mit der Einordnung des SüD in eine bestimmte Varietätenkategorie auseinander (u. a. Braunmüller 1991, 1996, Fredsted 1997, Pedersen 200ob, 2009). Es wird systematisch versucht, das SüD in verschiedene Kategorien einzuordnen und zu bezeichnen, woraufhin andere Autoren Gegenargumente aufzeigen und die Varietät in eine andere Kategorie einzuordnen versuchen. Hierbei werden vor allem entweder die formalen oder die funktionalen Aspekte des SüD fokussiert; ein gleichgewichtiger Ansatz beider Seiten ist bisher nicht erfolgt. Folglich existiert eine enorme Anzahl von sich teilweise widersprechenden Argumenten für oder gegen eine bestimmte Varietätenkategorie. Eine zufriedenstellende varietätentypologische Einordnung des SüD ist den Autoren bisher nicht gelungen.

Die vorliegende Arbeit bedient sich einer anderen Vorgehensweise und wird nicht versuchen, eine Kategorie dem SüD anzupassen. Vielmehr soll - ausgehend vom Gegenstand an sich - das SüD in das komplexe Geflecht der verschiedenen Varietätentypen ${ }^{2}$ eingeordnet werden. Dabei wird bewusst darauf verzichtet, der Varietät SüD eine konkrete Bezeichnung zu geben. Das Ziel dieser metaanalytischen Arbeit ist es, die Überschneidungen und Abweichungen des SüD mit den einzelnen Varietätentypen detailliert darzustellen.

Die vorliegende Arbeit wird sich der Leitfrage annehmen, inwieweit sich das SüD varietätentypologisch einordnen lässt. Wie verhält sich SüD zu den prototypischen Varietätenkategorien? Wo entstehen Probleme bei einer varietätentypologischen Einordnung?

Es wird vermutet, dass sich das SüD mit seinen besonderen sprachsozialen sowie auch strukturellen Merkmalen keiner spezifischen Varietätenkategorie zuordnen lässt, sondern lediglich bestimmte Kriterien dieser Varietätentypen erfüllt. Durch eine detaillierte Analyse der begriffskonstituierenden und weiteren charakteristischen Kriterien der verschiedenen Varietätentypen wird aufgezeigt, dass das SüD keinem Varietätentyp gerecht wird - andersherum aber auch kein Varietätentyp vollkommen auf das SüD zutrifft.

Zunächst stellt Kapitel 2 die Varietät SüD vor. Hierfür werden die spezielle Sprachkontaktsituation in Südschleswig und die dänische Minderheit kurz dargestellt. Darauf-

\footnotetext{
1 Im Folgenden wird Südschleswigdänisch mit SüD abgekürzt.

2 Im Folgenden werden die Bezeichnungen (Varietäten-)Kategorie und Varietätentyp synonym verwendet.
} 
hin werden die Varietät SüD und die bisherige Diskussion zu den verschiedenen Bezeichnungen und Kategorisierungen dieser Varietät skizziert.

Kapitel 3 präsentiert die verschiedenen Varietätentypen, die bisher mit dem SüD in Verbindung gebracht wurden, sowie ihre begriffskonstituierenden sowie ihre zusätzlichen charakteristischen Kriterien. Dieses Kapitel basiert auf einer umfangreichen Analyse der Fachliteratur zu den jeweiligen Forschungsansätzen, aus denen die entsprechenden begriffskonstituierenden und weiteren wichtigen Kriterien der spezifischen Varietätentypen herausgefiltert werden. Der hierdurch entwickelte Kriterienkatalog dient als theoretische Basis für das weitere Vorgehen in dieser Arbeit.

In Kapitel 4 erfolgt eine ausführliche synchrone Betrachtung des SüD. Es werden die spezifischen sprachsozialen sowie auch strukturellen Merkmale des SüD unter Verwendung des zuvor erstellten Kriterienkatalogs erörtert.

Kapitel 5 gleicht die Merkmale des SüD systematisch mit Hilfe des Kriterienkatalogs mit den Varietätentypen ab und analysiert, inwieweit das SüD den einzelnen Varietätentypen entspricht. Es wird verglichen, welche begriffskonstituierenden Kriterien der Varietätentypen auf das SüD zutreffen und welche weiteren Kriterien der Varietätentypen das SüD aufweist. Diese Einordnung soll nicht - wie bisher - das SüD zu klassifizieren versuchen, sondern in einer metaanalytischen Vorgehensweise erklären, welche Begriffe inwieweit auf das SüD zutreffen - oder nicht.

Kapitel 6 fasst die Einordnungsversuche zusammen. Zuletzt wird ein Fazit gezogen und ein Ausblick gegeben. 


\section{Südschleswigdänisch}

Die sprachliche Varietät SüD ist gekennzeichnet durch den langjährigen Sprachkontakt der benachbarten und nahe verwandten Sprachen Deutsch und Dänisch. Weder der historische noch der politische Hintergrund zum deutsch-dänischen Grenzgebiet sind Gegenstand dieser Arbeit. Kenntnisse über diese Themen werden vorausgesetzt. ${ }^{3}$ Zur besseren Einordnung der südschleswigdänischen Varietät erfolgt im nächsten Unterkapitel allerdings ein kurzer Einblick in die Sprachkontaktsituation. Im Anschluss daran wird die daraus resultierende sprachliche Varietät SüD beschrieben. Der Fokus dieses Kapitels liegt auf den bisherigen, das SüD zu kategorisieren bzw. varietätentypologisch einzuordnen.

\subsection{Sprachkontaktsituation in Südschleswig}

Die deutsch-dänische Grenzregion ist geprägt von einem intensiven Kontakt der Sprachen Deutsch und Dänisch sowie von Varietäten dieser, beispielsweise Niederdeutsch und der dänische Dialekt Südjütisch. Es besteht eine traditionelle linguistische Vielfalt (Pedersen 2009: 298). Die dänische Sprache steht seit dem Spätmittelalter zunächst mit dem Niederdeutschen, später mit dem Hochdeutschen in Kontakt (Braunmüller 1995: 149).

Südschleswig, der nördliche Teil Schleswig-Holsteins, umfasst das historische Schleswig südlich der deutsch-dänischen Grenze. So schreibt Kühl (2005: 28):

Es wird im Süden begrenzt durch die Eider und durch den Nord-Ostsee-Kanal bis hin zur Ostsee. Auf Deutsch wird der Begriff „Landesteil Schleswig“ benutzt, aber seit einiger Zeit spricht man zunehmend auch von „Südschleswig“, obwohl dieser Begriff früher fast ausschließlich mit der dänischen Minderheit verknüpft war.

In Südschleswig ist die ursprüngliche Sprache der südjütische Dialekt (Pedersen 2003: 7). Durch die geographische Nähe zu Deutschland und dem daraus resultierenden intensiven Sprachkontakt kam es im Laufe der Zeit zu einem Sprachwandel (Fredsted 1999: 56). Während der ersten Hälfte des 19. Jahrhunderts wurde der traditionelle dänische Dialekt weitestgehend durch das damals dominierende Niederdeutsch verdrängt (Kühl 2008: 39). Durch politische Umstände wurde ab dem Jahr 1867 Hochdeutsch als Verwaltungs-, Kirchen- und Unterrichtssprache in ganz Schleswig eingeführt (Fredsted 2009a: 12, Kühl 2008: 41-42). Dies hatte einen zweiten, für das heutige Gebiet Südschleswig bedeutsamen Sprachwechsel zufolge. Die Varietäten Friesisch, Niederdeutsch und Südjütisch stehen seither von Seiten der deutschen Hochsprache unter Druck. Infolgedessen ist beispielsweise der traditionelle dänische Dialekt Südjütisch „mittlerweile südlich der Gren-

\footnotetext{
3 Für eine konkrete Darstellung der historischen und politischen Begebenheiten im deutsch-dänischen Grenzland siehe u. a. Fredsted (2009a, 2009b), Kühl \& Bohn (2005), Kühl (2008) und Pedersen (2009).
} 
ze de facto ausgestorben“ (Kühl 2008: 42). Dieser Sprachkontakt resultiert in einer Mehrsprachigkeit bzw. Zweisprachigkeit vieler Sprecher dieses Gebietes (Fredsted 1999: 56). Bis zum heutigen Zeitpunkt besteht in dem deutsch-dänischen Grenzgebiet keine Übereinstimmung der Sprach- und Landesgrenzen. Auch zwischen Sprachgebrauch und staatlich-politischer Zugehörigkeit gibt es oftmals keinen Einklang (Kühl 2008: 39). Trotz einer immerwährenden Mehrsprachigkeit in diesem Gebiet, veränderte der nationalromantische Grundgedanke - die Übereinstimmung von Sprache und Nationalität die Situation des Gebietes grundlegend (Kühl 2008: 39) und hat auch heute noch einen wesentlichen Einfluss auf das Ansehen der Mehrsprachigkeit innerhalb der dänischen Minderheit.

\subsection{Dänische Minderheit}

Als Folge der Grenzziehung zwischen Dänemark und Deutschland nach der Volksabstimmung von 1920 entstanden auf beiden Seiten der Grenze nationale Minderheiten (Fredsted 1999: 56-57). Bei diesen Minderheiten handelt es sich nicht um sprachliche Minderheiten im eigentlichen Sinne, da es im deutsch-dänischen Grenzgebiet nie eine „1:1-Übereinstimmung zwischen Sprache und Nationalität“ gegeben hat (Fredsted 1999: 56). Vielmehr handelt es sich um nationale Minderheiten, d. h. um „Gruppen, die offiziell als Minderheiten anerkannt sind“ (Kühl 2005: 18). ${ }^{4}$

In Südschleswig entstand folglich die dänische Minderheit, deren Angehörige sich Dänemark zugehörig fühlen und sich mit dessen Kultur, Sprache etc. identifizieren (Kühl 2005: 11). Dänemark wird in diesem Zusammenhang als kin-state bezeichnet, d. h. als „verwandter Staat oder Zugehörigkeitsland. [...] In der Regel handelt es sich dabei um einen Staat, der als sprachliches, kulturelles oder nationales Heimatland aufgefasst oder definiert wird. Das gilt für Dänemark im Verhältnis zu der dänischen Minderheit in Deutschland“ (Kühl 2005: 11-12). Umgekehrt erkennt Dänemark „die dänische Gruppe südlich der Grenze als ,seine“ Minderheit und Teil der dänischen Kultur“ an (Kühl 2005: 22).

Der dänischen Minderheit gehören schätzungsweise 50.000 Mitglieder an (Stand: 2005), was ca. 10 \% der Gesamtbevölkerung der Region ausmacht (Kühl 2005: 34). Eine offizielle Registrierung der Mitglieder darf infolge der Bonn-Kopenhagener Erklärungen von 1955 nicht durchgeführt werden. Der zentrale Aspekt dieser Erklärungen „ist die Anerkennung des Prinzips der subjektiven Identitätswahl (,Minderheit ist, wer will'), das seitdem die Grundlage für die Minderheiten nördlich und südlich der deutsch-dänischen Grenze bildet“ (Kühl 2008: 27). Infolge dieses sogenannten Gesinnungsprinzips besteht die dänische Minderheit in Südschleswig aus denen, die sich selbst als zugehörig

4 Kühl (2005: 18) verweist in diesem Kontext auf die Problematik der Definition von nationalen Minderheiten, auf die hier nicht weiter eingegangen werden soll; hierzu siehe Kühl (2005: 18-19). Für die vorliegende Arbeit soll diese weite Definition genügen. 
beschreiben (Pedersen 2003: 9). Diese individuelle Entscheidung darf - ebenfalls in Folge der Bonn-Kopenhagener Erklärungen - weder überprüft noch in Frage gestellt werden (Pedersen 2009: 299). Das subjektive Merkmal des „Sich-Dänisch-Fühlen““, d. h. der Identifikation mit den Werten und Normen der dänischen Kultur, stellt das innere Kriterium der Zugehörigkeit dar (Pedersen 1991: 88). Äußere und somit objektive Kriterien sind unter anderem die Mitgliedschaft in einer der Organisationen und Vereine ${ }^{5}$ der dänischen Minderheit, die Mediengewohnheiten und das Bestreben, die eigenen Kinder in einen dänischen Kindergarten oder in eine dänische Schule zu geben (Pedersen 1991: 88-89). ${ }^{6}$ Diese objektiven äußeren Kriterien sind jedoch nicht obligatorisch für eine $\mathrm{Zu}$ gehörigkeit zur dänischen Minderheit. Die Beherrschung der dänischen Sprache ist ebenfalls nicht obligatorisch, stellt aber ein äußeres Kriterium dar (Pedersen 2003: 9). "[I]t is not a condition that the minority language is also the mother tongue" (Pedersen 2009: 299).

Je nachdem, welche Kriterien ein Mitglied der dänischen Minderheit erfüllt oder nicht, kann zwischen „mindestens drei Arten und Intensitäten der Gruppenzugehörigkeit differenziert werden“, die in konzentrischen Kreisen dargestellt werden können (Kühl 2004: 326-327). Im inneren Kreis - auch membership ,Mitgliedschaft' genannt besteht nach Kühl (2004: 327)

[...] eine völlige Übereinstimmung zwischen Identifikation und objektiven Merkmalen. Diese „Kerndänen“ fühlen sich als Dänen, bezeichnen sich als Dänen und sprechen Dänisch. Sie konsumieren dänische Kultur und orientieren sich an den als „dänisch“ definierten Phänomenen.

Der Kernkreis wird von einem weiteren Kreis umschlossen, „wo Sprache und Identifikation nicht unbedingt übereinstimmen, aber wo die der Minderheit sich zugehörig fühlenden Menschen [...] dennoch des Dänischen mächtig sind und eindeutige kulturelle Kompetenzen besitzen“ (Kühl 2004: 327). Diese Art der Zugehörigkeit wird als affiliation ,Affiliation' bezeichnet. Der dritte, äußere Kreis erfasst diejenigen, die ein subjektives Zugehörigkeitsgefühl aufweisen, bei denen allerdings „die Intensität der Übereinstimmung zwischen subjektiver nationaler Identifikation und den dazugehörigen objektiven Merkmalen“ (Kühl 2004: 327) abnimmt, je weiter sie sich dem äußeren Rand nähern. „Hier ist also eine Affinität (Affinity) zur Minderheit vorherrschend, die zum Teil nur kontextuell bedingt feststellbar ist“ (Kühl 2004: 327). Die konzentrischen Kreise sind

5 Die acht Hauptorganisationen der dänischen Minderheit sind Sydslesvigsk Forening, Sydslesvigsk Voelgerforening, Sydslesvigs danske Ungdomsforeninger, Dansk Kirke i Sydslesvig, Dansk Skoleforening for Sydslesvig, Dansk Sundhedstjeneste for Sydslesvig, Dansk Centralbibliotek for Sydslesvig und Flensborg Avis. Diese dienen als Informations- und Koordinationsorgan und repräsentieren die dänische Minderheit in der Öffentlichkeit (Pedersen 2003: 9-10).

6 Die Mitgliedschaft in dem Sportverein der dänischen Minderheit, sowie die Benutzung der dänischen Zentralbibliothek in Flensburg stellen nach Pedersen (1991: 89) keine eindeutigen äußeren Kriterien dar. 
„durchlässig, semipermeabel, und erlauben es Individuen, sich in ihrer Identifikation zwischen den jeweiligen Ebenen zu bewegen“" (Kühl 2004: 328). Demzufolge ist die nationale Identität bei nationalen Minderheiten wie der dänischen Minderheit „keine Frage des Entweder-Oders, sondern beinhaltet das Faktum des Sowohl-als-Auch“ (Kühl 2004: 329).

Fredsted (1999: 57) betont, dass sich in den äußeren Kreisen eine große Anzahl von Personen befindet und diese „nur eine lockere Zugehörigkeit [...] haben, indem sie z. B. zwar die Institutionen der Minderheit [...] wie Kindergärten, Schulen und Freizeiteinrichtungen für ihre Kinder nutzen, selber aber z. B. die Minderheitensprache nicht beherrschen." Die Zugehörigkeit zur dänischen Minderheit lässt sich somit nicht an der Erstsprache der Mitglieder festmachen (Pedersen 1991: 88). Von Seiten Dänemarks sowie der hinzugezogenen Dänen in Südschleswig stellt der nationalromantische Grundgedanke die Grundlage einer nationalen Minderheit dar. Demnach sollen Sprache und nationale Identität idealerweise übereinstimmen, d. h. Dänischgesinnte sollen die dänische Sprache sprechen, damit sie eine nationale Identität aufweisen. Sie fordern eine Einsprachigkeitsnorm mit einem Zusammenfall von Sprache und nationaler sowie auch ethnischer Identität (Pedersen 2003: 22, 2009: 299-300). Es besteht von den Kritikern der Zweifel, ob die Minderheit wahrhaftig dänisch ist, wenn die Mitglieder Dänisch nur in begrenzten Kontexten sprechen. Diese Kritiker sind der Auffassung, dass die Mitglieder der Minderheit nur dann eine nationale dänische Identität besitzen, wenn diese in den öffentlichen sowie auch privaten Kontexten Dänisch verwenden, weshalb sie fordern, dass Dänisch - und nicht wie üblich Deutsch - die Familiensprache ist (Pedersen 200oa: 123, 2005: 134).

Die Realität sieht allerdings anders aus. In Südschleswig besteht eine Zweisprachigkeitsnorm. So haben Deutsch und Dänisch Funktionsgebiete in der dänischen Minderheit. Weder der Gebrauch von Deutsch oder SüD, noch Sprachkontaktphänomene wie Codeswitching (d.h. der Wechsel zwischen Sprachen in einer Konversation; Trudgill 1992: 16) haben einen Einfluss auf eine individuelle dänische Nationalidentität (Pedersen 2003: 22-23). Demzufolge verwenden die Mitglieder der dänischen Minderheit im Alltag die sprachliche Varietät SüD, Standarddänisch, Deutsch oder Niederdeutsch (Pedersen 2005: 130). Es gibt allerdings eine funktionelle Verteilung der Sprachen innerhalb der Minderheit, sodass Dänisch und Deutsch in unterschiedlichen Kontexten verwendet wird. Standarddänisch wird in den Institutionen der dänischen Minderheit bevorzugt. Vor allem die dänischen Kindergärten und Schulen verfolgen eine Einsprachigkeitsnorm. Die standarddänische Varietät stellt für die meisten Angehörigen der Minderheit eine Institutionssprache dar (Pedersen 2002: 406). SüD hingegen wird in privaten Gruppen oder familiären Kontexten benutzt und markiert somit Bekennen und Loyalität zum Dänischen. Deutsch (d. h. Plattdeutsch, norddeutsche Umgangssprache oder Hochdeutsch) wiederum wird in allen anderen Sphären sowie in Kontexten der deutschen Mehrheitsgesellschaft verwendet (Braunmüller 1996: 36, Pedersen 2003: 22). 
Dieser Abschnitt verdeutlicht die besondere Sprachkontaktsituation der Region und zeigt die komplexen Voraussetzungen für die Entstehung des SüD auf.

\subsection{Südschleswigdänisch}

Der Begriff Varietät wird in dieser Arbeit in Anlehnung an Trudgill (1992: 77) als neutraler Terminus verwendet, um jegliche Art von Sprache zu beschreiben: „A neutral term used to refer to any kind of language - a dialect, accent, sociolect, style or register - that a linguist happens to want to discuss as a separate entity for some particular purpose. “ Eine Varietät tritt immer als eine sprachliche Form einer historisch-natürlichen Sprache auf. Eine historisch-natürliche Sprache wiederum bezeichnet ein Sprachsystem, das „heute oder in der Vergangenheit oder Zukunft von einer bestimmten Sprecherbevölkerung gesprochen oder auch geschrieben und traditionsgemäß mit einem eigenen Namen bezeichnet wurde“ (Berruto 2004: 189). Sie besteht aus einer oder mehreren Varietäten (Berruto 2004: 189). ${ }^{7}$ Weiterhin schreibt Berruto (2004: 188):

Der vortheoretischen beobachtenden Erfahrung ist bekannt, dass ein und dieselbe Sprache verschieden gesprochen (oder auch geschrieben) wird, in Abhängigkeit von Ort, Zeit, Sprecher/Schreiber und Umstand, oder, allgemeiner, den spezifischen sozialen Bedingungen, unter denen sie verwendet wird. Jede dieser verschiedenen Spielarten, Sprechweisen oder Existenzformen einer historisch-natürlichen Sprache kann man als Sprachvarietät oder einfacher Varietät bezeichnen.

Als Standardsprachen bzw. -varietäten werden jene Varietäten bezeichnet, die eine überregionale Norm besitzen, die ebenfalls als Norm in Institutionen - vor allem in der Schule - angesehen werden (Quist 2000: 182). ",Standard' wird geschrieben, er ist schriftlich kodifiziert [...] besitzt überregionale Reichweite und Gültigkeit, wird vorzugsweise in institutionellen Kontexten und offiziellen Kommunikationssituationen benutzt“ (Dittmar 1997: 201).

In Südschleswig werden zwei dänische Varietäten verwendet: Das Standarddänische und eine Varietät - das SüD -, die von einer Reihe Sprachkontaktphänomenen innerhalb der Phonologie, Grammatik und Semantik charakterisiert ist, die vor allem aus dem Deutschen transferiert wurden (Pedersen 2009: 302). So beschreibt Fredsted (2009b: 11) SüD als

[...] die gesprochene Varietät des Dänischen, die von der dänischen Minderheit im Landesteil Schleswig in Schleswig-Holstein gesprochen wird. Das von vielen Angehörigen der Minderheit gesprochene Dä-

7 Für eine ausführliche Abgrenzung der Begriffe Sprache, (Sprach-)Varietät, Standardsprache und Standardvarietät siehe Ammon (2004) und Berruto (2004). 
nisch ist weder Sønderjysk [...] aber auch kein Standarddänisch, sondern das sogenannte, Südschleswigdänisch' (SüD).

SüD ist somit eine Varietät der historisch-natürlichen Sprache Dänisch. Die Varietät ist abzugrenzen von dem Dänisch als Minderheitensprache der gesamten dänischen Minderheit. Während das Dänisch als offizielle Minderheitensprache zumeist das Standarddänisch meint, das durch die Europäische Charta der Regional- und Minderheitensprachen geschützt und verbreitet werden soll, so ist mit der Varietät SüD eine weitere däni sche Varietät gemeint, die von der deutschen Sprache beeinflusst wurde (Pedersen 2003: 15). Das SüD wird vor allem von denjenigen verwendet, die Deutsch als Erstsprache haben, Dänisch als Zweitsprache in den Institutionen der dänischen Minderheit erworben haben (Pedersen 2009: 302) sowie in Südschleswig aufgewachsen sind (Pedersen 200ob: 244).

Die Varietät SüD setzt sich aus drei wesentlichen Hauptfaktoren zusammen: sprachsoziale Faktoren (Funktion), strukturelle Faktoren (Form) und Mehrsprachigkeit (vgl. Abb. 1). Unter den sprachsozialen Faktoren werden jene verstanden, die sich auf die speziellen außersprachlichen Merkmale beziehen. Hierunter fallen alle wesentlichen Aspekte des SüD, die aus ethno- und soziolinguistischer Perspektive in der Forschungsliteratur diskutiert werden, wie beispielsweise das Gruppenzugehörigkeitsgefühl, der Kontext und die Region. Die strukturellen Faktoren betreffen konkret das sprachliche System. Hierzu zählen vor allem die linguistischen Realisierungen der Varietät. ${ }^{8} \mathrm{Zu}$ den strukturellen Faktoren gehören zudem allgemeine innersprachliche Merkmale, die vor allem in kontaktlinguistischen Analysen diskutiert werden, wie u. a. Mündlichkeit und Sprachkontaktphänomene wie Codeswitching. Mehrsprachigkeit, der dritte Aspekt, stellt die Basis des SüD dar und bildet die Grundlage der Entstehung des SüD. Die Mehrsprachigkeit resultiert aus der Sprachkontaktsituation heraus und hat zudem Einfluss auf die strukturellen Merkmale des SüD. Sie darf demnach bei einer varietätentypologischen Einordnung nicht außer Acht gelassen werden, sondern soll vielmehr quer zu allen anderen Faktoren betrachtet werden. So beschreibt Kühl (2008: 99) die Sprachsituation in der dänischen Minderheit als eine „dynamisch-bilinguale Situation [...] in der es keine Monolingualität gibt.“ Zu diesem Aspekt zählt nicht nur die individuelle Mehrsprachigkeit einzelner Sprecher, sondern ebenfalls, bedingt durch die spezielle Sprachkontaktsituation, eine gesellschaftliche Mehrsprachigkeit. ${ }^{9}$

8 Auf die konkreten linguistischen Varianten des Südschleswigdänischen auf den verschiedenen strukturellen Ebenen (Phonologie, Morphologie, etc.) wird in dieser Arbeit nicht eingegangen. Für eine konkrete Darstellung dieser siehe u. a. Christophersen (1985), Fredsted (1997, 2009b), Kühl (2008) und Pedersen (200oa, 2009).

9 Für eine ausführliche Darstellung der individuellen und gesellschaftlichen Mehrsprachigkeit allgemein siehe Riehl (2014). 


\section{Südschlewigdänisch}

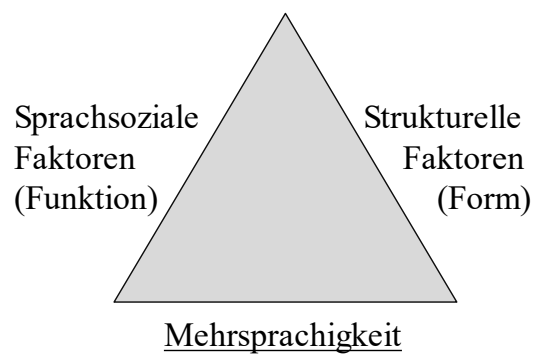

Abb. 1: Die drei Hauptfaktoren des SüD

\subsection{Kategorisierung des Südschleswigdänischen}

Die Varietät SüD erfährt in der bisherigen Forschungsliteratur eine Vielzahl an Kategorisierungs- und Bezeichnungsversuchen. Pedersen (200ob: 226) fasst die Problematik zusammen:

I et forsøg på at kategorisere sydslesvigdansk er der fremsat flere mere eller mindre definitive forslag. Det er i tidens løb blevet kaldt bilingvalt dansk, en dialekt, et blandings-sprog, et interferenssprog, et gruppesprog, et identifikationssprog, et kreolsprog, et kreoloidsprog og et regionalt mål eller et regionalsprog.

Die bisherigen Kategorisierungen und Bezeichnungen des SüD weisen deutliche Unterschiede auf und beruhen auf verschiedenen Perspektiven. Zum einen setzen u. a. Pedersen (2000a, 200ob, 2009) und Braunmüller (1995) an einer soziolinguistischen Perspektive an. Pedersen (2003) greift zudem noch einen ethnolinguistischen Ansatz auf. Bei dieser Perspektive liegt der Schwerpunkt auf den gesellschaftlichen und außersprachlichen, d. h. den funktionellen, Faktoren, die das SüD konstituieren und charakterisieren. Zum anderen verfolgen Fredsted (2009b) und Kühl (2008) einen kontaktlinguistischen Ansatz, der die formalen bzw. strukturellen Ausprägungen der südschleswigdänischen Varietät fokussiert.

Im Folgenden werden in Anlehnung an Pedersen (2000b: 225-245, 2009: 302-303) mögliche Kategorisierungen und alternative Bezeichnungen des SüD dargestellt und erläutert.

Eine Form des Reichsdänischen. Christophersen (1985) versteht unter der Bezeichnung Südschleswigdänisch eine Form des Reichsdänischen, die von südschleswigschen Anpassungen und Besonderheiten geprägt ist. Pedersen (200ob: 225) kritisiert in dem Zusammenhang den Gebrauch des Terminus rigsdansk ,Reichsdänisch', da dieser nicht eindeutig definiert ist. Auch Søndergaard (1985: 5) sieht SüD als eine Form des Reichsdä- 
nischen und beschreibt es als „tilstræbt rigsdansks talesprogskode“ , angestrebter reichsdänischer mündlicher Kode‘. Das Adjektiv angestrebt lässt schließen, dass Søndergaard ein reichsdänisches Normideal voraussetzt und somit eine normative Definition von SüD bevorzugt (Pedersen 20oob: 226). Zudem beschreibt auch Braunmüller (1991: 24) das SüD als eine Varietät des Reichsdänischen. In ihrer Darstellung kritisiert Pedersen (200ob: 225-226) jedoch auch diese Ansicht, da nicht nur der Begriff rigsdansk, Reichsdänisch', sondern ebenfalls die Termini rigsmål bzw. rigssprog, Reichssprache kontrovers diskutiert werden und keine Einigung besteht, was diese Konzepte genau umfassen. ${ }^{10}$

In diesem Zusammenhang werden sprachliche Variationen innerhalb der Varietät SüD oftmals als Abweichungen zur reichsdänischen Norm - d. h. als Fehler oder inkorrektes Dänisch - charakterisiert. So schreibt Christophersen (1985: 4):

I sydslesvigerens danske sprog trænger der en række germanismer ind, men som oftest betegner vi dem som sydslesvigismer, dels på grund af deres almindelige udbredelse - mange er slet ikke klar over, at de udtryk, de anvender, er ukorrekt rigsdansk.

Ferner beschreibt Braunmüller (1995: 144-147) das SüD als eine „undänische“ und „nachlässige“ Variante, „die von Germanismen und Konstruktionen geprägt ist, die jedoch in der dänischen Standardsprache nicht sehr häufig anzutreffen sind“. Konkrete linguistische Sprachbeispiele bezeichnet er als „äußerst fehlerhaft“ klingend.

Bilinguales Dänisch. Søndergaard (1985: 5) charakterisiert das SüD darüber hinaus als bilingvalt dansk, bilinguales Dänisch', d. h. als eine Form des Dänischen, die aufgrund der bilingualen Sprecher vom Deutschen geprägt ist. Pedersen (20oob: 226) hingegen präferiert die Bezeichnung bilingvalt sprog ,bilinguale Sprache', da sie der Auffassung ist, dass die Bezeichnung bilinguales Dänisch nicht das Merkmal betont, dass in diesem Fall Deutsch und Dänisch die in Kontakt tretenden Sprachen sind. Diese Bezeichnungen sieht Pedersen als Zusatzbezeichnung, nicht aber als Kategorisierung an.

Hybridisierte dänische Varietät. Dyhr (1990: 38) bezeichnet SüD als eine „hybridisierte dä[nische] Varietät“, die durch das Phänomen der Hybridisierung charakterisiert ist. Er verwendet den Terminus der Hybridisierung hier in Abgrenzung zur Bezeichnung der Sprachmischung (Dyhr 1990: 42). Diese neuartige Bezeichnung legt den Fokus somit auf die Form des SüD und ignoriert jegliche sprachsozialen Aspekte der Varietät.

Die bisherigen konkreten Kategorisierungsversuche in prototypische Varietätenkategorien werden im Folgenden kurz dargestellt:

1. Interferenz- oder Mischsprache. Braunmüller (1995: 144) klassifiziert das SüD als Interferenz- oder Mischsprache und begründet es mit der Tatsache, dass SüD viele sprachliche Merkmale aufweist, die für Deutsche typisch sind, die Dänisch als Fremdsprache erlernt haben. SüD ist demnach das Resultat der starken Einwirkung von der 
dominierenden Sprache Deutsch auf das Dänisch der Südschleswiger. Nach Braunmüller (1995: 146) ist das SüD ohne Deutschkenntnisse oft nur schwer zu verstehen.

Pedersen (200ob: 230-231) argumentiert mit Bakkers \& Muyskens (1995: 51) sowie auch Smiths (1995) Kriterien einer Mischsprache gegen die Annahme, dass es sich beim SüD um eine Mischsprache handelt. Nur bei einer Redefinition dieses Terminus ließe sich das SüD als Mischsprache klassifizieren. Bei dieser Auffassung wird lediglich der formale Aspekt des SüD berücksichtigt. Aus dieser Einseitigkeit heraus weitet Braumüller (1995) seinen Ansatz wie folgt aus:

2. Identifikations- und Gruppensprache. Da nicht nur die strukturellen Aspekte, sondern auch die funktionalen Merkmale des SüD als wesentlicher Faktor gelten (vgl. Abb. 1) und in einer Kategorisierung berücksichtigt werden müssen, beschreibt Braunmüller (1995: 150) das SüD zudem als Identifikations- und Gruppensprache:

Nach innen fungiert das [SüD] als Identifikationssprache für alle, die sich als Dänen fühlen. Nach außen bewirkt diese Sprache, die die meisten Deutschen nicht unmittelbar verstehen können, als ein Mittel, um Abstand zu dem ansonsten und überall dominierenden Teil der Bevölkerung herzustellen. [SüD] kann man aus diesem Grund als eine Gruppensprache bezeichnen, die innerhalb der Minderheit als Identifikationssprache fungiert und dazu beiträgt, die Minderheit gegenüber der Mehrheitsbevölkerung abzugrenzen.

Auf der strukturellen Ebene stellt das SüD folglich eine Mischsprache dar, auf der funktionellen Ebene wiederum eine Identifikations- und Gruppensprache (Pedersen 2ooob: 230-231).

3. Dialekt. Die Kategorisierung des SüD als Dialekt wird in der Forschungsliteratur ausgiebig diskutiert. Die meisten Autoren lehnen die Kategorie Dialekt - im traditionellen Sinne als eine geographisch abgrenzbare Varietät - in Bezug auf das SüD ab. „, They concluded that South Schleswig Danish fitted only into the geographical criteria " (Pedersen 2009: 303). Unter anderem ist Braunmüller (1995: 144) der Ansicht, dass die Kategorie Dialekt nicht auf das SüD zutrifft. Zwar hat SüD einige gemeinsame Merkmale mit dem traditionellen dänischen Dialekt der Region, Südjütisch, dennoch stellt Dänisch keinen traditionellen Dialekt dar (Braunmüller 1991: 24, 1995: 144, 1996: 34). Eine extreme Ansicht vertritt Christophersen (1985: 4), der die Kategorisierung des SüD als Dialekt als Höflichkeitsgeste bezeichnet, um die Einflüsse der deutschen Sprache nicht als Fehler bezeichnen zu müssen. Auch Søndergaard (1985) argumentiert gegen die Annahme, dass SüD ein Dialekt ist. Er betont zwar, dass das Kriterium der regionalen Abgrenzung gegeben ist, stellt aber fest, dass weitere Kriterien eines Dialekts nicht gegeben sind. In populärwissenschaftlichen Kontexten hingegen wird das SüD oftmals als Dialekt bezeichnet: "Turning from the scientific to the popular notion of the variety it is characteristic that many minority members regard it as a dialect in the sense of a sub-standard variety of Danish“ (Pedersen 2009: 314). 
Pedersen (200ob: 228) führt diese Dichotomie auf die Definitionsproblematik des Begriffs Dialekt zurück. Nach der kontinentaleuropäischen Auffassung eines Dialekts stellt das SüD keinen Dialekt dar (Braunmüller 1991: 24, 1995: 144, 1996: 34). Stützt man sich allerdings auf die angelsächsische Definition von Dialekt nach u. a. Trudgill (1992), so kann das SüD als dialektale Varietät bezeichnet werden. Allerdings werden unter dieser Begriffsauffassung auch Standardvarietäten als Dialekte klassifiziert, weshalb nach dieser Auffassung auch das Standarddänische einen Dialekt darstellt.

4. Regionalsprache. Die Kategorisierung des SüD als Regionalsprache wird erstmals bei Braunmüller (1996) diskutiert. Als Regionalsprache sieht er jene Sprache an, die in einer bestimmten Region gesprochen sowie geschrieben wird (Braunmüller 1996: 42). ${ }^{11}$

Pedersen (200ob: 244) argumentiert gegen diese Kategorisierung und betont zum einen, dass der Begriff redefiniert werden muss, damit dieser auf das SüD zutrifft. Zum anderen kritisiert sie, dass bei Regionalsprachen die Festlegung einer Region keinen eindeutigen Kriterien unterliegt. Auch die Abgrenzung des Begriffs zu Dialekt ist problematisch.

5. Ethnolekt. Pedersen (2002, 2005) bezeichnet das SüD unter anderem als Ethnolekt. „Men sprogkontaktfænomenerne resulterer i en selvstændig varietet som kaldes sydslesvigsk. Den kan [...] karakteriseres som en etnolekt, dvs. en etnisk gruppes sprog " (Pedersen 2002: 408). Sie bezieht sich hier lediglich auf die Tatsache, dass das SüD die Sprache einer ethnischen Gruppe ist, begründet diese Annahme jedoch nicht weiter. Auch in einem weiteren Artikel bezeichnet Pedersen (2005: 128) die Varietät als Ethnolekt: „Mindretalssproget dansk er ofte en etnolekt som kaldes sydslesvigsk. Den er karakteriseret ved en række træk, som skyldes påvirkninger fra tysk. "Eine aussagekräftige Argumentation hierfür ist nicht gegeben.

6. Soziolekt. Braunmüller (1995: 144) lehnt nicht nur die Bezeichnung des SüD als Dialekt, sondern auch als Soziolekt ab. Eine Begründung dieser Ansicht bleibt offen.

7. Kreolsprache. Braunmüller (1995: 152) ist der Ansicht, dass das SüD als eine dänische „Kreolsprache auf deutschem Substrat“ kategorisiert werden könnte, wenn der Prozess der Kreolisierung nicht negativ konnotiert wäre. Diese Auffassung betont vor allem den formalen Aspekt des SüD. Pedersen (200ob: 233) argumentiert hingegen, dass eine Kreolsprache immer die Erstsprache der Sprecher ist. Dies ist beim SüD nicht bzw. sehr selten gegeben.

8. Kreoloidsprache. Braunmüller (1996) und Fredsted (1997) kategorisieren die Varietät SüD als eine Kreoloidsprache im Sinne Trudgills (1992, 1994). Braunmüllers Argumentation beruht allerdings fälschlicherweise auf Begrifflichkeiten des Varietätentyps

11 Diese Definition von Regionalsprache grenzt sich von der Definition der Europäischen Charta der Regional- und Minderheitensprachen ab; siehe hierzu Council of Europe (1992). In Bezug auf das Südschleswigdänisch diskutiert Pedersen (2009: 313) diese Definition. Da es sich hierbei allerdings um eine rein politische Auffassung handelt, die dem Schutz von Regional- und Minderheitensprachen dienen soll und die Charta die Varietät SüD nicht explizit aufgreift, sondern lediglich Dänisch als Minderheitensprache definiert (Pedersen 2002: 402), werden diese Definitionen nicht weiter beleuchtet. 
Kreolsprachen, weshalb aus dieser Diskussion nicht hervorgeht, ob es sich beim SüD wahrhaftig um eine Kreoloidsprache handelt (Pedersen 20oob: 236). Fredsteds Argumentation hingegen ist zwar nachvollziehbar, dennoch kritisiert Pedersen (200ob: 236) diese Annahme. Sie argumentiert, dass das SüD eine Erstsprache sein muss, um dieser Kategorie gerecht zu werden. Lediglich eine Redefinition der Kategorie würde eine Klassifizierung des SüD als Kreoloidsprache zulassen (Pedersen 20oob: 234-236).

9. Zweitsprachen-Kreoloidsprache. In ihrer Diskussion zu den bisherigen Kategorisierungsversuchen des SüD greift Pedersen (20oob: 236) zudem den Terminus non-native creoloid ,Zweitsprachen-Kreoloidsprache nach Trudgill (1996) auf. Sie lehnt diesen allerdings mit der Begründung ab, dass eine Zweitsprachen-Kreoloidsprache eine Brücke zwischen zwei Sprechergruppen bildet, die keine Sprache gemeinsam haben. Dieses Merkmal ist beim SüD nicht gegeben.

10. Kontaktvarietät. Eine weitere Kategorisierung des SüD - aus kontaktlinguistischer Perspektive - nimmt u. a. Fredsted (2009a: 14) vor und kategorisiert es als

eine Kontaktvarietät, die durch den Einfluss der deutschen Sprache in der dänischen Minderheit im Landesteil Schleswig südlich der Grenze entstanden ist und sich von der dänischen Standardvariante, Rigsdansk, sowie von der dänischen dialektalen Varietät, Sønderjysk, beträchtlich unterscheidet.

Auch Kühl (2008: 48-49) schließt in ihrer Bezeichnung des SüD als „eine Varietät des Dänischen, die - wenngleich mit individuellen Unterschieden - Züge einer Kontaktspra che von Deutsch und Dänisch aufweist", das wesentliche Merkmal des Kontakts zweier Sprachen mit ein. Zudem schließt sie in ihrer Bezeichnung die zahlreichen individuellen Ausprägungen der einzelnen Sprecher mit ein.

Diese Zusammenfassung macht deutlich, dass eine eindeutige Kategorisierung des SüD bisher nicht hinreichend erfolgt ist. Aus ebendiesem Grund definiert Pedersen (2009: 314, 200ob: 244) eine neue Kategorie, die speziell auf das SüD zugeschnitten ist und ihrer Ansicht nach formale sowie funktionale Merkmale gleichermaßen einschließt. Es handelt sich hierbei um die soziolinguistische Bezeichnung border regional minority language ,grenzregionale Minderheitensprache‘. Es ist jedoch kritisch anzumerken, dass diese Kategorie bisher keine allgemeine Gültigkeit hat. „It is also to be analyzed whether other national border minorities have developed varieties that fit into the definition. Before that is clarified the category cannot be justified" (Pedersen 2009: 314).

Es lässt sich zusammenfassen, dass die südschleswigdänische Varietät zahlreiche Bezeichnungen und Kategorisierungen erfährt und mit insgesamt zehn verschiedenen prototypischen Varietätenkategorien in Verbindung gebracht wird. Keine dieser Varietätenkategorien scheint für das SüD zutreffend. 


\subsection{Problematik der Kategorisierung}

Die neuesten Forschung folgt zwei verschiedenen Perspektiven. Die sozio- und ethnolingustische Perspektive stützt sich auf Pedersens (200ob: 244, 2009: 313) Bezeichnung des SüD als gronseregionalt mindretalssprog oder border regional minority language, grenzregionale Minderheitensprache. Diese Bezeichnung stellt jedoch keine Kategorie im traditionellen Sinne dar, sondern ist eine speziell auf das SüD zugeschnittene Bezeichnung, die von Pedersen neu definiert wurde. Auf der anderen Seite verfolgt die kontaktlinguistische Perspektive die Kategorisierung des SüD unter dem weit gefassten Begriff der Kontaktvarietät (Fredsted 2009b: 11, Kühl 2008: 48-49).

Die bisherigen varietätentypologischen Einordnungsversuche in die obengenannten Kategorien scheinen zudem einem bestimmten Muster zu folgen. Die Autoren gehen von einer prototypischen Kategorie aus der Soziolinguistik bzw. Kontaktlinguistik aus und versuchen diese auf das SüD anzuwenden. Diese Methode wird in Abb. 2 veranschaulicht.


Abb. 2: Schematische Darstellung der Versuche einer Kategorisierung des SüD

Es wird deutlich, dass diese Vorgehensweise einer varietätentypologischen Kategorisierung zwei wesentliche Nachteile mit sich bringt. Ein Hauptproblem besteht darin, dass wie in Kapitel 2.4 verdeutlicht wurde - keine der Kategorien vollkommen auf das SüD passt. So schreibt Pedersen (200ob: 244):

Specielle kriterier inden for både sprogtilegnelsen, sprogbrugerniveauet og det socialpsykologiske niveau tyder på at vi har at gøre med en helt selvstændig dansk varietet, der kun gennem redefineringer kan indpasses i gængse og velbeskrevne kategorier.

Die Kategorien werden oftmals redefiniert, um dem Phänomen des SüD gerecht zu werden. Pedersen (200ob: 226) bringt diese Problematik auf den Punkt: „Karakteristisk for mange af kategorierne er at de er blevet redefineret i forsøget på at få sydslesvigdansk til at passe ind." Die bisher auf das SüD angewandten Kategorien mussten redefiniert und 
umgeformt werden, damit sie dem Phänomen SüD gerecht werden (vgl. Abb. 2, gestrichelte Linie). Das Resultat sind verschiedene redefinierte Kategorien.

Ein weiteres Problem besteht darin, dass keine der Kategorien alle Merkmale des SüD erfassen (vgl. Abb. 2, überstehende Ecken). „Den danske varietet sydslesvigsk passer ikke rigtigt ind i nogen af de kategorier den er forsøgt placeret i“ (Pedersen 20oob: 243). Während die neudefinierte Bezeichnung auf einem soziolinguistischen Ansatz beruht und die Funktion der Varietät betont, stützt sich die zweite Klassifizierung auf eine kontaktlinguistische Herangehensweise und legt den Fokus auf die strukturellen Faktoren. Das in Abb. 1 (vgl. Kapitel 2.3) dargestellte Gleichgewicht ist in keiner der bisherigen Kategorisierungen gegeben, d. h. eine Kombination beider Seiten und somit eine Verschränkung von Funktion und Form sowie die Berücksichtigung der Mehrsprachigkeit als Basis ist bisher nicht gelungen. Zudem handelt es sich bei der ersten Bezeichnung um eine neudefinierte - und folglich keine prototypische - Kategorie.

Der Ausgangspunkt eines jeden Kategorisierungsversuches war bisher der prototypische Varietätentyp bzw. die Kategorie an sich. Da dies bisher zu keinem zufriedenstellen den Ergebnis führte, wird in der vorliegenden Arbeit eine umgekehrte Herangehensweise gewählt und vom Objekt - d. h. von der Varietät des SüD - ausgegangen.

\section{Schlussfolgerung zu Kapitel 2}

Die komplexe Sprachkontaktsituation im deutsch-dänischen Grenzland mit ihrer traditionellen sprachlichen Mannigfaltigkeit resultierte in der Entstehung einer neuen sprachlichen Varietät - dem SüD. Diese Varietät wird von einer beträchtlichen Anzahl der Angehörigen der dänischen Minderheit in Südschleswig verwendet. Bisher gibt es keinen Konsens darüber, wie das SüD varietätentypologisch einzuordnen ist. Während Fredsted (2009b) und Kühl (2008) mit der weit gefassten Kategorie Kontaktvarietät einen kontaktlinguistischen Ansatz verfolgen und den formalen Aspekt der Varietät betonen, wird von soziolinguistischer Seite der funktionelle Aspekt betont und SüD mithilfe einer neudefinierten Bezeichnung als grenzregionale Minderheitensprache (Pedersen 2009) beschrieben.

Die Problematik einer varietätentypologischen Einordnung des SüD wurde angedeutet. Keine traditionelle Varietätenkategorie greift das SüD gleichermaßen mit den funktionellen und strukturellen Eigenheiten. Darüber hinaus lässt sich das SüD in keine Varietätenkategorie problemlos und ohne Redefinition dieser Kategorie einordnen. Das soll im Verlauf dieser Arbeit genauer analysiert werden. Hierfür werden im folgenden Kapitel die Varietätentypen voneinander abgegrenzt und definiert. 



\section{Relevante Varietätentypen und ihre Kriterien}

Dieses Kapitel bildet die theoretische Grundlage der vorliegenden Arbeit. Im Folgenden wird auf die in Bezug auf das SüD zehn diskutierten Varietätentypen (Kategorien) aus Kapitel 2.4 eingegangen. Zudem werden vier weitere, für das SüD relevante Varietätentypen in die Diskussion aufgenommen.

Die Varietätentypen werden einzeln vorgestellt und es wird dargelegt, inwieweit die jeweiligen Definitionen in der Forschungsliteratur diskutiert werden. Zu jedem Varietätentyp wird zunächst das begriffskonstituierende Kriterium herausgearbeitet, d. h. jenes Kriterium, das den jeweiligen Varietätentyp primär bestimmt. Daraufhin werden weitere, mit den einzelnen Varietätentypen in Verbindung gebrachte Kriterien beschrieben. Die Kriterien werden nach jeder Darstellung tabellarisch zusammengefasst.

In Kapitel 3.2 werden die aufgezeigten Kriterien von den Varietätentypen gelöst und separat dargestellt, um eine erfolgreiche Anwendung dieser Kriterien auf das SüD zu ermöglichen.

\subsection{Varietätentypen}

Die Darstellung der Varietätentypen ist komplex und bedarf einer detaillierten Analyse. Die Forschungsliteratur bietet ein weites Spektrum an variierenden und zum Teil kontroversen Definitionen. Eindeutige Definitionen sind äußerst selten, was nicht nur eine klare Darstellung der Varietätentypen, sondern auch eine Abgrenzung der Varietätentypen zueinander sowie die Einordnung einer spezifischen Varietät - hier des SüD - er schwert.

Ferner erschweren die diversen Klassifizierungsmodelle von Varietäten die Einordnung einer spezifischen Varietät. Ein mögliches soziolinguistisches Varietätenmodell der deutschen Varietäten wurde von Löffler (2010) entwickelt und veranschaulicht optisch „die Komplexität jedes Einteilungsversuches der Sprachwirklichkeit“ (Löffler 2010: 79; vgl. Abb. 3). 


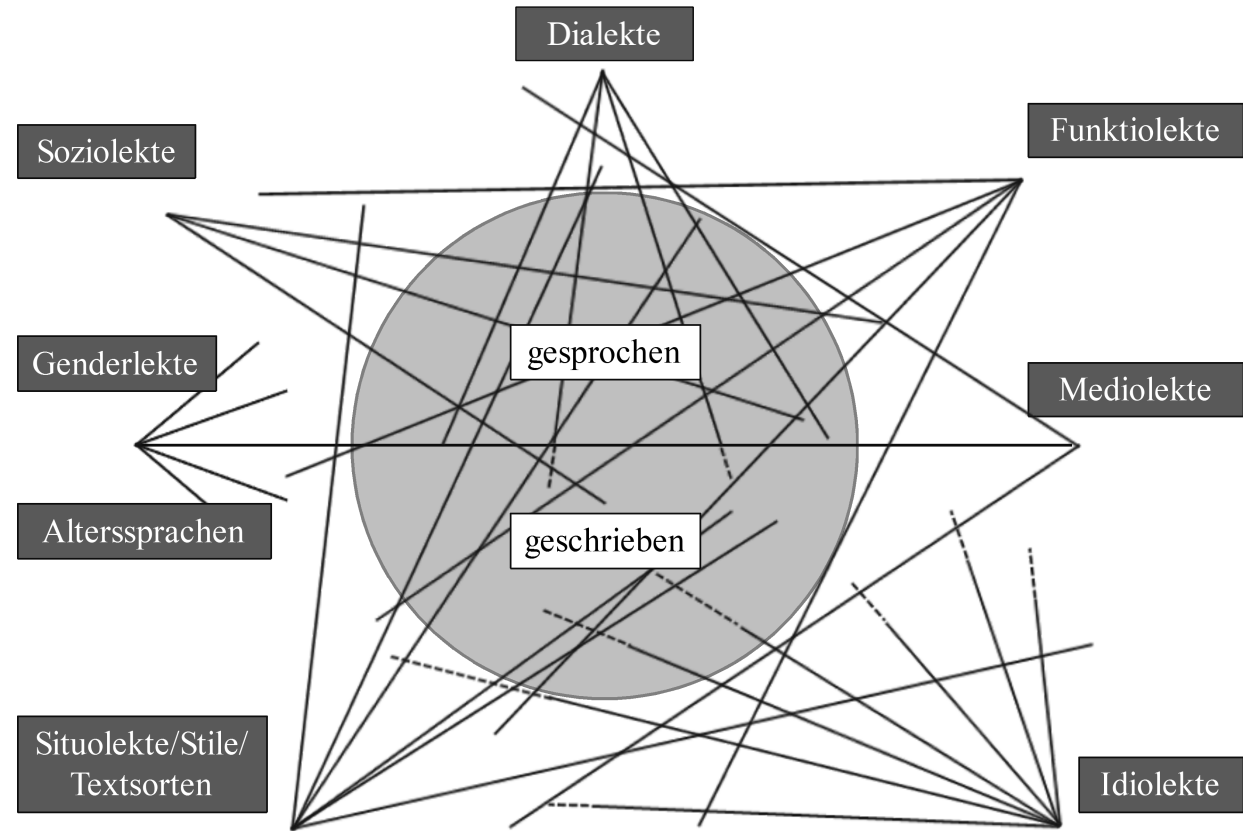

Abb. 3: Soziolinguistisches Varietätenmodell als Sprachwirklichkeitsmodell (nach Löffler 2010: 79)

Dieses Modell soll „zeigen, dass die Sprachwirklichkeit ein übergangsloses Kontinuum darstellt und dass alle Klassifizierungsversuche eine Frage des Standpunktes sind und immer nur unzureichend sein können“" (Löffler 2010: 79).

Um eine Varietät zu klassifizieren, ist es notwendig, dass „[d]ie Kategorien der Klassifizierung [...] im weitesten Sinne extralinguistisch [sind], das heißt, sie sollten aus dem Bereich der sozialen Konstellation (Gruppierung) oder Interaktion stammen“ (Löffler 2010: 80). Dies bedeutet, dass eine Klassifizierung sich auf die „fundamentalen extralinguistischen Dimensionen gründen“" muss (Berruto 2004: 193).

Letztlich sind es aber konkrete sprachliche Merkmale und das sprachliche Erscheinungsbild, die eine Varietät von einer anderen unterscheidet (Löffler 2010: 80). Die konkreten linguistischen Merkmale sind für allgemeine prototypische Varietätentypen äuBerst schwer zu fassen und eine detaillierte Darstellung wäre im Rahmen dieser Arbeit zu umfangreich. Daher werden zunächst lediglich sprachsoziale Kriterien einer Kategorie fokussiert und strukturelle Merkmale nur bei expliziter Benennung aufgenommen.

Andere Klassifizierungsmodelle von Varietätentypen gründen sich auf der Annahme, dass es verschiedene Dimensionen (Kontinua) gibt, in denen spezifische Varietätentypen eingeordnet werden können (u. a. Berruto 2004, Dittmar 1997). Diese Arbeit distanziert sich von der in der germanistischen Linguistik üblichen Einteilung von Varietäten in die Dimensionen diatopisch (geographische Dimension), diaphasisch (situative Dimension) und diastratisch (soziale Dimension) (und manchmal diachron (zeitliche Dimension) 
und diamesisch (mediale Dimension)) (u. a. Berruto 2004: 193-194, Dittmar 1997: 177180) aufgrund des zu hohen Komplexitätsgrades. Je mehr Dimensionen einbezogen werden, um der Sprachwirklichkeit näher zu kommen, desto komplexer wird die Klassifizierung einer spezifischen Varietät. Bei einem Dimensionsraum mit mehr als drei Kontinua sind die Verschränkungen der Dimensionen kaum noch nachvollziehbar und anschaulich darstellbar. Diese Arbeit bedient sich daher keiner Einteilung in Dimensionen, damit die mögliche varietätentypologische Einordnung des SüD nachvollziehbar dargestellt werden kann. Dies bedeutet jedoch nicht, dass die Tatsache, dass es verschiedene Dimensionen in der Sprachwirklichkeit gibt, vernachlässigt wird. Ganz im Gegenteil - es soll als Voraussetzung jeglicher Klassifizierungsversuche angenommen werden, dass einzelne Varietätentypen in der Sprachwirklichkeit nicht nur auf einer Dimension, sondern mehreren Dimensionen anzusiedeln sind. ${ }^{12}$

Der vorangegangene Absatz verdeutlicht die Komplexität der Einordnung von Varietätentypen. Die Annäherung an die Sprachwirklichkeit führt zu in sich verschränkten Modellen, die die Sprache in ihrem „dichte[n] multidimensionale[n] Netz (wenn nicht [...] Gestrüpp) von Einheiten und Beziehungen“ (Daneš 2005: 45) darzustellen versucht, die sich für diese Arbeit als zu komplex erweisen. Im Folgenden soll der Begriff Oberkategorie herangezogen werden, um die in der Forschungsliteratur zunehmende Komplexität $\mathrm{zu}$ vereinfachen und sich von den ausschließlich in der germanistischen Linguistik verwendeten Termini der Dimensionen abzugrenzen.

Eine Oberkategorie erfüllt ein spezifisches Oberkriterium. Varietätentypen, die dieses Merkmal als begriffskonstituierendes Kriterium aufweisen, werden in diese Oberkategorie eingeordnet. In Anlehnung an Dittmar (1997) sollen die in dieser Arbeit betrachteten Varietätentypen in die folgenden Oberkategorien (mit ihren jeweiligen Oberkriterien) eingeteilt werden:

a. personale Varietäten (Person),

b. räumliche Varietäten (Raum),

c. situative Varietäten (Situation),

d. soziale Varietäten (soziale Gruppe),

e. kontaktbedingte Varietäten (Kontakt) und

f. kodifizierte Varietäten (Kodifizierung).

Es ist erneut zu betonen, dass diese Einteilung in Oberkategorien eine vereinfachte Darstellung der Sprachwirklichkeit ist. Durch eine Vermeidung des Terminus Dimension werden die Überlappungen minimiert und eine hierarchische Darstellung mit klaren Strukturen ermöglicht. Dies gilt jedoch nur für die schematische Darstellung. Die einzelnen Varietätentypen werden, begründet in der Eigenschaft ihres begriffskonstituierenden Merkmals, einer Oberkategorie zugeordnet. Dennoch ist die Grundannahme dieser Arbeit, wie oben bereits erwähnt, die, dass ein Varietätentyp in der sprachlichen Realität

12 Für eine kurze Darstellung der Probleme der Ordnungsdimensionen siehe Dittmar (1997: 177-180). Für weitere Varietätenmodelle siehe Sinner (2014: 39-79). 
äußerst selten nur ein Merkmal aufweist. Vielmehr setzt sich dieser zumeist aus vielen weiteren Merkmalen zusammen, was eine Verschränkung mit anderen Oberkategorien wahrscheinlich macht.

Die folgende Abb. 4 zeigt die Einteilung der Varietätentypen. Diese werden zunächst unterteilt in die Oberkategorien (abgerundete Kästen). Ihnen untergeordnet sind die einzelnen prototypischen Varietätentypen (unterstrichen), die in Bezug auf das SüD als relevant erachtet werden.

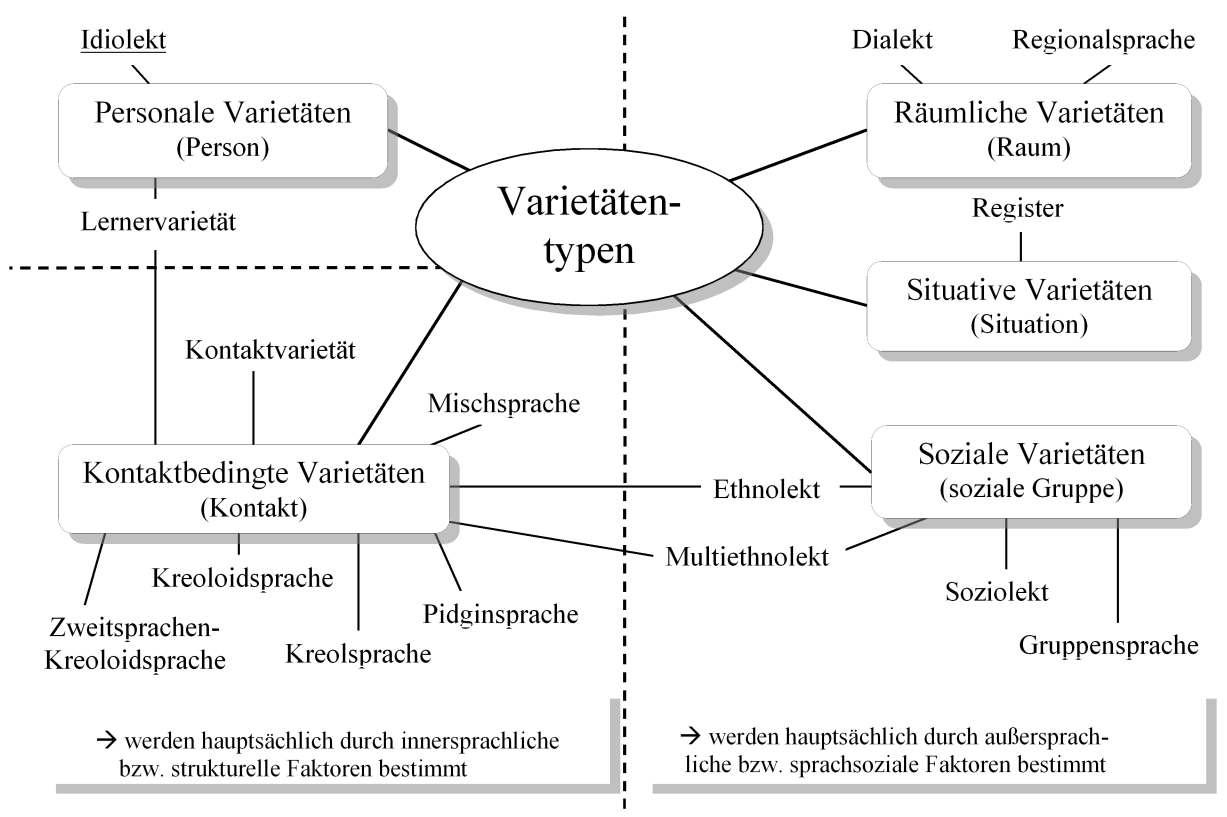

Abb. 4: Die relevanten Varietätentypen

Es ist anzumerken, dass sich zu fast allen Oberkategorien noch weitere Varietätentypen als die in Abb. 4 genannten, finden lassen. Mangels Relevanz in Bezug auf das SüD werden diese nicht aufgeführt.

Zudem wird die Oberkategorie kodifizierte Varietäten mit dem Oberkriterium Norm in Abb. 4 nicht aufgenommen, da dieser Oberkategorie lediglich Standardvarietäten und standardnahe Umgangssprachen zugeordnet werden (Dittmar 1997: 180). In Bezug auf das SüD werden diese Varietätentypen nicht diskutiert, da das SüD weder eine schriftliche und überregionale Norm hat noch in Institutionen verwendet wird (Pedersen 200oa: 110, 2009: 305). ${ }^{13}$ Somit lassen sich der Abb. 4 die ausschließlich für das SüD relevanten Varietätentypen entnehmen.

13 Siehe Kapitel 2.3 für die hier verwendete Definition von Standardvarietät. 
Die kontaktbedingten Varietätentypen lassen sich hauptsächlich durch strukturelle Faktoren bestimmen, während die räumlichen, sozialen und situativen Varietätentypen sich durch sprachsoziale Faktoren bestimmen lassen. In den folgenden Unterkapiteln werden diese einzelnen Varietätentypen kritisch dargestellt, abgegrenzt und definiert.

\subsubsection{Personale Varietäten}

$\mathrm{Zu}$ den personalen Varietäten werden jene gezählt, deren begriffskonstituierendes Kriterium die Person darstellt. Unter diese Kategorie fallen die Varietätentypen Idiolekt und Lernervarietät. Beide Varietätentypen wurden bisher nicht in Bezug auf SüD diskutiert. In den folgenden Unterkapiteln wird verdeutlicht, dass eine Aufnahme in Bezug auf diese Arbeit relevant ist.

Idiolekt. Bei einem Idiolekt handelt es sich um eine spezifische Art von Varietät, die nicht nur kontrovers diskutiert wird, sondern dessen Existenz sogar strittig ist. Eine kurze Darstellung und Diskussion dieses Begriffs in Bezug auf eine spätere Anwendung auf das SüD ist dennoch sinnvoll, da das SüD oftmals mit individuellen Realisierungen in Verbindung gebracht wird.

Im weiten Sinne wird der Terminus Idiolekt als „[f]ür einen bestimmten Sprecher charakteristischer Sprachgebrauch“ (Bußmann 2008: 274) definiert und als „die unverwechselbare Sprache eines Individuums“ (Dittmar 1997: 181) bezeichnet. So versteht Oksaar (2000: 37) unter einem Idiolekt „sowohl den Sprachbesitz eines Individuums als auch seine sprachliche Verhaltensweise, die Sprachäußerung, d. h. die individuelle Realisierung des Sprachsystems.“ Idiolekt isoliert „,jenen Sektor, der Individuelles in Abgrenzung vom Räumlichen, Sozialen, Historischen, Situativen etc. markiert“ (Dittmar 1997: 183). Der begriffskonstituierende Faktor liegt demnach rein in der Kategorie Person bzw. im Individuum selbst.

Die Definition des Begriffs scheint leicht greifbar, dennoch wird die Existenz der Idiolekte hinterfragt und von vielen Soziolinguisten sogar gänzlich abgelehnt (u. a. Labov 2001, Weinreich et al. 1968: 188, Trudgill 2000: 21). „For some researchers, the language variation patterns are idiolects. But according to traditional variationist analysis [...] idiolects are not a theoretical reality" (Hazen 2002: 501). Die soziolinguistischen Ansätze zur Varietätentypologie vertreten die Auffassung, dass eine genaue Betrachtung von Sprechergruppen bereits ausreicht und eine Berücksichtigung des Individuums, das als Produkt ebendieser sozialen Gruppen und Kontexte anzusehen ist, nicht als sinnvoll erscheint (Hazen 2002: 501). „[T]he individual speaker, can only be understood as the product of a unique social history, and the intersection of the linguistic patterns of all the social groups and categories that define that individual" (Labov 2001: 33-34). Diese Dis- 
kussion wird hier nicht weiter ausgeführt. ${ }^{14}$ Es soll lediglich darauf hingewiesen werden, dass diese zwei stark voneinander abweichenden Ansätze diskutiert werden. Wie bei den Darstellungen der anderen Varietätentypen noch deutlich wird und wie es Löffler (2010: 79) bereits präzisierte, sind „alle Klassifizierungsversuche eine Frage des Standpunktes“.

In dieser Arbeit wird hingegen angenommen, dass idiolektale Variationen existieren, da in Bezug auf das SüD starke individuelle Ausprägungen beschrieben werden (Kühl 2008). In dieser Arbeit wird angenommen: „[E] ach individual's linguistic pattern differs in some respects from that of everyone else" (Labov 2001: 34). Demnach wird ein Idiolekt hier definiert als die Sprache einer Person zu einem bestimmten Zeitpunkt in einem bestimmten Stil (Trudgill 2000: 26). Die „stilistische Variation in unterschiedlichen Kontexten“ (Dittmar 1997: 181) wird hiermit ausgeklammert. Das wesentliche Merkmal dieses Varietätentyps ist die „einmalige individuelle Identität“ (Dittmar 1997: 179). Somit beschränkt sich ein Idiolekt einzig und allein auf das begriffskonstituierende Kriterium Individuum.

Tab. 1 fasst die Kriterien eines Idiolekts zusammen. Das begriffskonstituierende Kriterium wird in der zweiten Zeile (mittig) aufgeführt. Hierbei wird zunächst das wesentliche Oberkriterium genannt und daraufhin das spezifizierte Unterkriterium. Die linke Spalte fasst die sprachsozialen Kriterien zusammen; die rechte Spalte die strukturellen Kriterien.

\begin{tabular}{l|l|l|}
\multicolumn{2}{l|}{ Idiolekt } \\
\hline \multicolumn{2}{l|}{ Person: Individuum } \\
\hline sprachsoziale Kriterien & \multicolumn{2}{l|}{ strukturelle Kriterien } \\
\hline- & - & \\
\hline
\end{tabular}

Tab. 1: Kriterien einer idiolektalen Varietät

Lernervarietät. Einen weiteren speziellen Varietätentyp stellt die Lernervarietät dar. Diese zählt hauptsächlich zu den personalen Varietäten (vgl. Abb. 4), denn „[d]ie Beschreibung von [...] Lernervarietäten ist durch die Dimension Sprecher mit personaler Identität festgelegt“ (Dittmar 1997: 243). Es kann jedoch auch in Anlehnung an Dittmars (1997: 241) Unterteilung zu den kontaktbedingten Varietäten geordnet werden. Da das SüD, wie in Kapitel 2.4 bereits beschrieben, oftmals als inkorrektes Dänisch bzw. als Dänisch von deutschsprachigen Lernern dargestellt wird (Fredsted 1997), ist es erforderlich, den Begriff Lernervarietät in dieser Arbeit zu definieren.

Unter dem Varietätentyp Lernervarietät „wird die erfolgreiche bzw. nicht-erfolgreiche Dynamik der Aneignung einer zweiten Sprache in verschiedenen Übergangsstadien

14 Für eine ausführlichere Diskussion zum Varietätentyp Idiolekt siehe Hazen (2002), Labov (2001), Oksaar (2000), Trudgill (2000) und Weinreich, Labov \& Herzog (1968). 
von der Ausgangssprache bis hin zur Zielsprache verstanden“ (Dittmar 1997: 240). Dittmar (1997: 240) führt seine Definition fort:

Sprecher mit einer bestimmten bereits erlernten Ausgangssprache, die eine andere Zielsprache erlernen, entwickeln [...] eine Kompetenz in der Zweitsprache; die Interlanguages, die bei der Erlernung der Zielsprache jeweils zur Verfügung stehen, nennt man ,Lernervarietäten'. Es handelt sich um Übergangssysteme, die durch spezifische, phonologische, morphologische, semantische, syntaktische und pragmatische Regeln ausgezeichnet sind.

Im Zentrum der Definition einer Lernervarietät, und somit das begriffskonstituierende Kriterium, steht der Prozess des Spracherwerbs einer Zweitsprache. „Lernervarietäten sind individuell variierende zweitsprachliche Repertoire [...], die aus den verschiedensten Gründen als Zweitsprachen erworben werden“ (Dittmar 1997: 235).

Lernervarietäten werden in der Forschungsliteratur als Idiolekte oder als Soziolekte behandelt - je nach Auffassungsstandpunkt. Ein Argument für die Betrachtung von Lernervarietäten als Idiolekt bietet Dittmar (1997: 240):

Eine Parallele zwischen Idiolekt und Lernervarietät (Lernerlekt) ist darin zu sehen, daß Lerner, z. B. erwachsene Zweitsprachenlerner, sich ihre zweite Sprache in mehr oder weniger großen Zeitspannen als Individuen mit besonderen Persönlichkeitsmerkmalen in Abhängigkeit vom sozialen Kontext erwerben.

Lernervarietäten können zudem ähnliche Züge aufweisen wie Soziolekte (vgl. Kapitel 3.1.4). Das ist der Fall, wenn „erwachsene Lerner auf einem bestimmten (meist den Normen der Zielsprache angenäherten) Niveau stehen bleiben (fossilieren)“ (Dittmar 1997: 241), was zumeist in Arbeitskontexten geschieht. Hier können sich „Interimlekte, die von Arbeitsmigranten über längere Zeiträume erworben werden“ (Dittmar 1997: 241) herausbilden. In Kontexten, in denen diese Varietäten der Zielsprache relativ nahe kommen, sind die linguistischen Abweichungen jedoch ethnisch und sozial markiert und „können als Soziolekte betrachtet werden, die eine mehr oder weniger heterogene Gruppe repräsentieren“ (Dittmar 1997: 241). Da es sich bei den Sprechern des SüD allerdings nicht um Arbeitsmigranten handelt, ist die soziolinguistische Definition von Lernervarietät in Bezug auf das SüD irrelevant. ${ }^{15}$ Lediglich die Lernervarietät in Bezug auf das Individuum ist hier von Bedeutung. Auch wenn hier der Fokus auf dem Individuum liegt, ist das Kriterium Kontakt nicht auszuschließen - wie in Abb. 4 verdeutlicht wird. Es wird angenommen, dass durch die individuelle Mehrsprachigkeit des Sprechers ein Varietätenbzw. Sprachkontakt auf der individuellen, kognitiven Ebene des Sprechers stattfindet.

15 Für eine genauere Beschreibung von Lernervarietät im soziolinguistischen Sinne als Gruppenphänomen siehe Dittmar (1997: 241). 
Einbezogen werden muss zudem Bußmanns (2008: 397) Definition einer Lernersprache, die diese als „[r]elativ systematische und stabile Zwischenstufe des Sprachkönnens während des Spracherwerbs“ definiert. Sie führt fort, dass die Lernervarietät „sowohl Regeln der Ausgangs- und der Zielsprache als auch solche, die keiner von beiden angehören, sondern z. T. nach universalen Prinzipien in den Lernenden selbst angelegt sind [umfasst]“. Es handelt sich bei Lernervarietäten folglich um Übergangssysteme, die „lediglich ein Stadium auf dem Weg von der Ausgangs- zur Zielsprache“ sind (Kühl 2008: 106). Die Zielvorstellung der Lernervarietäten ist die zu erwerbende Zweitsprache in ihrer Standardform.

Die Kriterien einer Lernervarietät werden in Tab. 2 zusammengefasst:

Lernervarietät

\begin{tabular}{ll|l|}
\hline \multicolumn{3}{c|}{ Person: Zweitsprache (Erwerbsprozess) } \\
\hline sprachsoziale Kriterien & strukturelle Kriterien \\
\hline Person: & $-\begin{array}{l}\text { Individuum } \\
\text { nie Erstsprache }\end{array}$ & Prozess: \\
\hline Kontakt: & $-\begin{array}{l}\text { zwei oder mehrere } \\
\text { Sprachen (indivi- } \\
\text { duelle Ebene) } \\
\text { Mehrsprachigkeit } \\
\text { (individuell) }\end{array}$ & \\
\hline
\end{tabular}

Tab. 2: Kriterien einer Lernervarietät

\subsubsection{Räumliche Varietäten}

Zur Oberkategorie der räumlichen Varietäten zählen jene Varietätentypen, die als begriffskonstituierendes Kriterium Raum aufweisen und somit räumlich abgegrenzt werden können. Es gibt viele Termini, die geographische Varietäten in der germanistischen Linguistik beschreiben. So schreibt Sinner (2014: 91), dass „[i]m Zusammenhang mit geographischer Variation [...] vielfach von lokalen Varietäten, von Mundart, Dialekt, Regiolekt, überregionaler Umgangssprache u. Ä. die Rede [ist]“. Im Folgenden werden lediglich die Begriffe Dialekt und Regionalsprache aufgenommen, da diese in Bezug auf das SüD die einzigen räumlichen Varietäten sind, die in der Forschungsliteratur ausgiebig diskutiert werden.

Dialekt. Die eindeutige Definition des Begriffs Dialekt birgt verschiedene Probleme. Zunächst ist anzumerken, dass Dialekt ein in der Forschungsliteratur, speziell in der Dialektologie, kontrovers diskutierter Begriff ist, der durch die Vielzahl an möglichen, oftmals voneinander abweichenden Ansätzen der Begriffsauffassung kaum fassbar ist: „Dialect [...] continues to be a battleground for terminological dispute, on a number of 
fronts, and from a number of differing sociolinguistic traditions“ (Britain 2004: 272). Das Spektrum des Dialektbegriffs ist groß und umfasst sowohl weit als auch eng gefasste Definitionen. Britain (2004: 268) bringt die Problematik auf den Punkt: „The term 'dialect', meanwhile, lacks definitional consensus perhaps more than any other in the field.“ Eben deshalb ist es fast immer problematisch eine Varietät eindeutig als Dialekt zu kategorisieren.

Im Wesentlichen ist zwischen zwei Forschungszweigen zu unterscheiden. Die angelsächsische Forschung (u. a. Russ 1990, Trudgill 1992) verwendet einen weit gefassten Dialektbegriff und bezeichnet mit dem Begriff dialect, Dialekt' alle sprachlichen Varietäten einer historisch-natürlichen Sprache. Auch die Standardvarietät stellt nach dieser Auffassung einen Dialekt dar. „To Anglo-Saxon sociolinguists [...] everyone speaks a dialect of some kind (and a few speak a dialect which happens to be a standard variety)“ (Britain 2004: 268).

In der kontinentaleuropäischen Forschung wird hingegen ein eng gefasster Dialektbegriff herangezogen. Hier steht das Merkmal Raum als begriffskonstituierendes Kriterium im Zentrum. Ein Dialekt ist demnach eine Varietät, die regional begrenzt ist bzw. sich kleinräumig eingrenzen lässt (u. a. Bußmann 2008: 131-132, Dittmar 1997: 187).

Aufgrund dessen, dass sich der angelsächsische Dialektbegriff stark mit dem Begriff der Varietät überschneidet, wird in dieser Arbeit die enger gefasste Definition angenommen. Somit wird hier ein Dialekt als ein Varietätentyp angesehen, der das Merkmal Raum bzw. Region als konstitutives Merkmal aufweist. Jedoch ist zu beachten, dass der Raum „durch weitere [Faktoren] ergänzt werden muß, um typologische Abgrenzungen von Varietäten nach eindeutigen Kriterien zu ermöglichen“ (Dittmar 1997: 183). Es gibt folglich weitere Kriterien, die eine Varietät erfüllen muss, damit sie als Dialekt kategorisiert werden kann.

Zum einen trifft man in der Forschungsliteratur auf das Kriterium, dass ein Dialekt niemals standardisiert bzw. normiert ist. Es gibt weder eine standardisierte Form noch eine Norm, die eingehalten werden kann. Zum anderen wird davon ausgegangen, dass ein Dialekt keine kodifizierte Schriftsprache besitzt, sondern lediglich als rein gesprochene Form auftritt (Bußmann 2008: 131-132, Dittmar 1997: 187). Somit sind die gängigen Merkmale eines Dialekts: „kleinräumig, nicht kodifiziert, nur gesprochen“ (Dittmar 1997: 211).

Diese gängigen Kriterien werden oftmals als nicht ausreichend beschrieben (Dittmar 1997: 187). Daher fügen verschiedene Ansätze weitere detailliertere Kriterien hinzu (u. a. Dittmar 1997, Löffler 1982, Kotsinas 2000). Es soll lediglich eines dieser Kriterien mit aufgenommen werden, da dieses in Bezug auf das SüD von Pedersen (200ob: 229, 2009: 312) in Anlehnung an Kotsinas $(1988,2000)$ diskutiert wird. Es handelt sich hierbei um das Kriterium Etablierung, das besagt, dass alle einheimischen Sprecher der Region des Dialekts diese Varietät beherrschen (Kotsinas 2000: 69). So schreibt Pedersen (2009: $312):$ „[A] dialect is regarded as an original, spoken language in a well-defined geographical area $[\ldots]$. 
Außerdem wird in Bezug auf die Verschränkung der drei Dimensionen (diatopisch, diaphasisch, diastratisch) diskutiert, inwieweit Dialekte auch von der sozialen Schicht geprägt sind (Bußmann 2008: 131). Dennoch wird dies als Kriterium nicht mit aufgenommen, da, wie bereits beschrieben, diese Verschränkungen in dieser Arbeit außer Acht gelassen werden. Dass eine sprachliche Variante in der Sprachwirklichkeit auf eine geographische und gleichzeitig auch auf eine soziale Varietät hindeuten kann, wird als gegeben angesehen. Dennoch konstituiert das Kriterium soziale Schicht nicht explizit den Varietätentyp Dialekt.

Tab. 3 fasst die Kriterien einer dialektalen Varietät zusammen:

\section{Dialekt}

\begin{tabular}{l|ll|}
\hline \multicolumn{2}{|c|}{ Region: kleinräumige Region } \\
\hline sprachsoziale Kriterien & strukturelle Kriterien \\
\hline Raum: & Medium: & $\begin{array}{l}- \text { mündlich } \\
- \text { nicht schriftlich }\end{array}$ \\
\hline Kodifizierung: $\quad-$ keine Norm & \\
\hline
\end{tabular}

Tab. 3: Kriterien einer dialektalen Varietät

Regionalsprache. Der Varietätentyp Regionalsprache wird hier aus der Perspektive der dänischen Forschungsliteratur betrachtet und leitet sich von dem Terminus regionalsprog ,Regionalsprache‘ ab. Dieser unterscheidet sich von dem in der Germanistik verwendeten, rein politisch definierten Terminus Regionalsprache der Europäischen Charta der Regional- und Minderheitensprachen. ${ }^{16}$

In Bezug auf das SüD diskutiert Braunmüller (1996) den Terminus Regionalsprache. Hierunter versteht er eine Sprache, die in einer bestimmten Region gesprochen bzw. geschrieben wird. In diesem Sinne ist das konstitutive Kriterium einer Regionalsprache der Raum bzw. die Region. Regionalsprachen lassen sich schwer von Dialekten abgrenzen (Pedersen 200ob: 239), da beide dasselbe begriffskonstituierende Kriterium aufweisen. Der wesentliche Unterschied besteht darin, dass die Regionalsprache ein relativ großes und nicht leicht abgrenzbares Gebiet umfasst (Jørgensen 1983: 20) und somit mittelräumig ist, während ein Dialekt als kleinräumig gilt.

Pedersen (200ob: 238) beschreibt auch in diesem Fall das Kriterium Etablierung. Sie verweist auf die Definition einer Regionalsprache nach Jørgensen (1983) und beschreibt, dass eine Regionalsprache dem Dialekt ähnlich ist. Dies bedeutet, dass Regionalsprachen ebenfalls in rein mündlicher Form auftreten und keine eigene Norm haben, sondern im Wesentlichen der Standardnorm folgen. ${ }^{17}$

Tab. 4 fasst die Kriterien einer Regionalsprache zusammen:

16 Hierzu siehe Council of Europe (1992). 


\begin{tabular}{|c|c|c|c|}
\hline \multicolumn{4}{|c|}{ Region: mittelräumige Region } \\
\hline \multicolumn{2}{|c|}{ sprachsoziale Kriterien } & \multicolumn{2}{|c|}{ strukturelle Kriterien } \\
\hline Raum: & - Etablierung & Medium: & $\begin{array}{l}\text { - mündlich } \\
\text { - nicht schriftlich }\end{array}$ \\
\hline Kodifizierung: & - keine Norm & & \\
\hline
\end{tabular}

Tab. 4: Kriterien einer Regionalsprache

\subsubsection{Situative Varietäten: Register}

$\mathrm{Zu}$ den situativen Varietäten zählen jene, die durch das Oberkriterium Situation bestimmt werden können. Für das SüD ist der Varietätentyp Register von Bedeutung, da der Gebrauch von SüD oftmals durch den Kontext bestimmt wird.

Bußmann (2008: 577-578) definiert Register als jede „[f]unktionsspezifische, d. h. für einen bestimmten Kommunikationsbereich (Institution) charakteristische Sprech- oder Schreibweise, z. B. die eines Pfarrers bei der Predigt, der Eltern gegenüber dem Kind, der Angestellten gegenüber Vorgesetzten“. Auch Dittmar (1997: 210) betont in seiner Definition von Register das Kriterium Situation bzw. Kontext:

,Register $[\ldots]$ aktiviert eine semantische Konfiguration in einer gegebenen sozialen Situation in Abhängigkeit von einer spezifischen kommunikativen Aufgabe (thematischer Gegenstand, Zweck, Skript), der Beziehungsqualität (Rollenbeziehungen erster und zweiter Ordnung) und der Diskursmodalitäten (Gattungen, Austauschstruktur und kulturelles Wissen).

Trudgill (1992: 62) grenzt die Situation noch weiter ein, indem er ein Register als eine Varietät beschreibt, die nicht nur auf den Kontext, sondern spezieller auf das Thema

17 In diesem Zusammenhang kritisiert Pedersen (20oob: 237-239) Braunmüllers (1996) Auffassung einer Regionalsprache, die besagt, dass Regionalsprachen gesprochen sowie auch geschrieben werden, eine linguistische Regionalnorm und eine pragmatische Norm haben. Ferner grenzt Braunmüller (1996) den Gebrauch einer Regionalsprache nicht nur regional ein, sondern auch sozial, indem er die Sprechergruppe auf die dänischgesinnten Südschleswiger begrenzt. Auch dieses Kriterium kritisiert Pedersen (20oob: 238) als nicht allgemeingültig. Zudem beschreibt Pedersen (200ob: 238), dass eine Regionalsprache in der Mitte des Spektrums Dialekt - Standardvarietät liegt. Dies entspricht in etwa der Definition des in der germanistischen Terminologie gängigen Begriffs Umgangssprache. Für eine genaue Darstellung der Definition und der Problematik von Umgangssprache siehe Löffler (2010) und Dittmar (1997). Diese Parallele zwischen Umgangssprache und regionalsprog ,Regionalsprache' übersieht Pedersen (200ob: 238) in ihrer Argumentation gegen die Annahme, dass es sich beim Südschleswigdänischen um eine Regionalsprache handelt. Hier wäre eine genauere Untersuchung des Zusammenhangs von Umgangssprache (und Regiolekt nach Dittmar 1997: 195) und der hier verwendeten Begriffsauffassung von Regionalsprache interessant, sprengt jedoch den Rahmen der vorliegenden Arbeit. 
oder eine Aktivität beschränkt ist. Das begriffskonstituierende Kriterium eines Registers ist somit Situation bzw. Kontext. ${ }^{18}$

Es ist anzumerken, dass vieles dafür spricht, „Register als prototypisch für institutionelle Situationen anzusetzen“ (Dittmar 1997: 232). Zudem schreibt Dittmar (1997: 212), dass „[d]ie Einhaltung normativer Vorschriften, die mit Registern einhergehen [...] in institutionellen Kontexten größer [sind]“. Aus diesem Grund soll Institution als weiteres Kriterium eines Registers mit aufgenommen werden. Da dieses Kriterium frequentiert auftritt, nicht aber bei jedem Register von Bedeutung ist, wird es lediglich als erweiterndes Kriterium aufgenommen.

Tab. 5 fasst die Kriterien eines Registers zusammen. Erweiternde Kriterien sind in Klammern gesetzt:

\begin{tabular}{l|l|} 
Register \\
\hline \multicolumn{2}{c|}{ Situation: Kontext } \\
\hline sprachsoziale Kriterien & strukturelle Kriterien \\
\hline Situation: $\quad-\begin{array}{l}\text { (insbesondere In- } \\
\text { stitutionen) }\end{array}$ & - \\
\hline
\end{tabular}

Tab. 5: Kriterien eines Registers

\subsubsection{Soziale Varietäten}

$\mathrm{Zu}$ der Oberkategorie der sozialen Varietäten werden jene Varietäten gezählt, die sich prototypisch rein auf das Oberkriterium soziale Gruppe beziehen. Hierunter fallen unter anderem die Varietätentypen Gruppensprache, Ethnolekt und Soziolekt, die mit dem SüD bereits in Verbindung gebracht wurden. Es gibt zahlreiche weitere Varietäten, die dieser Oberkategorie zugeordnet werden können. Hierzu zählen unter anderem Berufssprachen, Jugendsprachen, Genderlekte etc. ${ }^{19}$ Diese werden in Bezug auf das SüD nicht für wichtig erachtet, da das SüD die begriffskonstituierenden Kriterien nicht erfüllt, und somit hier nicht aufgeführt. Neu aufgenommen wird die Kategorie Multiethnolekt, die implizit u. a. von Pedersen $(2005,2009)$ mit dem SüD in Verbindung gebracht wird.

Gruppensprache. Ein Varietätentyp, der oft mit dem SüD in Verbindung gebracht wird, ist der relativ weit gefasste und schwer definierbare Begriff Gruppensprache.

Eine Gruppensprache beruht mindestens auf einem Merkmal einer bestimmten sozialen Gruppe. Das begriffskonstituierende Kriterium stellt folglich allgemein das Merk-

18 Es lassen sich in der Forschungsliteratur viele detaillierte Beschreibungen des Registerbegriffs finden, die über das Thema der vorliegenden Arbeit hinausgehen. Unter anderem entwickelt Dittmar (1997: 211) eine sehr komplexe „Registerkonzeption“; siehe hierzu auch Dittmar (1997, 2004) und Sinner (2014).

19 Für eine genaue Darstellung dieser Varietätentypen siehe Bußmann (2008), Dittmar (1997) und Löffler (2010). 
mal soziale Gruppe dar. Diesbezüglich gibt es allerdings einige Definitionsschwierigkeiten. Zunächst muss festgelegt werden, welches Merkmal als konstitutiv für eine soziale Gruppe gelten kann. Oftmals wird angegeben, dass zu der Klassifizierung von sozialen Gruppen „meist Merkmale wie Beruf bzw. ausgeübte Tätigkeit, Alter, Geschlecht, Status oder Zugehörigkeit von Individuuen [sic] zu bestimmten Schichten herangezogen werden“ (Sinner 2014: 143). Löffler (2010: 114) wiederum ist der Auffassung, dass eine Gruppensprache vorliegt „[w]o immer eine nach sozialen, beruflichen, fachlichen, status- und ansehensbedingten Merkmalen gekennzeichnete Gruppe auch ein sprachliches Erkennungssymbol oder eine grammatisch-lexikalisch-intonatorische Varietät besitzt.“ Dennoch ist eine konkrete Abgrenzung einer sozialen Gruppe nur schwer zu erfassen. Zudem ist der Begriff Gruppe selbst diskussionswürdig. Es ist nicht eindeutig festgelegt ab wann eine Gruppe vorliegt. Fraglich ist beispielsweise, ob zwei Personen bereits eine Gruppe darstellen oder ob eine gesamte Nation noch als Gruppe gilt. Somit ist dieses sprachsoziale begriffskonstituierende Kriterium sehr vage.

In der germanistischen Forschung werden Gruppensprachen im Allgemeinen auch als Soziolekte bezeichnet. So klassifiziert u. a. Löffler (2010: 114) „jede Art Gruppensprache" als Soziolekt. Auch Bußmann (2008: 252) verweist im Eintrag zu Gruppensprache auf Soziolekt. Ammon definiert (2010: 628) Soziolekt als

(auch: Gruppensprache) Gesamtheit der sprachl[ichen] Besonderheiten einer sozialen Gruppe. Damit nicht jede Varietät oder Spr[ache] als S[oziolekt] (nämlich der betreffenden Sprachgemeinschaft) gilt, muss die Gruppe anders konstituiert sein als allein sprachl[ich], z. B. durch ein gemeinsames Hobby, einen gemeinsamen Arbeitsplatz und dgl. Von S[oziolekten] wird auch in Bezug auf bloße soziale Gruppierungen (Merkmalgruppen) gesprochen, nicht nur in Bezug auf aktuelle Gruppen (wo jede/r die/den anderen kennt). S[oziolekte] unterscheiden sich u. U. nur durch unterschiedl[iche] Häufigkeiten der Verwendung bestimmter Sprachformen, die dann durch Variablenregeln zu beschreiben sind $[\ldots]$

Diese weit gefassten Definitionen von Soziolekt entsprechen weitestgehend der in dieser Arbeit verwendeten Definition von Gruppensprache. Unter der Bezeichnung Soziolekt wird in dieser Arbeit jedoch etwas anderen aufgefasst (s. u.). Somit ergibt sich, dass das begriffskonstituierende Merkmal einer Gruppensprache einzig die soziale Gruppe ist.

Tab. 6 fasst die Kriterien einer Gruppensprache zusammen: 


\begin{tabular}{l|l|}
\hline \multicolumn{2}{c|}{ soziale Gruppe } \\
\hline sprachsoziale Kriterien & strukturelle Kriterien \\
\hline- & - \\
\hline
\end{tabular}

Tab. 6: Kriterien einer Gruppensprache

Soziolekt. Der Begriff Soziolekt wird in Bezug auf das SüD von Braunmüller (1995) kurz diskutiert und abgelehnt. In seiner Arbeit findet sich jedoch weder eine explizite Definition der Kategorie noch eine Begründung für die Ablehnung. Infolgedessen wird der Varietätentyp Soziolekt in dieser Arbeit aufgenommen. Im Folgenden werden der Terminus und die kontroversen Begriffsansätze dargestellt und anschließend für diese Arbeit abgesteckt.

Die Entstehung des Terminus Soziolekt wird dadurch begründet, dass auch soziale Unterschiede in sprachlicher Variation abgebildet werden. So schreibt Durrell (2004: 201):

A major motivation for the term sociolect was the perceived need to distinguish between linguistic varieties correlating with social factors rather than geography, and sociolects are commonly defined as varieties of language determined by social environments or associated with a particular social group [...]

Gleich dem Dialektbegriff mangelt es auch beim Soziolektbegriff an einer eindeutigen Definition. Das liegt vor allem darin begründet, dass die Kategorie Soziolekt aufbauend entwickelt wurde, um den Dialektbegriff zu erweitern. Deshalb gibt es auch hinsichtlich des Soziolektbegriffs zunächst eine angelsächsische und eine kontinentaleuropäische Auffassung. Die angelsächsische Terminologie baut auf der Bezeichnung der weit gefassten Begriffsauffassung von Dialekt auf und beschreibt die soziale Variation von Sprache als social dialect ,Sozialdialekt'. Durrell (2004: 201) schreibt hierzu:

This term is widely held to be synonymous with sociolect, but its formation reflects assumptions about the structure of linguistic variation characteristic of English-speaking countries, where it is not unusual for the term dialect to be used with reference to any variety [...] [eigene Hervorhebung bei any]

Die kontinentaleuropäische Forschung bedient sich hingegen des Begriffs Soziolekt (nicht Sozialdialekt). Diese unterschiedlichen Bezeichnungen sagen jedoch in etwa dasselbe aus und können als Synonyme angesehen werden.

Diese Unterscheidung zwischen angelsächsischer und kontinentaleuropäischer Bezeichnung ist nicht die einzige Dichotomie. Eine zweite Problematik betrifft die konkrete 
Definition eines Soziolekts. Wie bereits erläutert, gibt es in der Forschungsliteratur zum einen eine sehr weit gefasste Definition, die Soziolekt im allgemeinen Sinne als Gruppensprache ansieht (u. a. Bußmann 2008, Löffler 2010) und zum anderen auf eine eng gefasste Definition, die Soziolekt als Varietät einer sozialen Schicht ansieht bzw. als abhängig von sozialen Faktoren (u. a. Durrell 2004).

Durrell (2004: 201) kritisiert die weite Definition des Begriffs und ist der Auffassung, dass hiermit impliziert wird, dass jede Art von Varietät als Soziolekt klassifiziert werden kann, wenn sie eine signifikante Korrelation mit einer oder mehreren sozialen Variable(n), wie zum Beispiel Alter, Geschlecht oder Ethnizität, aufweist. ${ }^{20}$ Dieser Gedanke führt zu der zweiten Auffassung des Begriffs Soziolekt, der lediglich die soziale Schicht als begriffskonstituierendes Kriterium ansieht: „[T] he term [sociolect] is most often used in connection with variation linked to social class [...], and some linguists would restrict the term to this usage, equating sociolect with class dialect" (Durrell 2004: 201). In einer früheren Definition von Kubczak (1987: 269) wird diese Problematik präzisiert: „Insgesamt erscheint es sinnvoll, Soziolekte zwecks einer überschaubareren Eingrenzung nur mit Bezug auf Schichten und zunächst noch ganz unabhängig von irgendwelchen Bewertungen zu bestimmen." Dieser Argumentation nach definiert diese Arbeit einen Soziolekt als „ein solches Subsystem bzw. eine solche Varietät [...], dessen/deren Sprechergruppe gerade mit einer oder mehreren soziologisch ermittelten Sozialschicht(en) identisch ist“ (Kubczak 1987: 269). Demnach stellt das begriffskonstituierende Kriterium soziale Schicht das einzige Kriterium dar.

Die Kriterien eines Soziolekts werden in Tab. 7 dargestellt:

Soziolekt

\begin{tabular}{l|l|}
\hline \multicolumn{2}{c|}{ soziale Gruppe: soziale Schicht } \\
\hline sprachsoziale Kriterien & strukturelle Kriterien \\
\hline- & - \\
\hline
\end{tabular}

Tab. 7: Kriterien einer soziolektalen Varietät

Ethnolekt. Der Begriff Ethnolekt ${ }^{21}$ ist ein relativ junger. Im weiten Sinne ist ein Ethnolekt eine Varietät einer Sprache, die die Sprecher als Mitglieder einer ethnischen Gruppe markiert, die ursprünglich eine andere Sprache oder Varietät benutzen (Clyne 2000: 86). Androutsopoulos (2007: 117) beschreibt Ethnolekte als

20 Diese Problematik trifft indessen auf die hier verwendete Kategorie Gruppensprache zu.

21 Ethnolekt wird hier synonym mit dem von Androutsopoulos (2007: 117) verwendeten Terminus Einzelethnolekt verwendet. Einzelethnolekte sind eine Subform von Ethnolekten im weiten Sinne (Clyne 200o: 86). Clyne (2000: 86) definiert Ethnolekte allgemein als Varietäten, die eine ethnische Gruppe markieren und differenziert weiter zwischen Einzelethnolekten sowie Multiethnolekten. In der germanistischen Linguistik ist eine Distinktion zwischen den Bezeichnungen Einzelethnolekt und Ethnolekt oftmals nicht anzutreffen (u. a. Wiese 2006). 
[...] Erscheinungsformen einer Sprache, die von Angehörigen einer ethnischen Gruppe verwendet werden. Im Gegensatz zur Arealität (Dialekt) bzw. zur sozialen Schichtung (Soziolekt) ist für ihren Geltungsbereich das Merkmal der Ethnizität ihrer Sprecher, deren Minderheitenstatus dabei impliziert wird, ausschlaggebend. [eigene Hervorhebung]

Das begriffskonstituierende Kriterium eines Ethnolekts stellt somit die Ethnizität einer sozialen (ethnischen) Gruppe dar. Unter einer ethnischen Gruppe wiederum wird eine soziokulturelle Gruppe von Menschen verstanden, die sich als eine soziale Einheit - mit einer eigenen Kultur - fühlen und sich von anderen sozialen Gruppen abgrenzen lassen (Trudgill 1992: 30-31). In Bezug auf Ethnolekte ist der Minderheitenstatus von Bedeutung. Die Varietät drückt eine „identitäre Funktion“ (Androutsopoulos 2007: 117) aus und wird von Clyne (2000: 86) als „identity marker“ bezeichnet, weshalb die Verwendung eines Ethnolekts eine Gruppenzugehörigkeitsfunktion ausdrückt.

Abb. 4 (vgl. Kapitel 3.1) ist zu entnehmen, dass Ethnolekte auch zu den kontaktbedingten Varietäten gezählt werden können, da ein weiteres wesentliches Kriterium der Sprachkontakt ist (Gravengaard \& Quist o. J.), ohne den die Entstehung eines Ethnolekts nicht möglich wäre. In dieser Sprachkontaktsituation hat die Erstsprache der ethnischen Gruppe einen wesentlichen Einfluss auf die von ihnen verwendete Varietät der sie umgebenden Mehrheitssprache, die ihre Zweitsprache darstellt. Hieraus entwickelt sich der Ethnolekt (Androutsopoulos 2007: 117). Die ethnolinguistische Herkunft der Sprecher ist an strukturellen Merkmalen der Varietät erkennbar (Androutsopoulos 2007: 117). Voraussetzung für die Entstehung ist somit auch die Mehrsprachigkeit der Sprechergruppe (Deckert \& Vickers 2011: 54).

Zwar hat dieser Varietätentyp seinen Ursprung im Zweitspracherwerb, dennoch handelt es sich bei dieser neuentstandenen Varietät keineswegs um ein Übergangsystem, da diese Varietät eine eigene (Ziel-)Norm aufweist (Androutsopoulos 2007: 119, Wiese 2006: 250). Zudem ist davon auszugehen, dass Ethnolekte lediglich in mündlicher Form auftreten (Gravengaard \& Quist o. J.), weshalb lediglich von einer mündlichen Norm ausgegangen werden kann.

Die Kriterien eines Ethnolekts werden in Tab. 8 zusammengefasst: 


\begin{tabular}{|c|c|c|c|}
\hline \multicolumn{4}{|c|}{ soziale Gruppe: Ethnizität } \\
\hline \multicolumn{2}{|c|}{ sprachsoziale Kriterien } & \multicolumn{2}{|c|}{ strukturelle Kriterien } \\
\hline Person: & $\begin{array}{l}\text { - Zweitsprache } \\
\text { - nie Erstsprache }\end{array}$ & Prozess: & $\begin{array}{l}\text { - kein Übergangssys- } \\
\text { tem }\end{array}$ \\
\hline soziale Gruppe: & $\begin{array}{l}\text { - Gruppenzugehö- } \\
\text { rigkeitsfunktion }\end{array}$ & Medium: & - mündlich \\
\hline Kodifizierung: & - mündliche Norm & & \\
\hline Kontakt: & $\begin{aligned} \text { - } & \text { zwei Varietäten } \\
\text { - } & \text { Mehrsprachigkeit } \\
& \text { (individuell \& ge- } \\
& \text { sellschaftlich) }\end{aligned}$ & & \\
\hline
\end{tabular}

Tab. 8: Kriterien einer ethnolektalen Varietät

Multiethnolekt. Eine spezielle Art von ethnolektaler Varietät ist der Varietätentyp Multiethnolekt. Diese Kategorie fand erst jüngst Eingang in die Forschungsliteratur und ist deshalb schwer definier- und abgrenzbar. Wiese (2011: 84) definiert den Begriff Multiethnolekt nach seinen Wortbestandteilen: „Multiethno-“ beschreibt den heterogenen ethnischen Hintergrund der Sprecher und „-lekt“ lenkt den Fokus auf jene Merkmale, die diese Art des Sprechens charakterisieren.

Im Wesentlichen ähnelt dieser Varietätentyp den zuvor dargestellten Ethnolekten und weist demnach auch alle Kriterien dieses Varietätentyps auf (vgl. Tab. 8). Der fundamentale Unterschied liegt in der Sprachkontaktsituation. Bei Multiethnolekten stehen durch die unterschiedlichen Herkunftssprachen der Sprechergruppe mehr als zwei Varietäten bzw. Sprachen in Kontakt (Gravengaard \& Quist o. J.). Somit ist diese Varietät im Gegensatz zu Ethnolekten - nicht mehr auf eine Erstsprache zurückzuführen (Androutsopoulos 2007: 118).

In der neueren Forschungsliteratur wird diskutiert, ob Multiethnolekte zudem zwei weitere wesentliche Kriterien aufweisen. Zum einen werden Multiethnolekte oftmals auf urbane Regionen beschränkt (Quist 2008: 44, Wiese 2006: 247), da die dort auftretenden heterogenen und mehrsprachigen Milieus die Entstehung eines solchen Varietätentyps begünstigen (Quist 2000: 145). In diesen Milieus ist es nicht selten, dass zum Beispiel in den Schulen mehr als $70 \%$ der Schüler zweisprachig aufwachsen (Quist 2000: 145). Demnach stellt Region ein weiteres Kriterium von Multiethnolekten dar. Dennoch ist anzumerken, dass dieses Kriterium ein recht neues ist und von manchen Forschern in anderen Zusammenhängen abgelehnt wird (u. a. Sollid 2013: 66). Aufgrund dessen wird dieses Charakteristikum als erweiterndes Kriterium aufgenommen.

Zum anderen wird oftmals angenommen, dass multiethnolektale Varietäten lediglich bei jugendlichen Sprechern auftreten. Die bisherigen Forschungsergebnisse zu multieth- 
nolektalen Varietäten u. a. in Berlin (Wiese 2006) und Rinkeby (Stockholm) (Kotsinas 200o) beziehen sich lediglich auf jugendliche Sprecher in urbanen Milieus. In ihrem Modell beschreibt Wiese (2006: 251) die Dualität der Multiethnolekte aus Kontakt- und Jugendsprache. Demnach werden unter diesem Ansatz noch das sprachsoziale Kriterium Alter sowie das für diese Sprechergruppe typische Phänomen der etablierten Entlehnungen aus anderen Sprachen angesehen. Diese werden hier aufgrund von Unstimmigkeiten in der Forschungsliteratur ebenfalls als erweiternde Kriterien aufgenommen. ${ }^{22}$

Tab. 9 fasst die Kriterien einer multiethnolektalen Varietät zusammen:

\begin{tabular}{|c|c|c|c|}
\hline \multicolumn{4}{|c|}{ soziale Gruppe: Ethnizität } \\
\hline \multicolumn{2}{|c|}{ sprachsoziale Kriterien } & \multicolumn{2}{|l|}{ strukturelle Kriterien } \\
\hline Person: & $\begin{array}{l}\text { - Zweitsprache } \\
\text { - nie Erstsprache }\end{array}$ & Prozess: & $\begin{array}{l}\text { - kein Übergangssys- } \\
\text { tem }\end{array}$ \\
\hline Raum: & - (Region) & Medium: & - mündlich \\
\hline soziale Gruppe: & $\begin{array}{l}\text { - } \text { Gruppenzugehö- } \\
\text { rigkeitsfunktion } \\
\text { - }\end{array}$ & spezifische Phänomene: & - (Entlehnungen) \\
\hline Kodifizierung: & - mündliche Norm & & \\
\hline Kontakt: & $\begin{aligned} \text { - } & \text { mehr als zwei Va- } \\
& \text { rietäten } \\
\text { - } & \text { Mehrsprachigkeit } \\
& \text { (individuell \& ge- } \\
& \text { sellschaftlich) }\end{aligned}$ & & \\
\hline
\end{tabular}

Tab. 9: Kriterien einer multiethnolektalen Varietät

\subsubsection{Kontaktbedingte Varietäten}

Die letzte Oberkategorie stellen die kontaktbedingten Varietäten dar, die als Oberkriterium Kontakt aufweisen. Unter Kontakt werden hierbei zwei Arten von Sprachkontakt gezählt. Zum einen der kognitive Sprachkontakt zweier oder mehrerer Sprachen bzw. Varietäten innerhalb eines individuellen Sprechers und zum anderen der gesellschaftliche Sprachkontakt, bei dem zwei oder mehrere Sprachen bzw. Varietäten auf der kollektiven Ebene in Kontakt treten (Riehl 2014: 11-12).

22 So wendet sich unter anderem Androutsopoulos (2007: 121) gegen die Annahme, dass es sich bei Multiethnolekten um Jugendsprachen handelt. 
Kontaktvarietät. Die Aufnahme der Kategorie Kontaktvarietäten in diese Arbeit liegt darin begründet, dass der aktuelle Forschungsstand zur südschleswigdänischen Varietät diese als Kontaktvarietät definiert (vgl. Kapitel 2.4).

Generell handelt es sich bei Kontaktvarietäten um jene Varietäten, die in einer Ver bindung zu Sprachkontakt stehen. Sinner (2014: 244) beschreibt, dass Kontaktvarietäten (oder Kontaktsprachen) die Bezeichnung für sowohl die Varietäten sind, „die (i) aus his torischen Sprachkontaktsituationen hervorgegangen sind, als auch für die Varietäten, die (ii) in aktuellen Sprachkontaktsituationen gebraucht werden“. Hierbei kritisiert Sinner (2014: 244) jedoch, dass oftmals nicht

ersichtlich würde, auf welche der angesprochenen Realitäten jeweils abgezielt wird. Bei den (ii) zuzuordnenden Fällen wird z. T. nicht zwischen Lernervarietäten - also instabilen Spracherwerbs- oder Interimssprachen - und muttersprachlichen Varietäten (von Zweisprachigen) oder Ethnolekten unterschieden.

Folglich handelt es sich bei der Bezeichnung Kontaktvarietät um einen sehr weit gefassten Begriff, der als begriffskonstituierendes Kriterium Kontakt aufweist. Es ist jedoch offen, ob sich der Kontakt aus einer Sprachkontaktsituation entwickelt hat, oder aktuell ein Sprachkontakt stattfindet. Auch die personalen, sozialen und situativen Unterschiede werden bei dieser Definition ignoriert.

Tab. 10 fasst die Kriterien einer Kontaktvarietät zusammen:

\section{Kontaktvarietät}

\begin{tabular}{l|l|}
\hline \multicolumn{2}{c|}{ Kontakt: zwei oder mehrere Sprachen } \\
\hline sprachsoziale Kriterien & strukturelle Kriterien \\
\hline- & - \\
\hline
\end{tabular}

Tab. 10: Kriterien einer Kontaktvarietät

Mischsprache. Mischsprache ist ein Begriff für eine „[a]ls Resultat von Sprachkontakt und wechselseitiger Beeinflussung zweier oder mehrerer Ausgangssprachen entstandene Sprache“ (Bußmann 2008: 440). Das begriffskonstituierende Kriterium für diesen Varietätentyp ist folglich Kontakt. Die weit gefasste Definition entspricht im Wesentlichen der von Kontaktvarietäten allgemein. Dennoch liegt der Schwerpunkt der Bezeichnung auf der strukturellen Ebene, denn es wird in der Forschungsliteratur vor allem der Faktor des „Mischens“ von unterschiedlichen Elementen der jeweiligen Ausgangssprachen betont (Bußmann 2008: 440).

Die Definition von Mischsprachen kann als vage bezeichnet werden, weshalb die „Frage der Mischsprachen als eigene Form von Varietäten aufgrund von Sprachkontakt [...] in der Sprachwissenschaft ebenfalls sehr umstritten [ist]“ (Sinner 2014: 254). 
In Bezug auf das SüD bezieht sich Pedersen (200ob: 230-232) auf die Definitionen von Smith (1995) und Bakker \& Muysken (1995). Nach Smith (1995: 332) sind die Voraussetzung zur Entstehung einer Mischsprache eine bilinguale Gruppe (Mehrsprachigkeit (gesellschaftlich)) und ihr Bestreben, ihren ethnischen Status zu definieren, redefinieren, zu erlangen oder wieder zu erlangen (Ethnizität). Er ergänzt, dass dieses oft in einer language mixture, Sprachmischung ' resultiert und führt fort:

The most frequent type encountered is that where the grammar of one of the languages originally spoken in the group in question is combined with the content-words of another language known to the group [...]. The resultant language replaces the original ethnic language(s), and is in general the only language spoken.

Ferner sollen die drei Kriterien von Bakker \& Muysken (1995: 51) mit aufgenommen werden. Demnach gilt als Voraussetzung für die Entstehung einer Mischsprache, dass die Sprechergruppe bilingual ist, bevor die Sprachen vermischen. Außerdem haben die entstehenden Sprachen eine in-group-Funktion (Gruppenzugehörigkeitsfunktion) und sind keine Brücke der Verständigung (keine Brückenfunktion). Zuletzt identifizieren sich die Sprecher mit der Gruppe der neuen Sprache. Diese Merkmale sind jedoch lediglich die sozialen Voraussetzungen. Die wesentlichen strukturellen Charakteristika werden bei Pedersens (200ob: 230-232) Darstellung und Diskussion von Mischsprache jedoch nicht beachtet. Hierbei handelt es sich um das spezielle strukturelle Phänomen, dass Mischsprachen das Lexikon aus der einen und die Morphosyntax aus der anderen Ausgangssprache beziehen (Sommer 2002: 81). „The grammatical system (syntax, morphology, phonology) of the intertwined languages is often derived from the language known best by the first generation of speakers, and from the language which it resembles most in its pronunciation [...]“ (Bakker \& Muysken 1995: 50). Sommer (2002: 81) beschreibt Mischsprachen als einen eher seltenen Varietätentyp:

Eine Mischsprache ist eine innerhalb kurzer Zeit entstandene Sprache, die sich aus den Elementen von (im Wesentlichen) zwei Sprachen zusammensetzt, wobei diese Elemente ohne große Veränderungen übernommen werden. Sie ist ein linguistischer Sonderfall, der selten auftritt und oft schnell wieder ausstirbt.

Die dargelegte Problematik erschwert die Definition einer Mischsprache. Einige Forscher verwenden Mischsprache für jegliche Varietäten, die im weitesten Sinne mit dem „Mischen“ zweier (oder mehrerer) Sprachen in Verbindung gebracht werden. Andere wiederum definieren Mischsprache als absoluten Sonderfall, der selten auftritt und bei dem das Lexikon der einen Sprache und die Morphosyntax der anderen Sprache ineinandergreifen. In dieser Arbeit wird der Sonderfall angenommen, um eine klare Abgren zung der Varietätentypen zueinander zu ermöglichen.

Die Kriterien einer Mischsprache werden in Tab. 11 dargestellt: 


\begin{tabular}{|c|c|c|c|}
\hline \multicolumn{4}{|c|}{ Kontakt: zwei oder mehrere Sprachen } \\
\hline sprachsoziale & & strukturelle Kriterien & \\
\hline soziale Gruppe: & 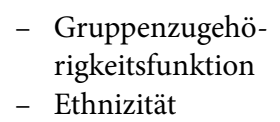 & spezifische Phänomene: & $\begin{array}{l}\text { - Lexikon der Sprache } \\
\text { A, Morphosyntax } \\
\text { der Sprache B }\end{array}$ \\
\hline Kontakt: & $\begin{array}{ll}\text { - } & \text { Mehrsprachigkeit } \\
& \text { (gesellschaftlich) } \\
\text { - } & \text { keine Brücken- } \\
& \text { funktion }\end{array}$ & & \\
\hline
\end{tabular}

Tab. 11: Kriterien einer Mischsprache

Pidginsprache. Der Varietätentyp Pidginsprache zählt ebenfalls zu den kontaktbedingten Varietäten und weist ebenfalls das begriffskonstituierende Kriterium Kontakt auf. Bußmann (2008: 532) definiert die Pidginsprache als eine aus einer kommunikativen Notsituation heraus entstandene Varietät:

Beim Kontakt von Sprechern von zwei oder mehr Sprachen ohne gegenseitiges Sprachverständnis werden Struktur und Vokabular der einzelnen muttersprachlichen Systeme durch mutual accommodation nachhaltig reduziert, um eine Verständigung herbeizuführen [...]

Auch Dittmar (1997: 236) beschreibt den Varietätentyp Pidginsprache als „eine grammatisch reduzierte, lexikalische Hilfssprache in der Funktion der kommunikativen Bewältigung von Handelskontakten“.

Pidginsprachen lassen sich hauptsächlich an ihren strukturellen Kriterien festmachen. In allgemeinen Definitionen werden die in der Sprachkontaktsituation neu entwickelten Strukturen als „reduziert“ (Dittmar 1997: 236) und „vereinfacht“ (Sinner 2014: 252) bezeichnet.

Trudgill (1994: 16) nennt als Voraussetzung für die Entstehung einer Pidginsprache den Prozess der Pidginisierung, der bei dem Erwerb einer Zweitsprache bei Jugendlichen und Erwachsenen auftreten kann, die über den kritischen Punkt des Zweitspracherwerbs hinaus sind. „Whenever adults and post-adolescents learn a new language, pidginization takes place [...]“ (Trudgill 1996: 5). ${ }^{23}$ Demnach stellt das Alter der involvierten Sprecher ein Kriterium der Pidginsprachen dar. Der Prozess der Pidginisierung ist unterteilt in die drei Subprozesse reduction ,Reduktion', admixture ,Beimengung' und simplification, Vereinfachung. ${ }^{24}$

23 Diese einfache Definition soll in diesem Zusammenhang genügen. Für eine ausführlichere Darstellung des komplexen Zusammenhangs zwischen Pidginsprache und Pidginisierung siehe u. a. Trudgill (1994, 1996). 
a. Reduktion: Dieser Prozess tritt als Teil des unvollständigen Zweitspracherwerbs in einer Sprachkontaktsituation auf (Trudgill 1992: 62). „Reduction [...] refers to the process whereby large parts of the source language that are available to native speakers are lost or are not acquired by pidginizing non-native speakers" (Trudgill 1992: 62). Er resultiert in einem verringerten Vokabular, weniger grammatischen Elementen und reduzierten stilistischen Alternativen (Trudgill 1994: 14). Den Grund für diesen Prozess sieht Trudgill (1994: 14) in der verringerten Reichweite des Sprachgebrauchs:

Since non-native speakers typically use language for a narrower range of purposes than native speakers, there are large areas of a target language which are simply not present in the usage of non-native speakers. This is to say, a language which has been subject to reduction has, as it were, large areas of itself missing [...]

b. Beimengung: Dieser Prozess beruht darauf, dass der Pidginsprache Elemente der Erstsprache der Lerner (Interferenzen) beigemengt werden (Trudgill 1992: 9). Dies führt Trudgill (1994: 14) auf die Tatsache zurück, dass erwachsene Lerner keine perfekten Fremdsprachenlerner sind. Vor allem in der Phonetik und Phonologie macht sich dies bemerkbar („foreign accent“), spiegelt sich aber ebenso in der Syntax, Semantik und im Diskurs wider (Trudgill 1994: 14).

c. Vereinfachung: Dieser Prozess ist erneut auf den unvollständigen Spracherwerb der erwachsenen Sprecher zurückzuführen - „[...] referring for the most part to regularisation and loss of redundancy“ (Trudgill 1994: 13). Durch den Prozess der Vereinfachung entsteht eine größere strukturelle Regularität, z. B. Vereinfachung der Strukturen irregulärer Verben oder Verlust des grammatischen Geschlechts (Trudgill 1992: 66).

Sobald der Grad der Reduktion, Beimengung und Vereinfachung relativ hoch ist und diese Prozesse stabil werden, kann eine Pidginsprache entstehen (Trudgill 1994: 14, 1996: 6). Insgesamt lässt sich zusammenfassen, dass eine Pidginsprache, in Bezug auf die Ausgangssprachen, eine reduzierte, gemischte und vereinfachte Sprache ist, die durch Fokussierung eine stabile Form erreicht hat (Trudgill 1994: 14). Die strukturellen Kriterien einer Pidginsprache sind folglich Reduktion, Beimengung und Vereinfachung.

Eine Pidginsprache weist zudem auch sprachsoziale Kriterien auf. Zum einen kann eine Pidginsprache niemals die Erstsprache der Sprecher sein. Es handelt sich hierbei folglich (mindestens) um eine Zweitsprache (Sinner 2014: 253; Trudgill 1994: 15).

Darüber hinaus wird in den Definitionen oftmals das Kriterium Situation bzw. Kontext für die Entstehung genannt. Eine Pidginsprache entsteht zumeist in Handelskontex-

24 Auch wenn diese Arbeit eine synchrone Betrachtungsweise anstrebt, sollen diese Prozesse, die der Entstehung des Varietätentyps vorangegangen sind, aufgenommen werden. Dies liegt darin begründet, dass die Auswirkungen dieser Prozesse in der synchronen Betrachtung einer spezifischen Varietät deutlich sind. 
ten, in denen die Notwendigkeit verbaler Kommunikation besteht (Dittmar 1997: 236, Sinner 2014: 252-253). Auch in Bezug auf den Gebrauch der Pidginsprache gilt das Kriterium Situation bzw. Kontext, da die Sprache nicht nur aus diesen Kontexten heraus entsteht, sondern ihre Verwendung auch auf diese Kontexte begrenzt bleibt (Sinner 2014: 253). In Bezug auf den speziellen Kontext der Entstehung von Pidginsprachen ist als weiteres Kriterium die Brückenfunktion zu nennen. Durch die Entwicklung einer pidginisierten Varietät werden kommunikative Hürden überbrückt um eine Verständigung zu ermöglichen, „wenn aufgrund sozialer Gründe [...] keine der beteiligten Gruppen die Sprache der anderen Gruppe lernt" (Sinner 2014: 253).

Die Kriterien einer Pidginsprache werden in Tab. 12 dargestellt:

Pidginsprache

\begin{tabular}{ll|ll|}
\hline \multicolumn{3}{c|}{ Kontakt: zwei oder mehrere Sprachen } \\
\hline sprachsoziale Kriterien & strukturelle Kriterien \\
\hline Person: & - nie Erstsprache & Prozesse: & - Reduktion \\
& - Zweitsprache & - Beimengung \\
& & \\
\hline soziale Gruppe: & - Alter & \\
\hline Situation: & - Kontext & \\
\hline Kontakt: & - Brückenfunktion \\
& $-\begin{array}{l}\text { Mehrsprachigkeit } \\
\text { (gesellschaftlich) }\end{array}$ & \\
\hline
\end{tabular}

Tab. 12: Kriterien einer Pidginsprache

Kreolsprache. Wenn in sehr seltenen Fällen eine Pidginsprache dem Prozess der Kreolisierung unterliegt, kann eine sogenannte Kreolsprache entstehen (Trudgill 1994: 15). Da eine Kreolsprache aus einer Pidginsprache heraus entsteht und hierbei Kontakt als begriffskonstituierendes Kriterium gilt, wird dieses Kriterium hier übernommen. Die strukturellen Kriterien Beimengung und Vereinfachung sind ebenfalls zentrale Merkmale einer Kreolsprache, wohingegen dies für das Kriterium Reduktion nicht gilt (Trudgill 1994: 16). Der Prozess der Kreolisierung wird auch als expansion ,Expansion' bezeichnet und meint damit die Reparatur der vorangegangenen Reduktion. „Expansion may occur, less or more rapidly, when the pidgin language, originally employed simply as non-native lingua franca, becomes more and more important as a means of communication within a particular community" (Trudgill 1994: 15). Durch Expansion wird die vorausgegangene strukturelle Reduktion aufgehoben und der Wortschatz, die Grammatik und die stilistische Variation ausgebaut (Trudgill 1994: 16). Dies ist vor allem auf die Ausweitung des Sprachgebrauchs auf andere Kontexte zurückzuführen (Trudgill 1992: 21). Somit entfällt das Kriterium Situation bzw. Kontext bei Kreolsprachen. Außerdem werden kreoli- 
sche Varietäten von Kindern als Erstsprache erlernt (Dittmar 1997: 239, Trudgill 1992: 32). Vereinfacht können Kreolsprachen folglich als „aus Pidgins hervorgegangene Muttersprachen von Sprachgemeinschaften“ (Sinner 2014: 254) bezeichnet werden.

Da eine Kreolsprache aus einer Pidginsprache hervorgeht, ist der historische Hintergrund ein wesentliches Merkmal der Entstehung einer Kreolsprache. In einer diachronen Analyse müssten somit die weiteren charakteristischen Kriterien einer Pidginsprache an dieser Stelle mit aufgenommen werden. Da diese Arbeit allerdings eine synchrone Perspektive verfolgt, entfallen diese Kriterien.

Tab. 13 zeigt die Kriterien einer Kreolsprache auf:

\section{Kreolsprache}

\begin{tabular}{l|ll|}
\hline \multicolumn{3}{c|}{ Kontakt: zwei oder mehrere Sprachen } \\
\hline sprachsoziale Kriterien & strukturelle Kriterien \\
\hline Person: & Prozesse: & - Expansion \\
& & - Beimengung \\
& & - Vereinfachung \\
\hline
\end{tabular}

Tab. 13: Kriterien einer Kreolsprache

Kreoloidsprache. Trudgill (1994) unterscheidet im weiteren Verlauf seiner Darstellung von kreolischen Varietäten zwischen den Kategorien Kreol- und Kreoloidsprachen. Aus der obengenannten synchronen Perspektive heraus, lässt sich eine Kreol- von einer Kreoloidsprache schwer abgrenzen, da der wesentliche Unterschied in der Entstehung liegt (Trudgill 1996: 8).

Unter Kreoloidsprachen werden jene Sprachen gezählt, die zwar Beimengung und Vereinfachung in Relation zu den Ausgangssprachen aufweisen und in einem gewissen Grad den Prozessen der Pidginisierung unterlagen, die jedoch niemals Pidginsprachen gewesen sind (Trudgill 1994: 16). Da in diesem Fall keine Reduktion stattgefunden hat, entfällt ebenso der Prozess der Expansion (Trudgill 1992: 22).

Ferner schreibt Trudgill (1992: 22): „[...] and it maintains throughout its development a community of native speakers. " Insofern stellt eine Kreoloidsprache, genau wie die Kreolsprache, die Erstsprache der Sprecher dar (Pedersen 20oob: 236).

Die Kriterien einer Kreolsprache werden in Tab. 14 zusammengefasst: 


\begin{tabular}{l|ll|}
\hline \multicolumn{3}{c}{ Kontakt: zwei oder mehrere Sprachen } \\
\hline sprachsoziale Kriterien & strukturelle Kriterien \\
\hline Person: & Prozesse: & - keine Expansion \\
& & - Beimengung \\
& & - Vereinfachung \\
\hline
\end{tabular}

Tab. 14: Kriterien einer Kreoloidsprache

Zweitsprachen-Kreoloidsprache. Non-native creoloids ,Zweitsprachen-Kreoloidsprachen' nach Trudgill (1996: 8-9) sind Varietäten, die aus einer pidginisierten Form entstehen, indem sie die lingua franca von Sprechergruppen werden, die keine Sprache gemeinsam haben und zudem die Zielsprache nicht die Erstsprache der Sprecher ist. Das begriffskonstituierende Kriterium stellt Kontakt dar, ohne den eine Zweitsprachen-Kreoloidsprache nicht entstehen könnte. Aus dieser Definition lassen sich zudem zwei weitere Kriterien erschließen. Zum einen die Brückenfunktion als ein Kriterium dieser Varietät; zum anderen kann eine Zweitsprachen-Kreoloidsprache niemals die Erstsprache der Sprecher sein.

Da eine Zweitsprachen-Kreoloidsprache aus einer pidginisierten Form heraus entsteht, sind die drei Prozesse Reduktion, Beimengung und Vereinfachung ebenfalls Kriterien. Es ist allerdings zu betonen, dass diese in nicht so starker Ausprägung stattfinden, wie bei einer Pidginsprache (Trudgill 1996: 9). Zudem ist anzumerken, dass die Voraussetzung für die Entstehung einer pidginisierten Form erwachsene (bzw. jugendliche) Sprecher sind (Trudgill 1996: 5). Demnach stellt das Alter der Sprechergruppe ebenfalls ein Kriterium dar.

Die Kriterien einer Zweitsprachen-Kreoloidsprache werden in Tab. 15 zusammengefasst:

Zweitsprachen-Kreoloidsprache

\begin{tabular}{ll|ll|}
\hline \multicolumn{3}{c}{ Kontakt: zwei oder mehrere Sprachen } \\
\hline sprachsoziale Kriterien & strukturelle Kriterien \\
\hline Person: & - nie Erstsprache & Prozesse: & - Reduktion \\
& - Zweitsprache & - Beimengung \\
& & - Vereinfachung \\
\hline soziale Gruppe: & - Alter & \\
\hline Kontakt: & - Brückenfunktion & \\
& - Mehrsprachigkeit & \\
\hline
\end{tabular}

Tab. 15: Kriterien einer Zweitsprachen-Kreoloidsprache 
Sabrina Goll

\subsubsection{Zusammenfassung der Varietätentypen}

In Tab. 16 sind alle Kriterien der Varietätentypen zusammengefasst. Diese Darstellung dient der Abgrenzung der Varietätentypen untereinander und soll einen Vergleich ermöglichen. 
Südschleswigdänisch - Probleme einer varietätentypologischen Einordnung

\begin{tabular}{|c|c|c|c|c|c|c|c|c|c|c|c|c|c|c|c|c|}
\hline 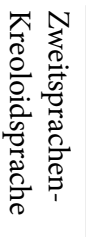 & 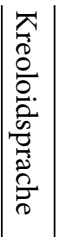 & 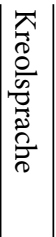 & 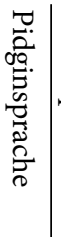 & 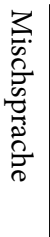 &  & 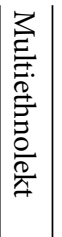 & 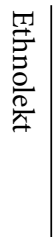 & $\begin{array}{l}\mathscr{L} \\
\mathbb{N} \\
\frac{0}{0} \\
\frac{0}{7}\end{array}$ & 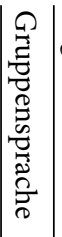 & 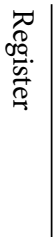 & 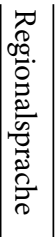 & 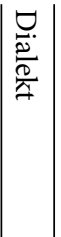 & 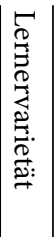 & \begin{tabular}{|l}
$\overline{2}$ \\
$\frac{2}{0}$ \\
$\frac{0}{2}$ \\
$\frac{7}{7}$
\end{tabular} & 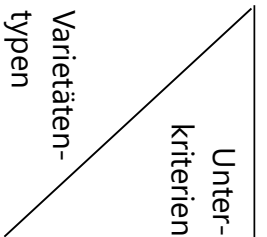 & 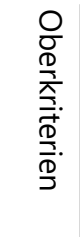 \\
\hline & & & & & & & & & & & & & + & + & Individuum & \multirow{3}{*}{$\begin{array}{l}\frac{D}{D} \\
\frac{D}{U} \\
\underline{O}\end{array}$} \\
\hline 1 & + & + & 1 & & & 1 & 1 & & & & & & 1 & & Erstsprache & \\
\hline+ & & & + & & & + & + & & & & & & + & & Zweitsprache & \\
\hline & & & & & & I & & & & & + & $\stackrel{+}{+}$ & & & Region & \multirow{2}{*}{$\begin{array}{l}\text { 뀽 } \\
\stackrel{\complement}{3}\end{array}$} \\
\hline & & & & & & & & & & & + & + & & & Etablierung & \\
\hline & & & + & & & & & & & $\stackrel{+}{+}$ & & & & & Kontext & \multirow{2}{*}{ 물 } \\
\hline & & & & & & & & & & I & & & & & spez. Institution & \\
\hline & & & & & & & & + & \multirow{4}{*}{+} & & & & & & soziale Schicht & \multirow{4}{*}{$\begin{array}{l}\text { O } \\
N \\
\text { Q } \\
\frac{c}{0} \\
\frac{0}{0}\end{array}$} \\
\hline \multirow[t]{3}{*}{+} & & & + & & & ક & & & & & & & & & Alter & \\
\hline & & & & + & & + & + & & & & & & & & Ethnizität & \\
\hline & & & & + & & + & + & & & & & & & & Gruppenzugeh. & \\
\hline \multirow{2}{*}{ 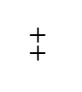 } & \multirow{2}{*}{+} & \multirow{2}{*}{+} & \multirow{2}{*}{+} & \multirow{2}{*}{+} & \multirow{2}{*}{+} & & + & & & & & & \multirow{2}{*}{+} & & zwei Sprachen & \multirow{4}{*}{ 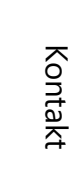 } \\
\hline & & & & & & + & & & & & & & & & mehrere Sprachen & \\
\hline+ & & & + & 1 & & & & & & & & & & & Brückenfunktion & \\
\hline \multirow[t]{3}{*}{+} & & & + & $\stackrel{+}{+}$ & & + & + & & & & & & + & & Mehrsprachigkeit & \\
\hline & & & & & & & & & & & 1 & 1 & & & eig. schriftl. Norm & \multirow{2}{*}{ 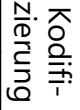 } \\
\hline & & & & & & + & + & & & & 1 & 1 & & & eig. mündl. Norm & \\
\hline+ & + & + & + & & & & & & & & & & & & Vereinfachung & \multirow{5}{*}{$\begin{array}{l}\text { D } \\
\text { D } \\
\text { D } \\
\widetilde{D} \\
\widetilde{D}\end{array}$} \\
\hline+ & + & + & + & & & & & & & & & & & & Beimengung & \\
\hline \multirow[t]{7}{*}{+} & & & + & & & & & & & & & & & & Reduktion & \\
\hline & 1 & + & & & & & & & & & & & & & Expansion & \\
\hline & & & & & & 1 & 1 & & & & & & + & & Übergangssystem & \\
\hline & & & & & & + & + & & & & + & + & & & mündlich & \multirow{2}{*}{$\begin{array}{l}\text { 정 } \\
\text { 을 } \\
\frac{1}{3}\end{array}$} \\
\hline & & & & & & & & & & & 1 & 1 & & & schriftlich & \\
\hline & & & & + & & & & & & & & & & & Lex A/MorphSyn B & \multirow{2}{*}{ 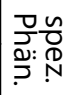 } \\
\hline & & & & & & ક & & & & & & & & & Entlehnungen & \\
\hline
\end{tabular}

Tab. 16: Kriterien der Varietätentypen

++ begriffskonstituierende Kriterien; + weitere charakteristische Kriterien; - Negation des Kriteriums; $(+)$ erweiternde Kriterien. Leere Zellen bedeuten, dass diese Kriterien in der Definition der einzelnen Varietätentypen nicht von Bedeutung sind. 


\subsection{Kriterien}

Im folgenden Unterkapitel werden die herausgefilterten sprachsozialen und strukturellen Kriterien von den einzelnen Varietätentypen gelöst betrachtet und zusammengefasst.

\subsubsection{Sprachsoziale Kriterien}

Die Oberkriterien stellen die sozialen Kriterien Person, Region, soziale Gruppe, Kodifizierung, Situation und Kontakt dar. In Kapitel 3.1 wurden zu diesen Oberkriterien weitere Unterkriterien herausgefiltert, die in der folgenden Tab. 17 zusammengefasst werden:

\begin{tabular}{l|l|l|l|l|l|} 
Person & Raum & Situation & soziale Gruppe & Kontakt & Kodifizierung \\
\hline Individuum & Region & Kontext & soziale Schicht & $\begin{array}{l}\text { zwei } \\
\text { Sprachen }\end{array}$ & $\begin{array}{l}\text { eigene } \\
\text { schriftliche } \\
\text { Norm }\end{array}$ \\
\hline Erstsprache & Etablierung & $\begin{array}{l}\text { (insbesondere) } \\
\text { Institution }\end{array}$ & Alter & $\begin{array}{l}\text { mehr als zwei } \\
\text { Sprachen }\end{array}$ & $\begin{array}{l}\text { eigene } \\
\text { mündliche } \\
\text { Norm }\end{array}$ \\
\hline Zweitsprache & & & Ethnizität & $\begin{array}{l}\text { Brücken- } \\
\text { funktion }\end{array}$ & \\
\hline & & & $\begin{array}{l}\text { Gruppen- } \\
\text { zugehörigkeits- } \\
\text { funktion }\end{array}$ & $\begin{array}{l}\text { Mehr- } \\
\text { sprachigkeit }\end{array}$ & \\
\hline
\end{tabular}

Tab. 17: Sprachsoziale Kriterien

Person. Dem Oberkriterium Person konnten die drei Unterkriterien Individuum, Erstsprache und Zweitsprache zugeordnet werden, die eine spezifische Varietät aufweisen kann.

Das Kriterium Individuum bezieht sich ausschließlich auf den individuellen Sprecher. Eine Varietät erfüllt dieses Kriterium, sobald der Gebrauch stark vom individuellen Sprecher abhängig ist. Zudem beinhaltet das Kriterium Person, ob eine Varietät die Erstoder Zweitsprache eines Sprechers darstellt. Die Bezeichnung Zweitsprache soll hier nicht ausschließlich auf das Erlernen einer zweiten Sprache der Sprecher bezogen sein, sondern kann auch die dritte, vierte etc. Sprache bzw. Varietät der Lerner darstellen. Es ist hinsichtlich des Kriteriums Zweitsprache anzumerken, dass hier der Erwerbsprozess von Bedeutung ist. In der Forschungsliteratur wird ein Unterschied zwischen Sprachenlernen, d. h. gesteuertem Zweitspracherwerb, und Sprachaneignung, d. h. ungesteuertem Zweitspracherwerb, gemacht (Kühl 2008: 107). Mit Ersterem wird das Lernen einer Sprache in formalen Kontexten mit Korrekturen und Beschäftigung mit den Regeln einer 
Sprache beschrieben. Die Sprachaneignung hingegen findet in informellen Kontexten „mit dem Ziel der Kommunikation und nicht so sehr unter dem Anspruch der Korrekt heit“ statt (Kühl 2008: 107). Bei Sprachenlernen wird oftmals die Perspektive einer korrekten Zielsprache angenommen. Bei einer Sprachaneignung ist diese Zielnorm zweitrangig.

Raum. Zum Oberkriterium Raum zählen alle Kriterien, die in Bezug zur geographischen Abgrenzung stehen. Hierunter fallen die Kriterien Region und Etablierung.

Eine Region ist schwer abzugrenzen und bezieht sich lediglich auf eine geographische Abgrenzung. Hier kann zusätzlich zwischen klein- und mittelräumigen Regionen unterschieden werden. Die Grenze zwischen diesen beiden Bezeichnungen ist jedoch fließend. Es wird angenommen, dass eine kleinräumige Region eine geographisch kleinere Fläche umfasst und sich im Verhältnis zu mittelräumigen Regionen leichter eingrenzen lässt.

Zum anderen fällt hierunter, ob eine Varietät in einer bestimmten Region etabliert ist, d. h. dass alle, in dieser Region geborenen und aufgewachsenen Einwohner, diese Varietät beherrschen (Etablierung).

Situation. Unter Situation werden die Kriterien Kontext und Institution gefasst.

Das Kriterium Kontext bezieht sich allgemein auf die kontextuelle Begebenheit der Verwendung einer Varietät. Eine spezifische Varietät erfüllt dieses Kriterium sobald die Verwendung dieser Varietät von dem Kontext abhängig ist.

Zudem wird als besondere Situation das Kriterium des Gebrauchs einer Varietät in Institutionen genannt. Wird eine spezifische Varietät lediglich oder hauptsächlich in Institutionen als öffentliche Sprache gesprochen, so gilt dieses Kriterium als erfüllt.

Soziale Gruppe. Unter dem Oberkriterium soziale Gruppe werden alle Kriterien gezählt, die sich weitestgehend auf eine soziale Gruppe beziehen. Die Problematik des Begriffs wurde in Kapitel 3.1.4 dargelegt. Eine Gruppe abzugrenzen ist nicht nur hinsichtlich der Quantität der Personen, sondern auch aufgrund der Merkmale einer Personengruppe, die als konstitutiv gelten können, vage. Die Unterkriterien sind die Zugehörigkeit zu einer sozialen Schicht, das Alter, die Ethnizität sowie die Gruppenzugehörigkeitsfunktion.

Bei sozialen Schichten handelt es sich um die traditionelle Einteilung der Gesellschaft in Sozialschichten nach verschiedenen soziologischen Variablen, wie beispielsweise Beruf, Bildung und Einkommen (Kubczak 1987: 269). ${ }^{25}$ Basiert die Verwendung einer Varietät auf der sozialen Schicht der Sprecher, gilt dieses Kriterium als erfüllt. Sobald der Gebrauch einer Varietät durch eine Altersspanne der Sprecher einzugrenzen ist, wird das Kriterium Alter erfüllt.

25 Für eine detaillierte Darstellung der kontroversen Begrifflichkeiten, die in Bezug auf sozialer Schicht bzw. sozialer Einteilung der Gesellschaft in der (Sozio-)Linguistik anzutreffen sind siehe Ash (2013) und Durrell (2004). 
Die Ethnizität ist ein komplexes Kriterium. „Ethnicity is in many ways a difficult concept and also much debated“ (Sollid 2013: 70). Allgemein bezieht sich das Kriterium Ethnizität auf die spezifischen kulturellen und historischen Gemeinsamkeiten einer Gruppe (Sollid 2013: 70). Diese Gruppe teilt aufgrund des gemeinsamen Hintergrunds einen Identitätssinn, der die Mitglieder dieser Gruppe verbindet (Devetak 1996: 204). ${ }^{26}$ Dieses Kriterium gilt als erfüllt, sobald eine Sprechergruppe hinsichtlich ihrer Kultur und Historie abgegrenzt werden kann. Oftmals stellen diese Gruppen Minderheiten dar.

Das Kriterium Gruppenzugehörigkeitsfunktion macht generelle Aussagen über die Zugehörigkeit der Sprecher zu einer bestimmten Gruppe. ${ }^{27}$ Deutet die Verwendung einer Varietät auf die Zugehörigkeit zu einer spezifischen Gruppe hin, gilt dieses Kriterium als erfüllt.

Kontakt. Dem Oberkriterium Kontakt werden jene Varietäten untergeordnet, die in Bezug zu Sprachkontaktsituationen stehen. Als Sprachkontakt werden aus soziolinguistischer Perspektive Situationen bezeichnet, in denen zwei oder mehrere Sprechergruppen, die keine gemeinsame Sprache haben, in Kontakt miteinander treten (Trudgill 1992: 45). Aus psycholinguistischer Perspektive kann Sprachkontakt auch auf kognitiver Ebene im Individuum selbst stattfinden (Riehl 2014: 11-12).

Da Sprachkontakt in der Regel stabile und intensive Mehrsprachigkeit beinhaltet (Höder 2012: 255), wird dieses Unterkriterium hier aufgenommen. Es lässt sich zwischen individueller und gesellschaftlicher Mehrsprachigkeit unterscheiden (Riehl 2014: 60). Trudgill (1992: 53) beschreibt Mehrsprachigkeit wie folgt:

A sociolinguistic situation in which more than one language is involved, usually involving also language contact and individual bilingualism. Note that many sociolinguists use the term 'bilingualism' to refer to individuals, even if they are trilingual, quadrilingual, etc., and reserve the term 'multilingualism' for nations or societies, even if only two languages are involved.

Aus dieser Definition geht hervor, dass die Termini Zwei- und Mehrsprachigkeit nicht einheitlich verwendet werden. In dieser Arbeit soll das Kriterium Mehrsprachigkeit sowohl für Individuen als auch für Gruppen verwendet werden.

Kodifizierung. Das Kriterium Kodifizierung trifft Aussagen über die mögliche schriftliche oder mündliche Norm, die eine Varietät aufweisen kann. Diese Norm muss keine standardsprachliche Norm sein, sondern kann sich lediglich auf die Varietät und deren eigene Norm beziehen.

26 Diese allgemeine Auffassung genügt an dieser Stelle. Für weitere Diskussionen zu Ethnizität siehe beispielsweise Deumert (2004), Devetak (1996) und Fought (2013).

27 Es wurde bewusst auf das komplexe, z. T. kontrovers diskutierte Kriterium Identität verzichtet, da das Konzept Identität ein subjektives und folglich schwer zu fassendes Konstrukt darstellt. Sobald eine Varietät einen identitätsstiftenden Faktor in Bezug auf eine Gruppe aufweist, so wird angenommen, dass eine Gruppenzugehörigkeitsfunktion vorliegt. Für weitere Informationen zu Identität siehe u. a. Krappmann (2004). 


\subsubsection{Strukturelle Kriterien}

Die Varietätentypen wurden zunächst durch ihre sprachsozialen Kriterien definiert (siehe Kapitel 3.1). Es gibt einige Varietätentypen, bei denen zudem strukturelle Kriterien bei der Definition eine wesentliche Rolle spielen. Diese strukturellen Kriterien werden in Tab. 18 zusammengefasst. Analog zu den sprachsozialen Kriterien sind den Oberkriterien weitere Unterkriterien untergeordnet.

\begin{tabular}{l|l|l|} 
Prozesse & Medium & spezifische Phänomene \\
\hline Vereinfachung & mündlich & $\begin{array}{l}\text { Lexikon der Sprache A, } \\
\text { Morphosyntax der Sprache B }\end{array}$ \\
\hline Beimengung & schriftlich & Entlehnungen \\
\hline Reduktion & & \\
\hline Expansion & & \\
\hline Übergangssystem & & \\
\hline
\end{tabular}

Tab. 18: Strukturelle Kriterien

Prozesse. Unter dem Oberkriterium Prozesse werden unter anderem die von Trudgill (1992) eingeführten Begrifflichkeiten Vereinfachung, Beimengung, Reduktion und Expansion gezählt. Eine genaue Definition und Darstellung findet sich in Kapitel 3.1.5.

Ein weiteres Unterkriterium stellt Übergangssystem dar. Sollte eine Varietät von begrenzter Dauer sein und ein Zwischenstadium darstellen, so ist dieses Kriterium erfüllt.

Medium. Unter Medium wird verstanden, ob eine Varietät lediglich in reiner mündlicher Form verwendet wird, oder ob es auch eine schriftliche Form der Varietät gibt. Diese Kriterien grenzen sich von den sprachsozialen Unterkriterien von Kodifizierung in dem Sinne ab, dass hier lediglich die reine mediale Form gemeint ist. Die Norm bleibt hierbei ungeachtet.

Spezifische Phänomene. Unter dem Oberkriterium spezifische Phänomene werden konkrete linguistische Merkmale verstanden, die eine Varietät aufweisen kann. Hierzu zählt zum einen das Kriterium, dass eine Varietät das Lexikon der einen Sprache und die Morphosyntax der anderen Sprache besitzt. Ein weiteres Merkmal sind Entlehnungen aus anderen Sprachen. Lehnelemente „sind - meist lexikalische Einheiten [...], welche in die entsprechende Varietät [...] eingeführt wurden, um deren Referenzpotential zu erweitern, sie werden als Teil der Systems/Lexikon von [dieser Varietät] behandelt, auch wenn deren fremder Ursprung noch transparent ist“ (Lüdi 1996: 242). Dieses spezifische Phänomen ist oftmals das Resultat von Sprachkontakt (Trudgill 1992: 45). Sobald in einer Varietät Entlehnungen aus anderen Sprachen etabliert sind, gilt dieses Kriterium als erfüllt. 


\section{Schlussfolgerung zu Kapitel 3}

Dieses Kapitel verdeutlicht die Komplexität der Definition von spezifischen Varietätentypen und die Abgrenzung von einzelnen Varietätentypen untereinander. Durch die Herausarbeitung begriffskonstituierender Kriterien der einzelnen prototypischen Varietätentypen, sowie weiterer charakteristischer Kriterien, die in Bezug auf diese Varietätentypen diskutiert wurden, konnte ein schematischer und übersichtlicher Kriterienkatalog für die einzelnen relevanten Varietätentypen erstellt werden. Anhand dieses Kriterienkataloges - getrennt von den prototypischen Varietätentypen - wird in Kapitel 4 herausgearbeitet, inwieweit diese Kriterien auf das SüD zutreffen. 


\section{Südschleswigdänisch: ein Merkmalkatalog}

In diesem Kapitel werden die Merkmale des SüD basierend auf den in Kapitel 3 formulierten Kriterien detailliert dargestellt (vgl. Tab. 17 und 18). Hierbei werden nicht alle Merkmale diskutiert, sondern lediglich jene dargestellt, die in der bisherigen Forschungsliteratur bereits als Merkmale des SüD diskutiert werden. Weitere spezifische Merkmale des SüD werden im Rahmen dieser Arbeit nicht außer Acht gelassen. Demnach stützt sich dieses Kapitel auf die Schnittmenge der herausgearbeiteten Kriterien der einzelnen Varietätentypen und der übereinstimmenden Merkmale des SüD. ${ }^{28}$ Um eine möglichst objektive Analyse zu ermöglichen, werden an dieser Stelle ausschließlich die in Kapitel 3 herausgearbeiteten Kriterien, unabhängig von den einzelnen Varietätentypen, betrachtet. Diese Trennung ermöglicht eine Betrachtung der Problematik ohne dabei eine Klassifizierung des SüD vorzunehmen.

\subsection{Sprachsoziale Merkmale}

\subsubsection{Person}

In ihrer Beschreibung des SüD schildert Fredsted (2009a: 15) den Umstand, dass es in der Ausprägung und der Verwendung von SüD individuelle Unterschiede gibt:

Während das SüD einiger Minderheitsangehöriger in hohem Maß Züge einer Kontaktsprache von Deutsch und Dänisch aufweist, ist es bei anderen eine vom Deutschen zwar beeinflusste, aber dem Standarddänischen sehr nahe Varietät, die sich lediglich in der Phonologie und Prosodie sowie gewissen „Südschleswigismen“ und Südschleswigbegriffen unterscheidet.

Demzufolge weist die südschleswigdänische Varietät kein festes linguistisches Muster auf, sondern variiert von Person zu Person. „Die Variabilität des SüD besteht allein in der Individualität ihrer Sprecher“ (Kühl 2008: 106). Diese unterschiedliche Verwendung des SüD existiert nicht allein zwischen den Sprechern, sondern ebenfalls auf einer intrapersonalen Ebene, da dem SüD auch eine kontextabhängige Variation innerhalb derselben Person nachgesagt werden (Kühl 2008: 49, Pedersen 20oob: 243). Eine Aufnahme des Merkmals Individuum erscheint daher sinnvoll. Bisher wurde dieses Charakteristikum außer Acht gelassen, da es eine varietätentypologische Kategorisierung erschwert (Kühl 2008: 49, Pedersen 200ob: 243).

Aufgrund des Umstandes, dass ein Großteil der Analysen ihren Fokus auf das Dänisch der dänischen Minderheit im Allgemeinen legt, werden konkrete Merkmale des SüD lediglich im Zusammenhang mit dem Dänisch als Minderheitensprache dargelegt.

28 Der Begriff Kriterium bezieht sich generell auf die Varietätentypen, während sich der Begriff Merkmal auf das SüD bezieht. 
Dies ist auch bezüglich einer Charakterisierung des SüD als Erst- oder Zweitsprache der Fall. In den älteren Forschungen zum SüD werden keine expliziten Aussagen formuliert, dass es sich beim SüD um die Zweitsprache der Sprecher handelt. Durch implizite Aussagen zu der Sprechergruppe des SüD lassen sich jedoch Rückschlüsse darauf ziehen, dass das SüD an sich keine Erstsprache sein kann, sondern (mindestens) die Zweitsprache darstellt. Dies geht beispielsweise aus Pedersens (2009: 302) Abgrenzung der Sprechergruppe des SüD hervor: „This variety [is] first of all spoken and written by those who had German as their first language and Danish as their second language acquired in Danish minority educational institutions. "Ebenso lässt sich aus Kühls (2008: 276) und Pedersens (2003: 136) Analysen des Dänischen in der dänischen Minderheit entnehmen, dass SüD in keinem Fall die Erstsprache der Sprecher darstellen kann. Die Erstsprachen der Angehörigen der dänischen Minderheit sind im Allgemeinen Standarddänisch, größtenteils aber Deutsch. Da die meisten Angehörigen der dänischen Minderheit Deutsch als Erstsprache aufweisen (Pedersen 2009: 302), findet der Sprachaneignungsprozess zumeist im ungesteuerten Zweitspracherwerb in den dänischen Institutionen statt, da Standarddänisch hier als Medium verwendet wird und nicht als Fremdsprachenunterricht stattfindet (Pedersen 200ob: 233). Diese Forschungsergebnisse lassen durchaus den Schluss zu, dass das SüD nicht die Erstsprache, sondern vielmehr die Zweitsprache der dänischgesinnten Südschleswiger darstellt.

\subsubsection{Raum}

Der Gebrauch des SüD ist auf die Region Südschleswig begrenzt, die von der deutschdänischen Grenze bis zum Fluss Eider reicht (Pedersen 2009: 298). Infolgedessen, dass die Verwendung des SüD geographisch abgegrenzt werden kann, stellt der Raum - präziser die Region - ein wesentliches Merkmal dar, das die Varietät konstituiert. Die Region Südschleswig stellt eine relativ leicht abgrenzbare und geographisch kleine Fläche dar. Demzufolge wird hier angenommen, dass die Varietät SüD in einer kleinräumigen Region verwendet wird.

Bezogen auf das Kriterium Etablierung beschreibt Pedersen (200ob: 238), dass die südschleswigdänische Varietät innerhalb der Region nicht etabliert ist, $d$. h. dass nicht alle Einwohner Südschleswigs SüD beherrschen. Demnach stellt Etablierung kein Merkmal des SüD dar.

\subsubsection{Situation}

Wie bereits in Kapitel 2.2 beschrieben wird, besteht in Südschleswig eine funktionelle Verteilung der Sprachen innerhalb der dänischen Minderheit. Demnach werden Dänisch (als Minderheitensprache) und Deutsch in verschiedenen Kontexten verwendet (Pedersen 2000a: 118). 
Das (Standard-)Dänische wird hauptsächlich in der kulturellen Öffentlichkeit - vor allem in den Kindergärten und Schulen - verwendet. Deutsch hingegen wird in der politischen Öffentlichkeit, sowie in privaten Kontexten verwendet. Sprachen innerhalb der Familie können zudem auch Friesisch oder Dänisch sein (Pedersen 1991: 90). Die Abgrenzung der Stellung des SüD in dieser funktionellen Verteilung der Sprachen in der dänischen Minderheit ist jedoch komplex. Braunmüller (1996: 36) und Pedersen (2009: 306) schreiben dem SüD eine kontextabhängige Verwendung zu. Es wird in privaten Kontexten sowie im familiären Umfeld verwendet. $\mathrm{Zu}$ den privaten Kontexten zählen auch schulische Situationen, in denen jugendliche Sprecher untereinander die südschles wigdänische Varietät verwenden. Im Unterricht, d. h. in der kulturellen Öffentlichkeit, wird jedoch das Standarddänische präferiert (Pedersen 2009: 305). Zudem wird SüD in stärkerer Ausprägung in informellen Kontexten verwendet (Fredsted 2009b: 16). Insgesamt lässt sich zusammenfassen, dass die Verwendung des SüD von der Situation bzw. dem Kontext einer Situation bestimmt wird. In Institutionen wird Standarddänisch präferiert, weshalb das SüD keine offizielle Verwendung in Institutionen findet.

\subsubsection{Soziale Gruppe}

Die Sprechergruppe des SüD beschränkt sich zunächst auf jene, die sich der dänischen Minderheit zugehörig fühlen. Kühl (2008: 48) schätzt, dass die meisten Angehörigen der dänischen Minderheit das SüD verwenden. Hierbei handelt es sich um diejenigen, die Deutsch als Erstsprache aufweisen und Dänisch als Zweitsprache in den Institutionen (Kindergärten und Schulen) der dänischen Minderheit erworben haben (Pedersen 2009: 302). Diese Sprechergruppe ist relativ klar abgrenzbar ist, daher stellt das weit gefasste Kriterium soziale Gruppe ein Merkmal des SüD dar.

Ein weiteres Merkmal des SüD ist das Kriterium Ethnizität. Ausgehend von der Annahme, dass die meisten Angehörigen der dänischen Minderheit das SüD verwenden, stellt die Sprechergruppe eine nationale Minderheit dar, die durch historische Begebenheiten entstanden ist. Rindler Schjerve (2004: 482) definiert nationale Minderheiten als „Minderheiten, die ihre ethnische Bezugsgruppe in einem Staatsvolk außerhalb ihrer Staatsgrenzen haben“. Diese stellen eine Subform der ethnischen Minderheiten dar. Auch Pedersen (2005: 133) bezeichnet die dänische Minderheit als eine ethnische Gruppe, die eine regionale transethnische Minderheitenethnizität aufweist. Demzufolge ist die Ethnizität der Sprecher ausschlaggebend für die Verwendung des SüD.

Zudem wird das Merkmal Gruppenzugehörigkeitsfunktion diskutiert. Vor allem aus der ethno- und soziolinguistischen Perspektive wird angenommen, dass die Benutzung der südschleswigdänischen Varietät in Beziehung zur südschleswigschen Identität und der Zugehörigkeit zur dänischen Minderheit steht (u. a. Pedersen 2000a: 111, 2009: 298). Die Verwendung des SüD drückt eine Art „Danishness“ aus (Pedersen 2009: 298). Pedersen (2003: 16) ist der Auffassung, dass diejenigen, die eine südschleswigdänische 
Sprachnorm anstreben, als Südschleswiger mit einer eigenen Minderheitenidentität betrachtet werden. So wird das Verwenden des SüD als Ausdruck der regionalen und nationalen Identität verstanden (Pedersen 2009: 314). Der Gebrauch des SüD dient innerhalb der Minderheit als Identifikationssprache, um die Zugehörigkeit zur dänischen Minderheit auszudrücken und gegenüber der Mehrheitsbevölkerung als Möglichkeit sich ihr gegenüber abzugrenzen (Braunmüller 1995: 150, Pedersen 2009: 307-308). Von Jugendlichen wird die Varietät oftmals zur Abgrenzung oder als Widerstand gegen die Einsprachigkeitsnorm/-politik der dänischen Institutionen verwendet (Pedersen 2003: 14). Pedersen (2002: 409) beschreibt zudem, dass die Varietät im Allgemeinen die Funktion hat, die Gemeinschaft mit anderen Mitgliedern und die Solidarität zur Minderheit zu unterstützen. Der Zweck der Verwendung des SüD kann von Person zu Person variieren. Folglich kann das SüD bei manchen Sprechern die Zugehörigkeit zur dänischen Mehrheit in Dänemark, zur dänischen Minderheit allgemein oder zu einer südschleswigschen Zugehörigkeit ausdrücken. Welcher Art Zugehörigkeit die Verwendung des SüD bei einer einzelnen Person ist, ist diskutabel, dennoch drückt die Verwendung des SüD allgemein eine Gruppenzugehörigkeitsfunktion aus. Auch Braunmüllers (1995) Bezeichnung des SüD als Identifikationssprache, d. h. als eine Sprache, die eine Identifikationsfunktion mit einer Gruppe aufweist, bestätigt, dass die Gruppenzugehörigkeitsfunktion ein Charakteristikum des SüD ist.

\subsubsection{Kontakt}

SüD ist eine „direkte und konsequente Fortsetzung, [...] ein neues Produkt des früheren intensiven Sprachkontakts mit dem deutschen Sprachgebiet“ (Braunmüller 1995: 150). Sowohl die historische Sprachkontaktsituation, als auch die daraus resultierende individuelle sowie gesellschaftliche Mehrsprachigkeit sind für die Entstehung der sprachlichen Varietät SüD verantwortlich. Kontakt kann somit als ein weiteres Merkmal des SüD aufgenommen werden.

Der Kontakt besteht hierbei zwischen den benachbarten historisch-natürlichen Sprachen Deutsch und Dänisch. Durch die Verwendung des (Standard-)Dänischen in Kontexten der dänischen Minderheit treten Deutsch und Dänisch in Kontakt. Zudem beeinflussen die weiteren Varietäten des Gebietes Südschleswig die Entwicklung der Varietät. So unter anderem der südjütische Dialekt, die norddeutsche Umgangssprache und Niederdeutsch (vgl. Kapitel 2.1).

Der deutschen Sprache der Mehrheitsbevölkerung wird oftmals eine „abschirmende Wirkung“ (Braunmüller 1995: 152) zugeschrieben. Sie vermindert den direkten Sprachkontakt des Dänischen in Dänemark mit dem Dänisch der dänischen Minderheit in Südschleswig. In dieser „Sprachinsel“ (Fredsted 1997) entwickelt sich die südschleswigdänische Varietät umgeben von der Mehrheitssprache Deutsch. 
Die spezielle Situation des Sprachkontaktes zwischen Deutsch und Dänisch resultiert in einer stabilen gesellschaftlichen Mehrsprachigkeit in Südschleswig (Kühl 2008: 49). Zudem haben alle Südschleswigdänischsprecher Deutsch als Erstsprache und sind somit individuell zweisprachig. Infolgedessen liegt dem SüD keine Brückenfunktion zugrunde. „Alle kan jo være sikre på at de bliver forstået, fordi alle har tysk som (ubevidst) første [...] sprog“ (Braunmüller 1996: 33). Auch Fredsted (2009a: 15) beschreibt, dass die „Voraussetzung für den Gebrauch des Südschleswigdänischen [...] die Bilingualität der Minderheitsangehörigen [ist], durch die es nicht zu Verständigungsschwierigkeiten kommt“. Hierbei ist anzumerken, dass „SüD sowohl ein Ergebnis individueller deutsch-dänischer Zweisprachigkeit als auch der stabilen sozietalen Mehrsprachigkeit ist" (Fredsted 2009a: 15). ${ }^{29}$ Der Gebrauch des SüD setzt somit das Merkmal individuelle Mehrsprachigkeit voraus, da alle absolut zweisprachig sind (Braunmüller 1996: 35-36). Zum anderen stellt die gesellschaftliche Mehrsprachigkeit ebenfalls ein Merkmal des SüD dar. Generell wird das Merkmal Mehrsprachigkeit als Basis der Varietät angesehen (Braunmüller 1995: 151; vgl. Abb. 1).

\subsubsection{Kodifizierung}

Aus den neueren Forschungsansätzen zum SüD wird deutlich, dass sich innerhalb der dänischgesinnten Südschleswiger eine eigene dänische Sprachnorm entwickelt hat (u. a. Fredsted 1997, 1999, Pedersen 2003). SüD wird als Normideal innerhalb der dänischen Minderheit gesehen und konkurriert mit der Norm des Standarddänischen (Pedersen 2000a: 108). Hiervon ausgenommen sind die dänischen Institutionen, die eine Norm des Standarddänischen einhalten und die Schüler nach dieser Norm korrigieren.

Die eigene Sprachnorm wird weitestgehend im mündlichen Sprachgebrauch ersichtlich. In der Schriftsprache scheint für das SüD (noch?) keine eigene Norm zu gelten, da hier Korrekturen vollzogen werden, die das Standarddänische als Normideal bevorzugen (Pedersen 2005: 129). „Denne sproglige korreksning tyder på at sydslesvigsk som normideal endnu ikke gælder litteratur" (Pedersen 200oa: 110). Somit kann das Merkmal der eigenen mündlichen Norm bestätigt, die eigene schriftliche Norm hingegen muss abgelehnt werden.

\footnotetext{
29 Fredsted (2009a) unterscheidet zwischen Zwei- und Mehrsprachigkeit. Zweisprachigkeit bezieht sie lediglich auf die individuelle Ebene, während Mehrsprachigkeit als gesellschaftliches Phänomen betrachtet wird. In dieser Arbeit stellt Zweisprachigkeit im Sinne Fredsteds die individuelle Mehrsprachigkeit dar, während Fredsteds Mehrsprachigkeit der gesellschaftlichen Ebene als gesellschaftliche Mehrsprachigkeit bezeichnet wird.
} 


\subsection{Strukturelle Merkmale}

\subsubsection{Prozesse}

Das SüD hat viele spezifische Merkmale auf den verschiedenen Strukturebenen wie beispielsweise der Phonologie, Syntax oder Semantik. ${ }^{30}$ Von den in Kapitel 3.2 herausgearbeiteten strukturellen Kriterien (vgl. Tab. 18), werden die Kriterien Beimengung und Vereinfachung in Bezug aus das SüD diskutiert. Unter Beimengungen werden Interferenzfehler verstanden, die durch ein unvollständiges Lernen der Sprache entstanden sind (Braunmüller 1996: 35). Auch wenn die vorliegende Arbeit sich von dem Begriff Interferenzen entfernt, der sich eher auf eine Fehleranalyse als auf eine objektive Betrachtung der Mischung zweier Sprachen bzw. Varietäten bezieht, wird hier angenommen, dass eine Beimengung stattfindet. Das SüD wird im Wesentlichen von „Südschleswigismen“ geprägt, die ihren Ursprung in der deutschen Sprache haben.

Zusätzlich zur Beimengung findet ebenfalls eine Vereinfachung statt (Fredsted 1999: 69). Dies bezieht sich nicht auf die rein sprachliche Ebene, sondern auf die kognitive Ebene des Sprechers. So beschreibt Fredsted (1997) Vereinfachungen als „forenklingstendenser, der i dette tilfælde består i en parallel brug af de to sprog på flere niveauer, samt blandingsformer“. Die Vereinfachung drückt sich dadurch aus, dass die Benutzung des SüD eine kognitive Vereinfachung der Sprachverarbeitung darstellt. ${ }^{31}$

\subsubsection{Medium}

Einige Autoren beschreiben das SüD als gesprochene Varietät des Dänischen (u. a. Fredsted 2009b: 11). Allerdings ist diese Sichtweise umstritten, da Minderheitenmitglieder diese Varietät auch als ein schriftliches Medium verwenden (Pedersen 2009: 305).

Zwar wird die südschleswigdänische Literatur von monolingualen Dänen aus Dänemark kritisiert, dennoch betonen die südschleswigdänischen Autoren, dass die Benutzung dieser Varietät die Zugehörigkeit zur dänischen Minderheit und deren Identität ausmachen (Pedersen 2009: 306). Dies lässt sich auch in der Zeitung der dänischen Min-

30 Im Folgenden soll auf diese sprachliche Variation jedoch nicht weiter eingegangen werden; siehe hierzu u. a. Christophersen (1985), Fredsted (1997, 2009a), Kühl (2008) und Pedersen (200ob, 2009).

31 In Bezug auf diese Vereinfachungstendenzen wäre eine Analyse unter Berücksichtigung des Diasystematisierungsansatzes (Höder 2012) von Bedeutung. In diesem Ansatz wird Mehrsprachigkeit - d. h. die multilinguale sowie auch multilektale Kompetenz eines Sprechers - als fundamentales Charakteristikum angesehen. Sprachsysteme innerhalb der mehrsprachigen Sprecher stellen multilinguale Systeme dar, in denen sowohl sprachspezifische als auch multilinguale Strukturen in einem grammatischen und lexikalischen System zusammengefasst werden. So wie bei Varietätenkontakt von einem System innerhalb des Sprechers ausgegangen wird, besteht hier die Annahme, dass auch dem Sprachkontakt ein System zugrunde liegt (Höder 2011: 241242). Die Etablierung von sogenannten Diakonstruktionen innerhalb dieses multilingualen Sprachsystems eines Sprechers bewirkt eine strukturelle Annäherung der beteiligten Sprachen. 
derheit Flensborg Avis beobachten, die seit den 1960ern teilweise auch die südschleswigdänische Varietät verwenden. Demzufolge wird das SüD als schriftliches Medium benutzt - jedoch ohne eine offizielle schriftliche Norm zu besitzen.

\subsubsection{Spezifische Phänomene}

Das SüD ist geprägt von vielen Sprachkontaktphänomenen. Hierbei muss unterschieden werden zwischen etablierten Phänomenen, die als fester Bestandteil des sprachlichen Systems gelten, und jenen, die „ad hoc im processing der Sprachkontaktproduktion“ entstehen (Kühl 2008: 53-54). Kühl (2008) nennt unter den nicht etablierten Phänomenen unter anderem das Codeswitching.

$\mathrm{Zu}$ den etablierten Sprachkontaktphänomenen zählen Entlehnungen, die etablierte lexikalisch-semantische Elemente des SüD darstellen und ihren Ursprung vornehmlich im Deutschen haben (Kühl 2008: 53-54). Diese Arbeit beschränkt sich auf diese etablierten Merkmale des SüD, da diese das gesamte System der sprachlichen Varietät betreffen. Sprachkontaktphänomene, die hingegen im Laufe einer Kommunikation auftreten und das gesamte System nicht direkt betreffen, werden nicht aufgenommen.

\subsection{Merkmalkatalog}

Die Kapitel 4.1 und 4.2 fassen die herausgearbeiteten Merkmale der südschleswigdänischen Varietät zusammen. Eine Vielzahl der Kriterien, die in Kapitel 3.2 herausgearbeitet wurden, treffen auf das $\mathrm{SüD} z u$, andere hingegen nicht. Es wird davon abgesehen einzelne Merkmale des SüD als begriffskonstituierend einzustufen. Eine Gewichtung einzelner Merkmale würde dem Ziel dieser Arbeit, der objektiven Einordnung, nicht gerecht werden.

Die Tab. 19 und 20 fassen die Ergebnisse zusammen und geben einen Überblick über die sprachsozialen und strukturellen Merkmale des SüD: 


\begin{tabular}{|c|c|c|c|c|c|}
\hline Person & Raum & Situation & soziale Gruppe & Kontakt & Kodifizierung \\
\hline Individuum & $\begin{array}{l}\text { Region } \\
\text { (klein- } \\
\text { räumig) }\end{array}$ & Kontext & Ethnizität & $\begin{array}{l}\text { zwei } \\
\text { natürlich- } \\
\text { historische } \\
\text { Sprachen }\end{array}$ & $\begin{array}{l}\text { keine } \\
\text { schriftliche } \\
\text { Norm }\end{array}$ \\
\hline $\begin{array}{l}\text { keine } \\
\text { Erstsprache }\end{array}$ & $\begin{array}{l}\text { keine } \\
\text { Etablierung }\end{array}$ & nicht Institution & $\begin{array}{l}\text { Gruppen- } \\
\text { zugehörigkeits- } \\
\text { funktion }\end{array}$ & $\begin{array}{l}\text { mehr als zwei } \\
\text { Varietäten }\end{array}$ & $\begin{array}{l}\text { mündliche } \\
\text { Norm }\end{array}$ \\
\hline \multirow[t]{2}{*}{ Zweitsprache } & & & & $\begin{array}{l}\text { keine } \\
\text { Brücken- } \\
\text { funktion }\end{array}$ & \\
\hline & & & & $\begin{array}{l}\text { Mehr- } \\
\text { sprachigkeit } \\
\text { (individuell } \\
\text { und gesell- } \\
\text { schaftlich) }\end{array}$ & \\
\hline
\end{tabular}

Tab. 19: Sprachsoziale Merkmale des SüD

\begin{tabular}{l|l|l|} 
Prozesse & Medium & spezifische Phänomene \\
\hline Vereinfachung & mündlich & Entlehnungen \\
\hline Beimengung & schriftlich & \\
\hline Übergangssystem & & \\
\hline
\end{tabular}

Tab. 20: Strukturelle Merkmale des SüD

\section{Schlussfolgerung zu Kapitel 4}

In Kapitel 4 wird die südschleswigdänische Varietät unter Berücksichtigung der in Kapitel 3 herausgearbeiteten Kriterien analysiert. Insgesamt weist das SüD Merkmale in allen sechs sprachsozialen Oberkategorien auf. Zudem wurden die strukturellen Merkmale des SüD herausgearbeitet. Anhand dieses objektiven Merkmalkatalogs des SüD werden in Kapitel 5 die Gemeinsamkeiten und Unterschiede zu den einzelnen Varietätentypen diskutiert. 


\section{Einordnung der Südschleswigdänischen}

Um die Leitfrage dieser Arbeit, wie sich das SüD varietätentypologisch einordnen lässt, zu beantworten, werden in diesem Kapitel die Merkmale des SüD (vgl. Tab. 19 und 20) mit dem Kriterienkatalog der Varietätentypen (vgl. Tab. 16) zusammengeführt. Auf diese Weise können Übereinstimmungen und Abweichungen zunächst veranschaulicht und im darauffolgenden Schritt diskutiert und analysiert werden.

\subsection{Kriterien der Varietätentypen und die Merkmale des SüD}

Die Entwicklung des Kriterienkataloges ausgehend von den einzelnen Varietätentypen und die Herausarbeitung der konkreten Merkmale machen es möglich, das SüD in die Kriterientabelle (vgl. Tab. 16) einzuordnen.

Die Tab. 21 zeigt die Überschneidungen und Abweichungen des SüD mit den einzelnen Varietätentypen: 


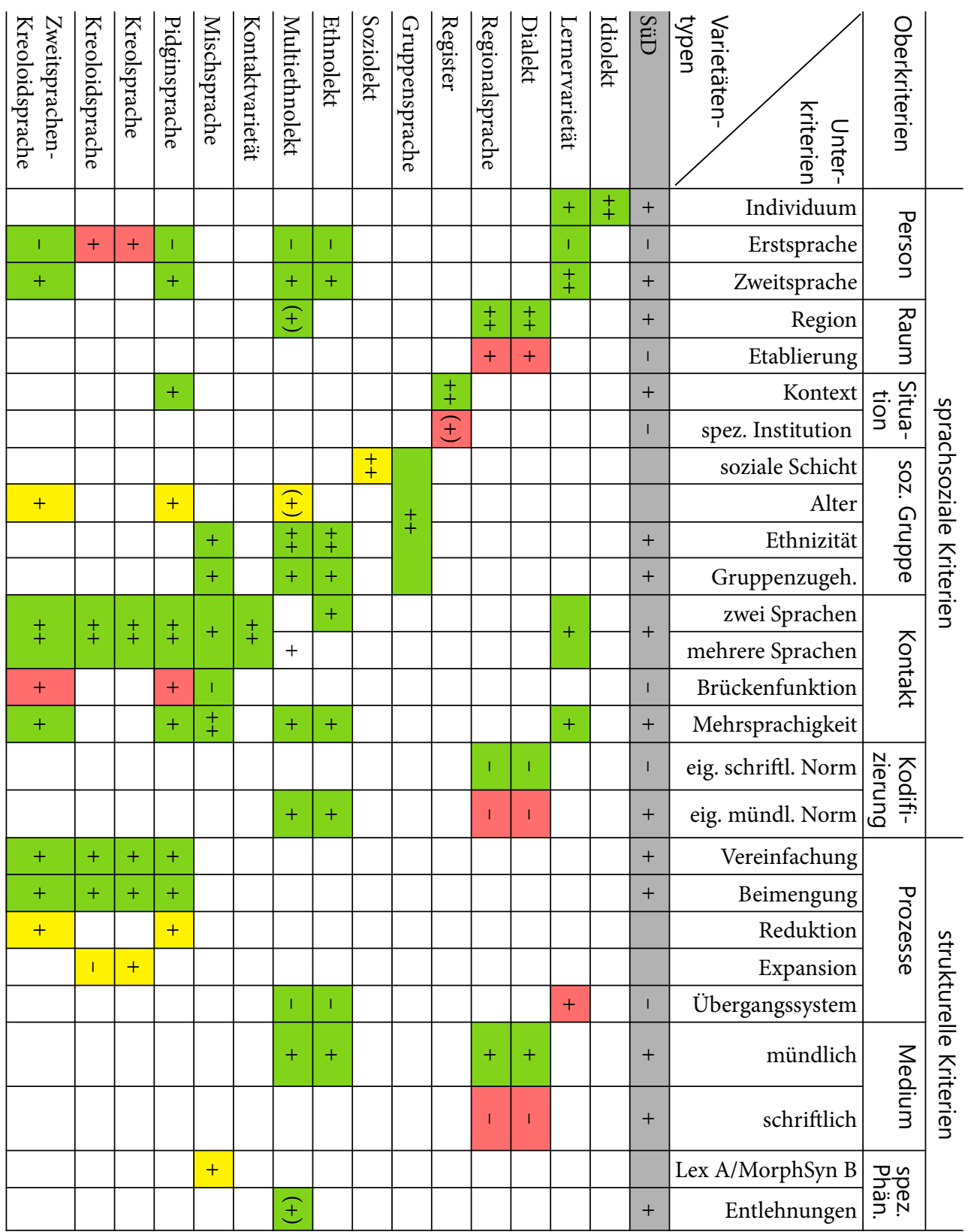

Tab. 21: Einordnung des SüD in den Kriterienkatalog

+ + begriffskonstituierende Kriterien; + weitere charakteristische Kriterien; - Negation des Kriteriums; (+) erweiternde Kriterien; grüne Zellen = Übereinstimmung mit SüD; rote Zellen = Abweichungen zum SüD; gelbe Zellen = werden in der Forschungsliteratur in Bezug auf das SüD nicht diskutiert. 


\subsection{Grobe Einordnung nach den begriffskonstituierenden Kriterien}

Tab. 21 verdeutlicht, dass das SüD Merkmale in allen sechs sprachsozialen Oberkriterien aufweist. Hierbei ist von Bedeutung, welche der speziellen begriffskonstituierenden Kriterien der Varietätentypen das SüD erfüllt. Da die begriffskonstituierenden Kriterien den jeweiligen Varietätentyp bestimmen, müssen diese vom SüD erfüllt werden, damit eine Kategorisierung möglich ist. Ist dies nicht gegeben, kann ohne weitere Betrachtung der anderen Kriterien eine Kategorisierung als solche ausgeschlossen werden. Infolgedessen werden in diesem Kapitel die begriffskonstituierenden Kriterien der Varietätentypen mit den Merkmalen der südschleswigdänischen Varietät abgeglichen.

Aus Tab. 21 wird ersichtlich, dass das SüD die begriffskonstituierenden Kriterien der folgenden Varietätentypen aufweist:

a. Idiolekt (Individuum)

b. Lernervarietät (Zweitsprache)

c. Dialekt* (Region)

d. Regionalsprache* (Region)

e. Register (Kontext)

f. Gruppensprache* (soziale Gruppe)

g. Ethnolekt* (Ethnizität)

h. Multiethnolekt (Ethnizität)

i. Kontaktvarietät* (Kontakt)

j. Mischsprache* (Mehrsprachigkeit)

k. Pidginsprache (Kontakt von zwei oder mehreren Sprachen)

1. Kreolsprache* (Kontakt von zwei oder mehreren Sprachen)

m. Kreoloidsprache ${ }^{\star}$ (Kontakt von zwei oder mehreren Sprachen)

n. Zweitsprachen-Kreoloidsprache* (Kontakt von zwei oder mehreren Sprachen) ${ }^{32}$

Bei diesen 14 Varietätenkategorien erscheint eine Kategorisierung daher prinzipiell möglich. Die bisherigen vielfältigen Kategorisierungsversuche des SüD lassen sich aufgrund dessen durchaus rechtfertigen. Fraglich ist die Kategorisierung des SüD als Soziolekt. Das begriffskonstituierende Kriterium dieses Varietätentyps - soziale Schicht - wird in Bezug auf das SüD in der Forschungsliteratur nicht diskutiert. Durch die in dieser Arbeit erfolgte Metaanalyse kann daher die Frage, ob das SüD dieses Kriterium erfüllt, nicht abschließend geklärt werden.

32 Die mit * gekennzeichneten Varietätentypen entsprechen jenen, die als Kategorie für das SüD in der For schungsliteratur bereits diskutiert werden (vgl. Kapitel 2.4). 


\subsection{Detaillierte Einordnung nach den weiteren Kriterien}

Im Folgenden werden die verbleibenden 14 Varietätentypen detailliert in Bezug auf die Merkmale des SüD analysiert. In den folgenden Unterkapiteln werden zuerst die gemeinsamen Merkmale und daraufhin die Unterschiede analysiert. Außerdem werden mögliche Schwierigkeiten des Abgleichs der Kriterien mit den Merkmalen des SüD beschrieben.

\subsubsection{Personale Varietäten}

Das SüD weist in Bezug auf das Oberkriterium Person die Merkmale Individuum, keine Erstsprache und Zweitsprache auf. In der Forschung zum SüD werden wiederholt idiolektale Abweichungen beschrieben. Ebenso wie Idiolekte zeichnet sich das SüD folglich durch die individuellen Züge der einzelnen Sprecher aus. Das einzige Kriterium eines Idiolekts - Individuum - wird demnach vollständig erfüllt. Da Idiolekte keine weiteren Kriterien aufweisen, kann geschlussfolgert werden, dass das SüD dem Varietätentyp vollkommen nachkommt. Es ist dennoch anzumerken, dass dieses Kriterium lediglich einen geringen Teil des SüD ausmacht. Weitere wesentliche Merkmale des SüD erfasst diese Varietätenkategorie nicht.

Das Merkmal Zweitsprache der südschleswigdänischen Varietät stellt das begriffskonstituierende Kriterium des Varietätentyps Lernervarietät dar. Ebenfalls besteht eine Übereinstimmung der weiteren Kriterien Kontakt (individuell), Mehrsprachigkeit (individuell) und keine Erstsprache. Das SüD erfüllt das strukturelle Merkmal der Lernervarietät hingegen nicht. Bei der südschleswigdänischen Varietät handelt es sich keineswegs um ein System, das übergangsweise während des Lernprozesses einer Zweitsprache im Individuum existiert. Es ist vielmehr ein gefestigtes System mit eigenen Normen. Auch Kühl (2008: 106) beschreibt das SüD als eine „durchaus stabile, eigenständige Varietät, die auch schon über Jahrzehnte besteht [...] und innerhalb der dänischen Minderheit ,vererbt' wird.“ Folglich erfüllt das SüD allgemein vier der fünf Kriterien einer Lernervarietät. ${ }^{33}$

33 Diese Schlussfolgerung bezieht sich auf das gesamte Südschleswigdänisch. In gewissen Einzelfällen ist es durchaus möglich, dass das SüD strukturelle Gemeinsamkeiten mit einem Übergangssystem hat und als solches charakterisiert werden. Zur Diskussion, ob SüD eine Lernervarietät ist, fügt Kühl (2008: 53) noch hinzu, dass dieser Kategorisierung eine defizitorientierte Sichtweise zugrunde liegt. Eine ressourcenorientierte Perspektive kategorisiert das SüD als Kontaktvarietät (Kühl 2008: 53). 


\subsubsection{Räumliche Varietäten}

In Bezug auf das Oberkriterium Raum ist für das SüD eine kleinräumige Region charakteristisch, in der die Varietät nicht etabliert ist. Das SüD erfüllt somit das begriffskonsti tuierende Kriterium Region der beiden Varietätentypen Dialekt und Regionalsprache. Eine genauere Betrachtung zeigt, dass eine kleinräumige Region - das Kriterium des Dialekts - am ehesten auf das SüD zutrifft. Ferner decken sich die Kriterien keine eigene schriftliche Norm und mündliches Medium mit den Merkmalen des SüD.

Neben diesen Übereinstimmungen gibt es wesentliche Abweichungen bezogen auf die Merkmale keine Etablierung, eigene mündliche Norm und schriftliches Medium. Hier weisen die Varietätentypen gegenteilige Kriterien auf (Etablierung, keine eigene mündliche Norm und kein schriftliches Medium).

Problematisch erweist sich weiterhin, dass zwar das Merkmal Region des SüD mit diesen Varietätentypen aufgegriffen wird, dennoch erneut wesentliche Merkmale ungeachtet bleiben. Hierunter fällt insbesondere das Merkmal Mehrsprachigkeit, das die Basis des SüD darstellt (vgl. Abb. 1).

\subsubsection{Situative Varietäten}

Das SüD weist in Bezug auf das Oberkriterium Situation das Merkmal Kontext auf. Zudem wird das SüD nicht als offizielle Sprache in Institutionen verwendet. Demnach deckt sich das Merkmal Kontext des SüD mit dem begriffskonstituierenden Kriterium des Varietätentyps Register.

In Bezug auf den Varietätentyp Register wird zudem diskutiert, ob dieser vornehmlich in institutionellen Kontexten verwendet wird. Sollte dies ein Kriterium eines Registers darstellen, gäbe es in diesem Punkt eine Abweichung zu den Merkmalen des SüD. Dies liegt darin begründet, dass das Standarddänisch und nicht das SüD in den offiziellen Kontexten der Institutionen verwendet wird.

\subsubsection{Soziale Varietäten}

Das weit gefasste Oberkriterium soziale Gruppe stellt ein Merkmal des SüD dar. Wie in Kapitel 4.1.4 bereits dargelegt, ist die Gruppe der Südschleswigdänischsprecher anhand relativ trivialer Merkmale eingrenzbar: Es wird von den meisten Angehörigen der dänischen Minderheit verwendet, die zudem Deutsch als Erstsprache und Dänisch als Zweitsprache in den Institutionen der dänischen Minderheit erworben haben. Somit gibt es eine Übereinstimmung des einzigen Kriteriums einer Gruppensprache und dem Merkmal des SüD. Problematisch erweist sich erneut die Tatsache, dass der Varietätentyp Gruppensprache lediglich einen Aspekt des SüD erfasst. Erneut wird beispielsweise u. a. die Basis Mehrsprachigkeit mit diesem weit gefassten Varietätentyp nicht berücksichtigt. 
Weiterhin weist das SüD die Unterkriterien Ethnizität und Gruppenzugehörigkeitsfunktion auf. Demnach wird das begriffskonstituierende Kriterium der Varietätentypen Ethnolekt und Multiethnolekt von der südschleswigdänischen Varietät erfüllt.

Bei detaillierter Betrachtung des Varietätentyps Ethnolekt im Vergleich mit den Merkmalen des SüD kann resümiert werden, dass alle Kriterien dieses Varietätentyps als Merkmale des SüD auftreten. Auf der Ebene der Person stellen sowohl der Varietätentyp Ethnolekt als auch das SüD die Zweitsprache, und keineswegs die Erstsprache, der Sprecher dar. Außerdem zeigt sich eine Überschneidung beim Kriterium Gruppenzugehörigkeitsfunktion. Sowohl das SüD als auch Ethnolekte beschreiben die Sprache einer ethnischen Minderheit. In beiden Fällen drückt die spezifische Varietät eine Zugehörigkeit zu der Minderheit aus. Weitere Gemeinsamkeiten mit diesem Varietätentyp sind das Vorkommen in mündlicher Form und eine eigene mündliche Sprachnorm, die sie verfolgen. Ferner entspringen sowohl das SüD als auch der Varietätentyp Ethnolekt aus einer Kontaktsituation in der zwei Sprachen involviert sind. Auch beim Kriterium Mehrsprachigkeit besteht eine Übereinstimmung. Dieser Varietätentyp bezieht sich jedoch nicht auf das für das SüD wesentliche Merkmal Region.

Zudem bestehen noch weitere wesentliche Unterschiede. Ethnolektale Varietäten sind eine Varietät der Mehrheitssprache und werden von dieser komplett umgeben (Sollid 2013: 63). Zwar ist das SüD ebenfalls umgeben von der Mehrheitssprache Deutsch, dennoch stellt das SüD keine Varietät des Deutschen, sondern des Standarddänischen dar, von dem es nur in bedingten Kontexten (Institutionen) umgeben ist. Ferner besteht im Hinblick auf die Formen der ethnischen Minderheiten eine erhebliche Diskrepanz. Während das SüD aus historischen Begebenheiten resultiert, handelt es sich bei den ethnischen Minderheiten, die Ethnolekte verwenden, um Migrantengruppen, die zu den neuen, hinzugezogenen ethnischen Minderheiten gezählt werden. Nach der Einteilung von Rindler Schjerve (2004: 482) stellen diese zwei Arten von ethnischen Minderheiten verschiedene Subformen dar. Inwieweit diese Abweichungen die Kategorisierung des SüD als Ethnolekt beeinflusst, bedarf einer weiteren Analyse.

Dieselbe Problematik betrifft den Varietätentyp Multiethnolekt. Dieser weist im Wesentlichen dieselben Kriterien wie der Varietätentyp Ethnolekt auf. Der wesentliche Unterschied besteht darin, dass bei einem Multiethnolekt mehr als zwei Sprachen zur Entstehung dieser neuen Varietät in Kontakt stehen, während Ethnolekte lediglich von zwei in Kontakt stehenden Sprachen geprägt ist. Dieser Aspekt führt zu einer weiteren komplexen Problematik: die allgemeine Abgrenzung zwischen einer Varietät und einer Sprache. Die Definitionen der Varietätentypen Ethnolekt und Multiethnolekt operieren mit dem Begriff Sprache. Es wird jedoch nicht explizit dargelegt, dass es sich hierbei um historisch-natürliche Sprachen handelt, wie sie in dieser Arbeit definiert werden. Es wird angenommen, dass bei der Bezeichnung Sprache nicht eindeutig zwischen Varietät und historisch-natürlicher Sprache abgegrenzt wird. Folglich ist eine Kategorisierung einer spezifischen konkreten Varietät eine reine Frage der Perspektive. Das Kriterium, dass mehrere Sprachen in Kontakt treten, wird in Bezug auf das SüD nur eingeschränkt er- 
füllt. Hierfür muss die Annahme getroffen werden, dass die Varietäten Niederdeutsch und norddeutsche Umgangssprache das Dänisch der dänischen Minderheit wesentlich beeinflussen. Sollten jedoch lediglich historisch-natürliche Sprachen gemeint sein, so ist es fraglich, ob das SüD dieses Kriterium erfüllt, da lediglich zwei historisch-natürliche Sprachen in Kontakt stehen: Deutsch und Dänisch.

Werden die drei erweiternden Kriterien eines Multiethnolekts (Region, Alter, Entlehnungen) in die Analyse integriert, wird die Frage der Übereinstimmung der Merkmale des SüD mit diesem Varietätentyp komplexer. Zunächst werden - im Gegensatz zu Ethnolekten - Multiethnolekte oftmals mit einer bestimmten Region in Verbindung gebracht. Infolgedessen greift ein Multiethnolekt das Merkmal Region des SüD auf, das bei einem Ethnolekt ignoriert wird. Dennoch besteht hier ein wesentlicher Unterschied: Während Multiethnolekte größtenteils in urbanen und multiethnischen Regionen auftreten, handelt es sich bei der Region Südschleswig um eine eher ländliche Region. Beim Kriterium Alter gibt es ebenfalls Abweichungen, da dieses Kriterium in Bezug auf das SüD nicht explizit diskutiert wird und deshalb kein Merkmal darstellt. Das strukturelle Kriterium Entlehnung wird vom SüD erfüllt. Folglich entstehen erhebliche Diskrepanzen zwischen den Merkmalen des SüD und den Kriterien des Varietätentyps Multiethnolekt unter Ergänzung der drei weiteren Kriterien.

\subsubsection{Kontaktbedingte Varietäten}

In Bezug auf das Oberkriterium Kontakt weist das SüD die Merkmale zwei Sprachen in Kontakt, mehrere Varietäten in Kontakt, keine Brückenfunktion sowie Mehrsprachigkeit auf. Im Folgenden werden die kontaktbedingten Varietäten in Bezug auf diese Merkmale und die weiteren charakteristischen Kriterien des einzelnen Varietätentypen abgeglichen. Das begriffskonstituierende Kriterium Kontakt des Varietätentyps Kontaktvarietät, worunter Fredsted (2009a) und Kühl (2008) das SüD zählen, weist das SüD auf. Das SüD hat sich aus der Sprachkontaktsituation im deutsch-dänischen Grenzland entwickelt und wird auch heute von verschiedenen, in der Region gängigen Varietäten beeinflusst. Demnach besteht eine Übereinstimmung des einzigen Kriteriums einer Kontaktvarietät und dem Merkmal des SüD. Jedoch ist auch hier anzumerken, dass dieser Varietätentyp eine Vielzahl an weiteren sprachsozialen sowie auch strukturellen Merkmalen des SüD nicht berücksichtigt. Beispielsweise werden die eingegrenzte Region und die Individualität Sprecher außer Acht gelassen (vgl. Tab. 21).

Weiterhin erfüllt das SüD das begriffskonstituierende Merkmal einer Mischsprache Mehrsprachigkeit. Sowohl das SüD als auch dieser Varietätentyp entstehen auf der Basis einer mehrsprachigen Gruppe, in der unvermeidlich die beteiligten Sprachen in Kontakt stehen. Die daraus resultierende Varietät weist keine Brückenfunktion auf. Demnach decken sich die Unterkriterien von Kontakt des SüD und der Mischsprache. Auch in Bezug auf das Oberkriterium soziale Gruppe finden sich Übereinstimmungen zwischen dem 
Varietätentyp und dem SüD (Ethnizität und Gruppenzugehörigkeitsfunktion). Eine wesentliche Abweichung besteht jedoch in Bezug auf das strukturelle Kriterium der Mischsprache. In der bisherigen Forschungsliteratur gibt es keine konkreten Aussagen über das SüD bezogen auf die Annahme, dass sich das Lexikon der einen Sprache mit der Morphosyntax einer anderen Sprache vereint. Aus den bisherigen Ergebnissen lässt sich jedoch annehmen, dass eine strikte Trennung von Lexikon und Morphosyntax sowie eine Zuordnung zu entweder Deutsch oder Dänisch nur schwer möglich sind. Eine genauere linguistische Untersuchung wäre an dieser Stelle von Bedeutung.

Ferner besteht eine Übereinstimmung zwischen dem SüD und dem Varietätentyp Pidginsprache. Das begriffskonstituierende Kriterium Kontakt wird vom SüD erfüllt. Ebenfalls deckungsgleich sind die sprachsozialen Kriterien keine Erstsprache, Zweitsprache und Mehrsprachigkeit. Es besteht zudem eine Übereinstimmung mit dem SüD in Bezug auf das Kriterium Kontext, jedoch muss hierbei bedacht werden, dass Pidginsprachen lediglich auf Handelskontexte beschränkt sind, was auf die Verwendung des SüD nicht zutrifft. Dies könnte eine Klassifizierung des SüD als Pidginsprache beeinflussen. Eine weitere Diskrepanz besteht in Bezug auf das Kriterium Brückenfunktion. Während eine Pidginsprache eine aus einer kommunikativen Notsituation entstandene Sprache darstellt, verfügen alle Sprecher des SüD über die gemeinsame Sprache Deutsch. Demnach weist das SüD keine Brückenfunktion auf. Das für eine Pidginsprache angenommene Kriterium Alter, wird in Bezug auf das SüD in der Forschungsliteratur nicht diskutiert. Im Bereich der strukturellen Kriterien bestehen Übereinstimmungen bei zwei der an der Pidginisierung beteiligten Kriterien - Beimengung und Vereinfachung. Das dritte Kriterium - Reduktion - wurde bisher hinsichtlich des SüD nicht diskutiert. ${ }^{34}$

Das begriffskonstituierende Kriterium (Kontakt) einer Kreolsprache wird durch das SüD ebenso erfüllt, wie die zwei wesentlichen Prozesse Beimengung und Vereinfachung. Der Prozess Expansion wird für das SüD bisher nicht diskutiert. ${ }^{35}$ Dessen ungeachtet wird das SüD dem personalen Kriterium der Kreolsprache nicht gerecht: SüD stellt keine Erstsprache der Sprecher dar.

Bei dem Varietätentyp Kreoloidsprache bestehen Übereinstimmungen mit dem SüD bezogen auf die Kriterien Kontakt, Vereinfachung und Beimengung. Dennoch besteht auch hier eine Diskrepanz in Hinsicht auf das Kriterium Erstsprache. Ferner wird das Kriterium keine Expansion in Bezug auf das SüD nicht diskutiert. ${ }^{36}$

Das Merkmal Kontakt des SüD erfüllt das begriffskonstituierende Kriterium des Zweitsprachen-Kreoloidsprache. Außerdem stimmen die sprachsozialen Kriterien keine Erstsprache, Zweitsprache und Mehrsprachigkeit überein. Kritisch ist erneut das Kriterium Alter, das in Bezug auf das SüD in der Forschungsliteratur keine Relevanz hat. Weiterhin besteht eine Diskrepanz zwischen der Brückenfunktion einer Zweitsprachen-Kreo-

34 Für eine kritische Auseinandersetzung zu dieser Problematik siehe Kapitel 5.4.

35 Hierzu siehe Kapitel 5.4.

36 Hierzu siehe wiederum Kapitel 5.4. 
loidsprache und dem Aspekt, dass SüD das gegenteilige Merkmal aufweist. Bei den strukturellen Kriterien besteht ebenfalls eine Übereinstimmung bei der Vereinfachung und Beimengung. Erneut ist unstimmig, ob das SüD dem Prozess der Reduktion unterliegt oder nicht.

Insgesamt bestehen viele Übereinstimmungen zwischen dem SüD und den kontaktbedingten Varietäten. Ungeachtet dessen beinhalten auch diese Varietätentypen nicht alle Merkmale des SüD. So bleiben beispielsweise die Merkmale der geographischen Abgrenzung und der sozialen Gruppe vollkommen ungeachtet.

\subsection{Probleme einer Kategorisierung}

Der Abgleich des Merkmalkatalogs des SüD mit den Kriterien der einzelnen prototypischen Varietätentypen verdeutlicht, dass die Übereinstimmungen des SüD mit den einzelnen Varietätentypen stark variiert. Die folgende Abb. 5 stellt die Abweichungen und Überschneidungen schematisch dar:

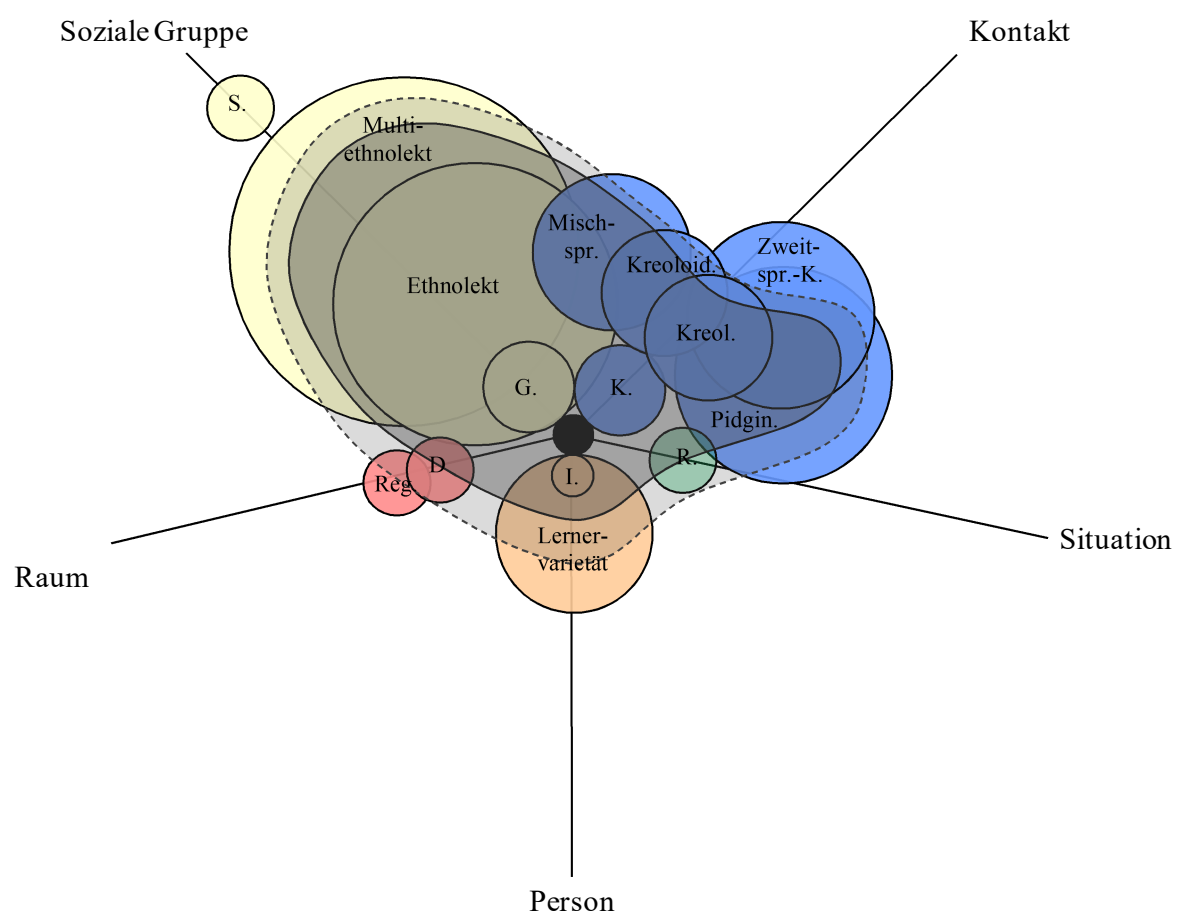

Abb. 5: Varietätentypologische Einordnung des SüD

D. = Dialekt; G. = Gruppensprache; I. = Idiolekt; K. = Kontaktvarietät; Kreol.=Kreolsprache; Kreoloid. = Kreoloidsprache; Mischspr. = Mischsprache; Pidgin. = Pidginsprache; $\mathrm{R} .=$ Register $;$ Reg. $=$ Regio nalsprache; S. = Soziolekt; Zweitspr.-K. = Zweitsprachen-Kreoloidsprache. 
Die einzelnen Varietätentypen werden durch Kreise visualisiert. Die Größe der Kreise steht dabei für die Menge der gemeinsamen Kriterien des SüD und des jeweiligen Varietätentyps. Dabei ist unwesentlich, ob die Kriterien der Varietätentypen und die Merkmale des SüD dieselbe Ausprägung haben. Je größer der Kreis, desto mehr Unterkriterien stimmen überein. Die dunkelgrau hinterlegte Fläche repräsentiert die südschleswigdänische Varietät. Die hellgraue Fläche soll den Umstand verdeutlichen, dass innerhalb der südschleswigdänischen Sprechergruppe eine Vielzahl an individuellen Ausprägungen existiert, die Auswirkungen auf eine Klassifizierung haben können (gestrichelte Linie). Im Zentrum der Abbildung steht das SüD (schwarzer Punkt). Je näher ein Varietätentyp diesem Punkt ist, desto mehr Kriterien dieses Varietätentyps werden vom SüD erfüllt. Das SüD wird in die fünf Oberkriterien soziale Gruppe (gelb), Kontakt (blau), Situation (grün), Person (orange) und Raum (rot) eingeteilt. Hierbei handelt es sich um jene Oberkriterien, die begriffskonstituierende Kriterien der hier betrachteten Varietätentypen aufweisen. Die Überschneidungen der einzelnen Varietätentypen untereinander werden teilweise berücksichtigt. Dennoch handelt es sich hierbei um eine schematische Darstellung und nur die relevantesten Überschneidungen der Varietätentypen untereinander werden dargestellt.

Die Metaanalyse der bisherigen Forschungsergebnisse, zusammengefasst in dieser Darstellung, verdeutlichen die Komplexität einer varietätentypologischen Einordnung der südschleswigdänischen Varietät in ein Geflecht aus prototypischen Varietätentypen. Die in der Forschungsliteratur anzutreffende Vielfalt an Kategorisierungsversuchen kann damit begründet werden, dass das SüD die begriffskonstituierenden Kriterien der analysierten Varietätentypen aufweist. Vor allem aber bestätigt diese Analyse, dass eine endgültige Klassifizierung des SüD nicht möglich ist.

Bei einer varietätentypologischen Einordnung des SüD lassen sich die einzelnen Varietätentypen in zwei Kategorisierungsgrade gliedern. Der 1. Kategorisierungsgrad umfasst umschlossene Varietätentypen, der 2. Kategorisierungsgrad umfasst überschneidende Varietätentypen, darunter (a) einfache Diskrepanzen und (b) komplexe Diskrepanzen.

Der erste Kategorisierungsgrad umfasst jene Varietätentypen, dessen Kriterien vollkommen von den Merkmalen des SüD erfüllt werden. Der zweite Kategorisierungsgrad beinhaltet jene Varietätentypen, dessen Kriterien sich teilweise mit den Merkmalen des SüD decken (einfache Diskrepanzen). Weist ein Varietätentyp zudem noch Kriterien auf, die in Bezug auf das SüD nicht explizit diskutiert werden, handelt es sich um komplexe Diskrepanzen. Im Folgenden werden die Kategorisierungsgrade konkretisiert.

Umschlossene Varietätentypen. Kategorisierungsgrad 1 (umschlossene Varietätentypen) umfasst die Varietätentypen, dessen Kriterien vollständig vom SüD erfasst werden. Hierzu zählen die Varietätentypen Idiolekt, Gruppensprache, Ethnolekt und Kontaktvarietät.

In diesem Bereich besteht das Problem, dass zwar alle Kriterien der einzelnen Varie tätentypen erfüllt werden, diese jedoch nicht alle Merkmale des SüD erfassen. 
Bei einer Kategorisierung des SüD als Idiolekt wird lediglich das Unterkriterium Individuum einbezogen. Dies stellt nur einen geringen Anteil der gesamten südschleswigdänischen Varietät dar. Weitere sprachsoziale sowie strukturelle Merkmale werden ignoriert. Dasselbe trifft auf die Varietätentypen Kontakt- und Gruppensprache zu. Der Varietätentyp Ethnolekt hingegen trifft auf mehr Merkmale des SüD zu. Kritisch anzumerken ist, dass dieser Varietätentyp nicht das räumliche Kriterium beinhaltet. Somit entfällt dieses wesentliche Merkmal des SüD bei einer Kategorisierung als Ethnolekt.

Eine Kategorisierung des SüD als ein aus diesem Kategorisierungsgrad stammenden Varietätentyp erweist sich somit als unzureichend. Das SüD wird aus dieser Perspektive nur einseitig betrachtet.

Überschneidende Varietätentypen. Kategorisierungsgrad 2 (überschneidende Varietätentypen) umfasst die Varietätentypen, deren Kriterien zwar erhebliche Übereinstimmung mit den Merkmalen des SüD aufweisen, bei denen allerdings mindestens eine Dis krepanz besteht (vgl. Tab. 21, rote Zellen). Weiterhin besteht bei all diesen Varietätentypen die Problematik, dass die einzelnen Varietätentypen keineswegs alle Merkmale des SüD beinhalten. Eine Kategorisierung als ein solcher Varietätentyp ist ebenfalls unzureichend und einseitig.

(a) Einfache Diskrepanzen. Zwischen den Kriterien der Varietätentypen und den Merkmalen das SüD bestehen im Wesentlichen Übereinstimmungen. Jedoch gibt es einzelne Kriterien, die vom SüD nicht erfüllt werden, da es das gegenteilige Merkmal aufweist. Hierzu zählen die Varietätentypen Lernervarietät, Dialekt, Regionalsprache und Register.

(b) Komplexe Diskrepanzen. Komplexe Diskrepanzen lassen sich bei jenen Varietätentypen finden, die Kriterien aufweisen, die in Bezug auf das SüD in der bisherigen Forschung nicht explizit diskutiert wurden: Soziolekt, Multiethnolekt, Mischsprache, Pidginsprache, Kreolsprache, Kreoloidsprache sowie Zweitsprachen-Kreoloidsprache (vgl. Tab. 21, orange Zellen). Im Folgenden werden die spezifischen Probleme dargelegt und diskutiert.

Ein Soziolekt wird durch das begriffskonstituierende Kriterium soziale Schicht bedingt. Ob die soziale Schicht allerdings einen Einfluss auf den Gebrauch des SüD hat, wird aus der bisherigen Forschungsliteratur nicht deutlich. Um folglich eine Klassifikation des SüD als Soziolekt vornehmen zu können, bedarf es weiterer Forschung.

Darüber hinaus wird in der bisherigen Forschung keine Abgrenzung der Südschleswigdänischsprecher hinsichtlich ihres Alters gezogen. Während Multiethnolekte dadurch gekennzeichnet sind, dass sie von jugendlichen Sprechern verwendet werden, so werden Pidgin- und Zweitsprachen-Kreoloidsprachen mit erwachsenen Sprechern in Verbindung gebracht, dessen unvollständiger Spracherwerb Einfluss auf die Varietät hat. Ob das SüD ebenfalls vom Alter der Sprecher beeinflusst wird, ist fraglich. Es lässt sich zunächst keine Sprechereinteilung hinsichtlich des Alters erkennen. Dennoch werden die bisherigen Analysen zum SüD größtenteils in schulischen Kontexten mit jugendlichen Sprechern vollzogen. Das kann zur Folge haben, dass die bisherigen verallgemeinerten Ergebnisse 
in der Forschungsliteratur zum SüD möglicherweise spezifische Phänomene der südschleswigdänischen Varietät jugendlicher Sprecher darstellen. Konkrete Analysen zu erwachsenen Südschleswigdänischsprechern erfolgten bisher nicht. Dies wäre von Bedeutung, um das Merkmal Alter zu spezifizieren.

Ein weiteres Unterkriterium, das in Bezug auf das SüD nicht diskutiert wurde, ist $R e$ duktion. Dieses Kriterium betrifft die Varietätentypen Pidginsprache und ZweitsprachenKreoloidsprache. Die Voraussetzungen zur Entstehungen dieser Varietätentypen ist jedoch ebendieses Kriterium. Eine Reduzierung des grammatischen Systems aufgrund von unvollständigem Spracherwerb bei erwachsenen Sprechern lässt sich beim SüD bisher nicht festmachen. Dies bedarf ebenfalls einer Analyse.

Weiterhin wird das Unterkriterium Expansion nicht in Bezug auf das SüD thematisiert. Dies Kriterium wird in Bezug auf den Varietätentyp Kreolsprache angenommen und in Bezug auf Kreoloidsprache abgelehnt. Ob eine Expansion in der südschleswigdänischen Varietät stattgefunden hat, ist aus der Forschungsliteratur bisher nicht ersichtlich. Da aus synchroner Perspektive kaum eine strukturelle Unterscheidung zwischen kreolischen und kreoloidenVarietäten gezogen werden kann, wäre eine diachrone Betrachtung der linguistischen Struktur des SüD von Bedeutung.

Das letzte offene Kriterium ist Lexikon der Sprache A, Morphosyntax der Sprache B, das bezogen auf das SüD nicht diskutiert wird. Eine strukturelle Analyse des SüD wäre von Bedeutung.

Abschließend ist anzumerken, dass eine Klärung dieser fünf offenen Kriterien - soziale Schicht, Alter, Reduktion, Expansion und Lexikon der Sprache A, Morphosyntax der Sprache $B$ - keineswegs eine endgültige Klassifizierung ermöglicht. Keiner der hier diskutierten Varietätentypen würde, selbst bei einer Erfüllung der offenen Kriterien, dem SüD vollkommen gerecht werden, sondern - im Gegenteil - weiterhin wesentliche Merkmale nicht erfassen.

\section{Schlussfolgerung zu Kapitel 5}

Durch die Zusammenführung des Kriterienkataloges der Varietätentypen und dem Merkmalkatalog der südschleswigdänischen Varietät ist eine detaillierte Analyse der diversen Übereinstimmungen und Abweichungen zwischen dem SüD und den einzelnen Varietätentypen erfolgt. Das SüD weist die begriffskonstituierenden Kriterien von insgesamt 14 der 15 betrachteten Varietätentypen auf. Folglich konnte eine Begründung für die vielfältigen Kategorisierungsversuche der Forschungsliteratur gefunden werden.

Die detaillierte Analyse zeigt die Probleme einer varietätentypologischen Einordnung des SüD auf. Hierbei kann zwischen zwei Kategorisierungsgraden unterschiedenen werden. Kategorisierungsgrad 1 fasst jene Varietätentypen zusammen, dessen Kriterien, die für eine Klassifizierung notwendig sind, alle von dem SüD erfüllt werden. Das SüD weist jedoch zusätzliche Merkmale auf, die unberücksichtigt bleiben. Dies wäre bei einer Kategorisierung des SüD als Idiolekt, Gruppensprache, Ethnolekt und Kontaktvari- 
etät der Fall. Varietätentypen, die dem Kategorisierungsgrad 2 zugeordnet werden, weisen neben Übereinstimmungen auch Abweichungen zu den Merkmalen des SüD auf. Eine Klassifizierung des SüD als eine dieser Varietätentypen setzt eine Redefinition (wie Pedersen 2000 biederholend anmerkt) der der Kategorien voraus. Hierzu zählen Lernervarietät, Dialekt, Regionalsprache, Register, Soziolekt, Multiethnolekt, Mischsprache, Pidginsprache, Kreolsprache, Kreoloidsprache und Zweitsprachen-Kreoloidsprache. Einen speziellen Subbereich bilden die Varietätentypen, die zudem Kriterien aufweisen, die in Bezug auf das SüD in der bisherigen Forschung nicht analysiert werden.

Diese Analyse verdeutlicht die Problematik einer varietätentypologischen Einordnung des SüD und verneint die anfangs aufgestellte Forschungsfrage, ob sich das SüD einer spezifischen Kategorie zuordnen lässt. Die Hypothese, dass sich das SüD mit seinen besonderen sprachsozialen sowie strukturellen Merkmalen keiner spezifischen Varietätenkategorie zuordnen lässt, sondern lediglich bestimmte Kriterien dieser Varietätentypen erfüllt, kann nach dieser detaillierten Metaanalyse bestätigt werden. Es wird gezeigt, dass das SüD keinem Varietätentyp gerecht wird, im Umkehrschluss aber auch kein Varietätentyp vollkommen auf das SüD zutrifft. 



\section{Fazit}

Die vorliegende Arbeit verdeutlicht die Schwierigkeiten einer varietätentypologischen Kategorisierung des SüD als eine Varietät der historisch-natürlichen Sprache Dänisch. Es konnte aufgezeigt werden, dass das SüD als keine der traditionellen Varietätentypen klassifiziert werden kann, ohne eine Redefinition dieser Kategorie vorzunehmen. Im Umkehrschluss wurde ebenfalls deutlich, dass keine Kategorie die spezifischen und mannigfaltigen Eigenheiten des SüD erfasst. Zusammenfassend lässt sich festhalten, dass das SüD mit keinem der betrachteten Varietätentypen vollkommen übereinstimmt.

Der in dieser Arbeit verwendeten Definitionen der einzelnen Varietätentypen folgend, wurde herausgearbeitet, dass das SüD die begriffskonstituierenden Kriterien von 14 der insgesamt 15 betrachteten Varietätentypen erfüllt. Durch die vielfältigen Merkmale des SüD in den Oberkategorien ist eine Kategorisierung als einer dieser 14 Varietätentypen durchaus möglich. Eben darin die Vielfältigkeit der Kategorisierungen des SüD in der Forschungsliteratur begründet.

In dieser Arbeit wurden die Schwierigkeiten einer endgültigen Klassifizierung festgemacht. Hierbei wurde zwischen zwei Kategorisierungsgraden der einzelnen Varietätentypen hinsichtlich einer Einordnung des SüD unterschieden: Der Kategorisierungsgrad 1 (umschlossene Varietätentypen) umfasst jene, deren Kriterien zwar vollkommen vom SüD erfüllt werden, jedoch nur einen geringen Teil der Merkmale des SüD aufgreifen. Hierzu zählen: Idiolekt, Gruppensprache, Ethnolekt und Kontaktvarietät. Die Varietätentypen Idiolekt sowie auch Gruppensprache und Kontaktvarietät erfassen lediglich einen geringen Teil der gesamten Merkmale des SüD. Der Varietätentyp Ethnolekt besitzt wesentlich mehr Kriterien, die die Merkmale des SüD abdecken. Jedoch ignoriert eine Kategorisierung des SüD als Ethnolekt die situativen Merkmale der sprachsozialen Ebene sowie die meisten strukturellen Merkmale.

Die übrigen Varietätentypen konnten dem Kategorisierungsgrad 2 (überschneidende Varietätentypen) zugeordnet werden. Die Kriterien dieser Kategorien decken sich zwar im Wesentlichen mit den Merkmalen des SüD. Dennoch weisen sie Diskrepanzen hinsichtlich einiger Kriterien auf. Sieben dieser Varietätentypen weisen zudem Kriterien auf, die in Bezug auf das SüD in der Forschungsliteratur nicht diskutiert werden (komplexe Diskrepanzen).

Aufgrund der Komplexität der varietätentypologischen Einordnung muss darauf hingewiesen werden, dass die Ergebnisse dieser Analyse nur unter Berücksichtigung der in dieser Arbeit herangezogenen Definitionen gelten.

Insgesamt können die Probleme einer varietätentypologischen Einordnung des SüD wie folgt zusammengefasst werden:

a. Die prototypischen Varietätentypen werden in der Forschungsliteratur nicht eindeutig definiert. Die Verwendung anderer Definitionen einer bestimmten Kategorie führt somit stets zu anderen Kategorisierungsergebnissen. Dies erschwert die Kategorisierung des SüD erheblich. 
b. Das SüD ist aufgrund der spezifischen Merkmale keineswegs prototypisch. Somit ist die Einordnung in eine der prototypischen Varietätenkategorien generell problematisch.

c. Bei konkreten Kategorisierungsversuchen des SüD bewirken unterschiedliche Gewichtungen der einzelnen Merkmale des SüD unterschiedliche Ergebnisse der Kategorisierung. Wird der Schwerpunkt beispielsweise auf das Merkmal Kontakt gelegt, ist die auf das SüD zutreffende Kategorie eine andere, als wenn der Schwerpunkt auf das sprachsoziale Merkmal soziale Gruppe gelegt wird.

d. Alle Varietätenkategorien erfassen nur einen Teil des SüD und ignorieren wichtige weitere Merkmale. Keine Kategorie erfasst das SüD mit allen Eigenheiten. Keine der prototypischen Kategorien gelingt es die sprachsozialen sowie die strukturellen Faktoren sowie die Basis der Mehrsprachigkeit des SüD zu erfassen. Somit ist eine Kategorisierung des SüD generell einseitig und unzureichend.

Die Ergebnisse dieser Arbeit verdeutlichen, dass die Forschung davon abrücken sollte, dem SüD eine bestimmte Varietätenkategorie aufzuzwingen, da dies aufgrund der spezifischen Merkmale des SüD nicht möglich ist. Die Tatsache, dass das SüD in keine prototypische Varietätenkategorie passt, muss dabei nicht als Manko, sondern als eine SüDimmanente Qualität angesehen werden. 


\section{Literatur}

Ammon, Ulrich. 2004. Standard variety. In Ulrich Ammon et al. (Hgg.), Sociolinguistics. An international handbook of the science of language and society (Handbücher zur Sprach- und Kommunikationswissenschaft 3), 2. Aufl., Bd. 1, 273-283. Berlin/New York: de Gruyter.

Ammon, Ulrich. 2010. Soziolekt. In Helmut Glück (Hg.), Metzler Lexikon Sprache, 4. Aufl., 268-273. Stuttgart/Weimar: Metzler.

Androutsopoulos, Jannis. 2007. Ethnolekte in der Mediengesellschaft. Stilisierung und Sprachideologie in Performance, Fiktion und Metasprachdiskurs. In Christian Fandrych \& Reinier Salverda (Hgg.), Standard, Variation und Sprachwandel in germanischen Sprachen (Studien zur deutschen Sprache 41), 113-155. Tübingen: Narr.

Ash, Sharon. 2013. Social class. In Jack Chambers, Peter Trudgill \& Natalie Schilling (Hgg.), The handbook of language variation and change, 2. Aufl., 350-367. Malden/Oxford: Blackwell.

Bakker, Peter \& Pieter Muysken. 1995. Mixed languages and language intertwining. In Jacques Arends, Pieter Muysken \& Norval Smith (Hgg.), Pidgins and creoles. An introduction (Creole Language Library 15), 41-53. Amsterdam/Philadelphia: Benjamins.

Berruto, Gaetano. 2004. Sprachvarietät - Sprache (Gesamtsprache, historische Sprache). In Ulrich Ammon et al. (Hgg.), Sociolinguistics. An international handbook of the science of language and society (Handbücher zur Sprach- und Kommunikationswissenschaft 3), 2. Aufl., Bd. 1, 188-195. Berlin/New York: de Gruyter.

Braunmüller, Kurt. 1991. Sydslesvigdansk - et interferenssprog? In Mette Kunøe \& Erik Vive Larsen (Hgg.), 3. Møde om Udforskningen af det Danske Sprog, 55-62. Århus: Aarhus Universitet.

Braumüller, Kurt. 1995. Südschleswigdänisch - eine Mischsprache? In Kurt Braunmüller, Beiträge zur skandinavischen Linguistik, 144-153. Oslo: Novus.

Braunmüller, Kurt. 1996. Sydslesvigdansk - et regionalsprog? In Institut for dansk Dialektforskning (Hg.), Talesprogsvariation og sprogkontakt. Til Inger Ejskær på halvfjerdsårsdagen den 20. maj 1996, 33-44. København: Reitzel.

Britain, David. 2004. Dialect and accent. In Ulrich Ammon et al. (Hgg.), Sociolinguistics. An international handbook of the science of language and society (Handbücher zur Sprach- und Kommunikationswissenschaft 3), 2. Aufl., Bd. 1, 267-273. Berlin/New York: de Gruyter.

Bußmann, Hadumod (Hg.). 2008. Lexikon der Sprachwissenschaft. 4. Aufl. Stuttgart: Kröner.

Christophersen, Hans. 1985. Det danske sprog i Sydslesvig. Birkerød: Rostras.

Clyne, Michael. 2000. Lingua franca and ethnolects in Europe and beyond. Sociolinguistica 14, 83-89.

Council of Europe. 1992. European Charter for Regional or Minority Languages (European Treaty Series 148). 〈conventions.coe.int/treaty/en/treaties/html/148.htm; Stand vom 10. 2. 2014 $\rangle$. 
Daneš, František. 2005. Dimensionen im Varietätenraum. In Alexandra N. Lenz \& Klaus Mattheier (Hgg.), Varietäten - Theorie und Empirie (VarioLingua 23), 39-49. Frankfurt am Main u. a.: Lang.

Deckert, Sharon K. \& Caroline H. Vickers. 2011. An introduction to sociolinguistics. Society and identity. London/New York: Continuum International.

Deumert, Ana. 2004. Ethnicity. In Ulrich Ammon et al. (Hgg.), Sociolinguistics. An international handbook of the science of language and society (Handbücher zur Sprachund Kommunikationswissenschaft 3), 2. Aufl., Bd. 1, 355-360. Berlin/New York: de Gruyter.

Devetak, Silvo. 1996. Ethnicity. In Hans Goebl et al. (Hgg.), Kontaktlinguistik. Ein internationales Handbuch zeitgenössischer Forschung (Handbücher zur Sprach- und Kommunikationswissenschaft 12), Bd. 1, 203-209. Berlin/New York: de Gruyter.

Dittmar, Norbert. 1997. Grundlagen der Soziolinguistik. Ein Arbeitsbuch mit Aufgaben (Konzepte der Sprach- und Literaturwissenschaft 57). Tübingen: Niemeyer.

Dittmar, Norbert. 2004. Register. In Ulrich Ammon et al. (Hgg.), Sociolinguistics. An international handbook of the science of language and society (Handbücher zur Sprachund Kommunikationswissenschaft 3), 2. Aufl., Bd. 1, 216-226. Berlin/New York: de Gruyter.

Durrell, Martin. 2004. Sociolect. In Ulrich Ammon et al. (Hgg.), Sociolinguistics. An international handbook of the science of language and society (Handbücher zur Sprachund Kommunikationswissenschaft 3), 2. Aufl., Bd. 1, 200-205. Berlin/New York: de Gruyter.

Dyhr, Mogens. 1990. Hybridisiertes Südjütisch. In Ludger Kremer \& Hermann Niebaum (Hgg.), Grenzdialekte (Germanistische Linguistik 101-103), 25-49. Hildesheim u. a.: Olms.

Fought, Carmen. 2013. Ethnicity. In Jack Chambers, Peter Trudgill \& Natalie Schilling (Hgg.), The handbook of language variation and change, 2. Aufl., 338-406. Malden/ Oxford: Blackwell.

Fredsted, Elin. 1997. Danskundervisning i grænselandet: ,Danskerne forærer deres dronning mere end tyskerne sin Bundespräsident'. 〈inet.dpb.dpu.dk/infodok/sprogforum/ sprg/fredsted.html; Stand vom 12. 2. 2014 .

Fredsted, Elin. 1999. Minoritätensprache als Gruppen- und Identifikationssprache. Zeitschrift für Fremdsprachenforschung 10, 53-72.

Fredsted, Elin. 2009a. Sprachen und Kulturen in Kontakt - deutsche und dänische Minderheiten in Sønderjylland/Schleswig. In Christel Stolz (Hg.), Neben Deutsch. Die autochthonen Minderheiten- und Regionalsprachen Deutschlands (Diversitas linguarum 23), 1-23. Bochum: Brockmeyer.

Fredsted, Elin. 2009b. Wenn Sprachen sich begegnen - Deutsch in dänischen Sprachvarietäten. In Christel Stolz (Hg.), Unsere sprachlichen Nachbarn in Europa. Die Kontaktbeziehungen zwischen Deutsch und seinen Grenznachbarn (Diversitas linguarum 24), 1-18. Bochum: Brockmeyer. 
Gravengaard, Gitte \& Pia Quist. o. J. Multietnolekt 〈dialekt.ku.dk/multietnolekt; Stand vom 12. 2. 2014 $>$.

Hazen, Kirk. 2002. The family. In Jack Chambers, Peter Trudgill \& Natalie SchillingEstes (Hgg.), The handbook of language variation and change, 500-525. Malden/Oxford: Blackwell.

Höder, Steffen. 2011. Niederdeutsch und Norddeutsch - ein Fall von Diasystematisierung. Niederdeutsches Jahrbuch 134, 113-136.

Höder, Steffen. 2012. Multilingual constructions: a diasystematic approach to common structures. In Kurt Braunmüller \& Christoph Gabriel (Hgg.), Multilingual individuals and multilingual societies (Hamburg Studies on Multilingualism 13), 241-257. Amsterdam/Philadelphia: Benjamins.

Jørgensen, J. Normann. 1983. De danske sprog i Hirtshals Kommune. In Elisabeth Hansen \& Jørn Lund (Hgg.), Skolen, samfundet og dialekten, 13-35. Frederikshavn: Dafolo.

Kotsinas, Ulla-Britt. 1988. Rinkebysvenskan - en dialekt? In Per Linell et al. (Hgg.), Svenskans beskrivning 16, 264-278, Linköping: Universitetet i Linköping.

Kotsinas, Ulla-Britt. 2000. Rinkebysvenskan - en dialekt. In Ulla-Britt Kotsinas et al. (Hgg.), Kontakt, variation och förändring. Studier $i$ Stockholmsspråk (Acta Universitatis Stockholmiensis 22), 59-72. Stockholm: Almqvist \& Wiksell International.

Krappmann, Lothar. 2004. Identität. In Ulrich Ammon et al. (Hgg.), Sociolinguistics. An international handbook of the science of language and society (Handbücher zur Sprach- und Kommunikationswissenschaft 3), 2. Aufl., Bd. 1, 405-412. Berlin/New York: de Gruyter.

Kubczak, Hartmut. 1987. Soziolekt. In Ulrich Ammon, Norbert Dittmar \& Klaus J. Mattheier (Hgg.), Soziolinguistik. Ein internationales Handbuch zur Wissenschaft von Sprache und Gesellschaft (Handbücher zur Sprach- und Kommunikationswissenschaft 3), Bd. 1, 268-273.

Kühl, Jørgen. 2004. Nationale Identität und kulturelles Gedächtnis. In Bea Lundt (Hg.), Nordlichter. Geschichtsbewußtsein und Geschichtsmythen nördlich der Elbe (Beiträge zur Geschichtskultur 27), 321-339. Köln: Böhlau.

Kühl, Jørgen. 2005. Nationale Minderheiten im dänisch-deutschen Grenzland - eine Einführung. In Jørgen Kühl \& Robert Bohn (Hgg.), Ein europäisches Modell? Nationale Minderheiten im deutsch-dänischen Grenzland 1945-2005 (IZRG-Schriftenreihe 11), 9-58. Bielefeld/Gütersloh: Verlag für Regionalgeschichte.

Kühl, Jørgen \& Robert Bohn (Hgg.). 2005. Ein europäisches Modell? Nationale Minderheiten im deutsch-dänischen Grenzland 1945-2005 (IZRG-Schriftenreihe 11). Bielefeld/ Gütersloh: Verlag für Regionalgeschichte.

Kühl, Karoline H. 2008. Bilingualer Sprachgebrauch bei Jugendlichen im deutsch-dänischen Grenzland (Philologia 127). Hamburg: Kovač. 
Labov, William. 2001. Principles of linguistic change. Bd. 2: Social factors (Language in Society 29). Malden/Oxford: Blackwell.

Löffler, Heinrich. 1982. Gegenstandskonstitution in der Dialektologie: Sprache und ihre Differenzierungen. In Werner Besch et al. (Hg.), Dialektologie. Ein Handbuch zur deutschen und allgemeinen Dialektforschung (Handbücher zur Sprach- und Kommunikationswissenschaft 1), Bd. 1, 441-463. Berlin/New York: de Gruyter.

Löffler, Heinrich. 2010. Germanistische Soziolinguistik (Grundlagen der Germanistik 28), 4. Aufl. Berlin: Schmidt.

Lüdi, Georges. 1996. Mehrsprachigkeit. In Hans Goebl et al. (Hgg.), Kontaktlinguistik. Ein internationales Handbuch zeitgenössischer Forschung (Handbücher zur Sprachund Kommunikationswissenschaft 12), Bd. 1, 233-245. Berlin/New York: de Gruyter.

Oksaar, Els. 200o. Idiolekt als Grundlage der variationsorientierten Linguistik. Sociolinguistica 14, 37-41.

Pedersen, Karen Margrethe. 1991. Dansk i Sydslesvig - førstesprog, andetsprog og fremmedsprog. In J. Normann Jørgensen (Hg.), Det danske sprogs status år 2001 - er dansk et truet sprog? (Københavnerstudier i tosprogethed 14), 77-106. København: Danmarks Lærerhøjskole, Institut for Dansk Sprog og Litteratur.

Pedersen, Karen Margrethe. 200oa. Dansk i Sydslesvig - funktion, status og sprogpolitik. In Anne Holmen \& J. Normann Jørgensen (Hgg.), Sprogs status i Danmark $i$ år 2011 (Københavnerstudier i tosprogethed 32), 91-127. København: Danmarks Pædagogiske Universitet.

Pedersen, Karen Margrethe. 20oob. Dansk sprog i Sydslesvig. Det danske sprogs status inden for det danske mindretal i Sydslesvig. Bd. 1. Aabenraa: Institut for Grænseregionsforskning.

Pedersen, Karen Margrethe. 200oc. Dansk sprog i Sydslesvig. Det danske sprogs status inden for det danske mindretal i Sydslesvig. Bd. 2. Aabenraa: Institut for Grænseregionsforskning.

Pedersen, Karen Margrethe. 2002. Et nordisk sprog som mindretalsandetsprog. In Auður Hauksdóttir et al. (Hgg.), Forskning i nordiske sprog som andet- og fremmedsprog. Rapport fra konference i Reykjavík 23.-25. maj 2001, 399-412. Reykjavík: Háskóli Îslands, Háskólaútgáfan.

Pedersen, Karen Margrethe. 2003. Et nordisk sprog uden for Norden - dansk i Sydslesvig. Sprog i Norden 2003, 7-25.

Pedersen, Karen Margrethe. 2005. Sprog, etniciteter og identiteter i den dansk-tyske grænseregion. In Steinar Imsen (Hg.), Grenser og grannelag $i$ Nordens historie, 123142. Oslo: Cappelen Akademisk Forlag.

Pedersen, Karen Margrethe. 2009. South Schleswig Danish - a border-regional minority language. In Alexandra N. Lenz, Charlotte Gooskens \& Siemon Reker (Hgg.), Low Saxon dialects across borders (Zeitschrift für Dialektologie und Linguistik. Beihefte 138), 297-316. Stuttgart: Steiner. 
Quist, Pia. 2000. Ny københavnsk 'multietnolekt'. Om sprogbrug blandt unge i sprogligt og kulturelt heterogene miljøer. Danske talesprog 1, 143-211.

Quist, Pia. 2008. Sociolinguistic approaches to multiethnolect. Language variety and stylistic practice. International Journal of Bilingualism 12, 43-61.

Riehl, Claudia Maria. 2014. Sprachkontaktforschung. Eine Einführung. 3. Aufl. Tübingen: Narr.

Russ, Charles V. J. 1990. The dialects of Modern German: a linguistic survey. London: Routledge.

Rindler Schjerve, Rosita. 2004. Minderheit. In Ulrich Ammon et al. (Hgg.), Sociolinguistics. An international handbook of the science of language and society (Handbücher zur Sprach- und Kommunikationswissenschaft 3), 2. Aufl., Bd. 1, 48o-486. Berlin/New York: de Gruyter.

Sinner, Carsten. 2014. Varietätenlinguistik. Eine Einführung. Tübingen: Narr.

Smith, Norval. 1995. An annotated list of creoles, pidgins, and mixed languages. In Jacques Arends, Pieter Muysken \& Norval Smith (Hgg.), Pidgins and creoles. An introduction (Creole Language Library 15), 331-374. Amsterdam/Philadelphia: Benjamins.

Sollid, Hilde. 2013. Ethnolects in Northern Norway. From national negligence to local linguistic pride. In Peter Siemund et al. (Hgg.), Multilingualism and language diversity in urban areas. Acquisition, identities, space, education (Hamburg Studies on Linguistic Diversity 1), 63-94. Amsterdam/Philadelphia: Benjamins.

Sommer, Joachim. 2002. Die sprachlichen Spuren der französischen Pelzhändler. Michif, eine franko-indianische Mischsprache in Nordamerika. In Hans-Dieter Paufler, Kerstin Störl \& Johannes Klare (Hgg.), Romanische Sprachen in Amerika. Festschrift für Hans-Dieter Paufler zum 65. Geburtstag (Studien zur romanischen Sprachwissenschaft und interkulturellen Kommunikation 8), 73-86. Frankfurt am Main u. a.: Lang.

Søndergaard, Bent. 1985. Bidrag til en karakteristik af sydslesvigdansk. Danske folkemål 27, 5-21.

Trudgill, Peter. 1992. Introducing language and society. London: Penguin.

Trudgill, Peter. 1994. Language contact and dialect contact in linguistic change. In UllaBritt Kotsinas \& John Helgander (Hgg.), Dialektkontakt, språkkontakt och språkförändring $i$ Norden. Föredrag från ett forskarsymposium (Meddelanden från Institutionen för nordiska språk vid Stockholms universitet 40), 13-22. Stockholm: Institutionen för nordiska språk.

Trudgill, Peter. 1996. Dual-source pidgins and reverse creoloids: Northern perspectives on language contact. In Ernst Håkon Jahr \& Ingvild Broch (Hgg.), Language contact in the Arctic. Northern pidgins and contact languages (Trends in Linguistics. Studies and Monographs 88), 5-14. Berlin/New York: Mouton de Gruyter.

Trudgill, Peter. 2000. Sociolinguistics - An introduction to language and society. 4. Aufl. London: Penguin. 
Weinreich, Uriel, William Labov \& Marvin I. Herzog. 1968. Empirical foundations for a theory of language change. In W. P. Lehmann \& Yakov Malkiel (Hgg.), Directions for historical linguistics. A symposium, 95-195. Austin/London: University of Texas Press.

Wiese, Heike. 2006. ,Ich mach dich Messer. Grammatische Produktivität in Kiez-Sprache (,Kanak Sprak'). Linguistische Berichte 207, 245-273.

Wiese, Heike. 2011. The role of information structure in linguistic variation. Evidence from a German multiethnolect. In Frans Gregersen, Jeffrey K. Parrott \& Pia Quist (Hgg.), Language variation - European perspectives III. Selected papers from the 5 th International Conference on Language Variation in Europe (ICLaVE 5), Copenhagen, June 2009 (Studies in Language Variation 7), 83-96. Amsterdam/Philadelphia: Benjamins. 